\title{
Overview of Existing Residential Energy-Efficiency Rating Systems and Measuring Tools
}

\author{
P. L. Hendrickson \\ B. A. Garrett-Price \\ T. A. Williams
}

October 1982

Prepared for the U.S. Department of Energy under Contract DE-AC06-76RLO 1830

Pacific Northwest Laboratory

Operated for the U.S. Department of Energy

by Battelle Memorial Institute 


\title{
DISCLAIMER
}

This report was prepared as an account of work sponsored by an agency of the United States Government. Neither the United States Government nor any agency thereof, nor any of their employees, makes any warranty, express or implied, or assumes any legal liability or responsibility for the accuracy, completeness, or usefulness of any information, apparatus, product, or process disclosed, or represents that its use would not infringe privately owned rights. Reference herein to any specific commercial product, process, or service by trade name, trademark, manufacturer, or otherwise, does not necessarily constitute or imply its endorsement, recommendation, or favoring by the United States Government or any agency thereof. The views and opinions of authors expressed herein do not necessarily state or reflect those of the United States Government or any agency thereof.

\author{
PACIFIC NORTHWEST LABORATORY \\ operated by \\ BATTELLE \\ for the \\ UNITED STATES DEPARTMENT OF ENERGY \\ under Contract DE-AC06-76RLO 1830
}

\begin{tabular}{|c|c|}
\hline \multicolumn{2}{|c|}{$\begin{array}{c}\text { National Technical Information Service } \\
\text { United States Department of Commerce } \\
5285 \text { Port Royal Road } \\
\text { 5pringfield, Virginia } 22151\end{array}$} \\
\hline \multicolumn{2}{|c|}{$\begin{array}{l}\text { NTIS Price Codes } \\
\text { Microfiche } A 01\end{array}$} \\
\hline \multicolumn{2}{|c|}{ Printed Copy } \\
\hline Pages & $\begin{array}{l}\text { Price } \\
\text { Codes }\end{array}$ \\
\hline 001-025 & $\mathrm{A} 02$ \\
\hline $026-050$ & $\mathrm{~A} 03$ \\
\hline $051-075$ & $\mathrm{~A} 04$ \\
\hline $076-100$ & A05 \\
\hline $10:-125$ & A06 \\
\hline $126-150$ & $\mathrm{~A} 07$ \\
\hline $151-175$ & $A 08$ \\
\hline $176-200$ & A09 \\
\hline $201-225$ & A010 \\
\hline $226-250$ & A011 \\
\hline $251-275$ & A 012 \\
\hline $276-300$ & $\mathrm{~A} 013$ \\
\hline
\end{tabular}


PNL -4359

UC-95d

OVERVIEW OF EXISTING RESIDENTIAL ENERGY-EFFICIENCY RATING SYSTEMS AND MEASURING TOOLS

P. L. Hendrickson

B. A. Garrett-Price

T. A. Williams

October 1982

Prepared for the U.S. Department of Energy under Contract DE-AC06-76RLO 1830

Pacific Northwest Laboratory Richland, Washington 99352 
, 


\section{SUMMARY}

This survey document is intended to provide an introduction to the current status of residential energy-efficiency rating systems throughout the country. Specifically, the document has been prepared to meet the following objectives:

1. identify, describe, and categorize rating systems that have been implemented,

2. identify and describe existing energy-efficiency measuring tools that are capable of being adapted to a rating system,

3. present characteristics of the existing systems/tools in tabular form to facilitate their comparison,

4. identify the generic advantages and disadvantages of each category of systems/tools.

Three categories of rating systems/tools were identified: prescriptive, calculational, and performance. Prescriptive systems include rating systems that assign points to various conservation features. Most systems that have been implemented to date have been prescriptive systems. The vast majority of these are investor-owned utility programs affiliated with the National Energy Watch program of the Edison Electric Institute. The calculational category includes computational tools that can be used to estimate energy consumption. This estimate could then be transformed, probably by indexing, into a rating. The available computational tools range from very simple to complex tools requiring use of a main-frame computer. Performance systems refer to residential energy-efficiency ratings that are based on past fuel consumption of a home. There are few of these systems.

For each identified system/tool, the name, address, and telephone number of the developer is included. In addition, relevant publications discussing the system/tool are cited.

The final section of the report discusses the extent of field validation/ verification of individual systems and tools. In general, there has been little validation/verification done.

A bibliography of literature relevant to the use and implementation of a home energy rating system is also included. 



\section{CONTENTS}

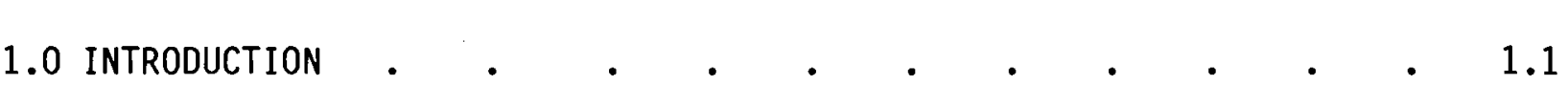

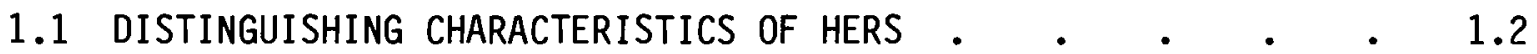

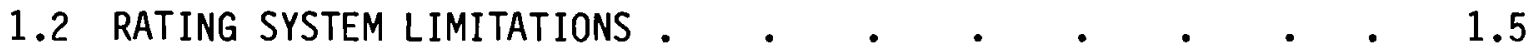

1.3 RELATIONSHIP BETWEEN HERS AND RCS AUDITS • • • • • $\quad$ • 1.6

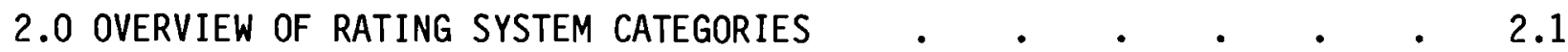

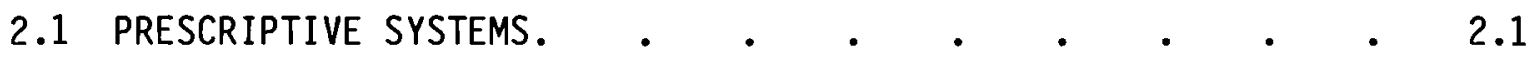

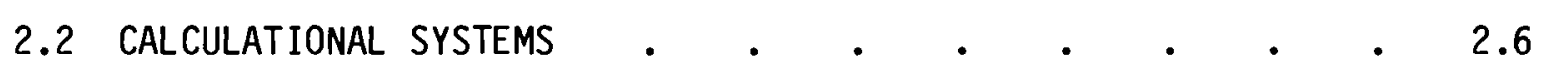

2.2.1 Detailed Computer Models. • • • • • $\quad$ • 2.8

2.2.2 Simplified Computer Models . . . . . 2.10

2.2.3 Hand Calculations . . . . . . . . . 2.13

2.2 .4 Slide Calculators . . . . . . . . . 2.15

2.3 PERFORMANCE SYSTEMS • . . . . . . . . . . 2.15

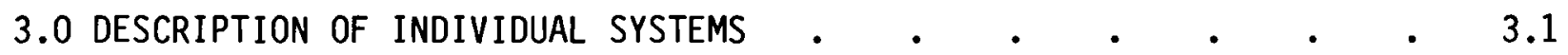

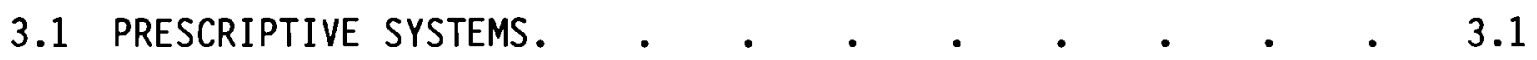

3.1.1 Utility Programs Affiliated with the EEI/NEW Program • 3.1 Edison Electric Institute National Energy Watch • • 3.2

Central Power and Light Energy Efficiency Award Program. $\quad 3.5$

Dallas Power and Light E-OK-Program. • . . $\quad$ - 3.7

Gulf States Utilities National Energy Watch Program • 3.9

Illiois Power Company National Energy Watch Program • 3.12

Kansas City Power and Light 150 Plus Program . • • 3.14

Pacific Gas and Electric Energy Conservation Home

Program . . . . . • • . . . . 3.16 
Texas Power and Light E-OK Program . . . • • 3.19

Union Electric Company National Energy Watch Program . 3.21

3.1.2 Prescriptive Systems Unaffiliated with EEI/NEW • • 3.23

City of Boulder Energy Conservation Point System • • 3.24

City of Visalia Energy Rating System • • • • 3.26

Duke Power Company Energy Efficient Structure Program • 3.29

National Homes Corporation Energy Performance Rating • 3.32

Energyworks, Inc. Mass-Save Pilot Project • • $\quad 3.34$

Public Service Company of Colorado $\mathrm{ECH}_{2}$ ONERGY
Program

Tennessee Valley Authority Energy Saver Homes Program • 3.38

Western Resources Institute Residential Energy

Evaluation Methodology . . . . . . . 3.41

3.1.3 Other Potential Prescriptive Systems . • • . 3.44

State of California Residential Building Standards • 3.45

State of Florida Model Energy Efficiency Code . 3.48

Lawrence Berkeley Laboratory Minnesota Energy
Conservation System ...
.

Owens-Corning Fiberglas Corporation Home Energy

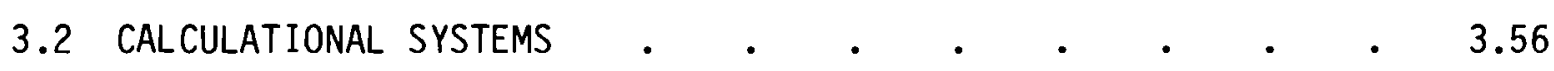

3.2.1 Calculational Rating Systems . . . . . 3.56

Public Service Company of New Hampshire NEW Audit • $\quad 3.57$

Public Service of New Mexico SMART Program • • 3.59

Solar Computer Corporation SOLCOM . . . . . 3.61

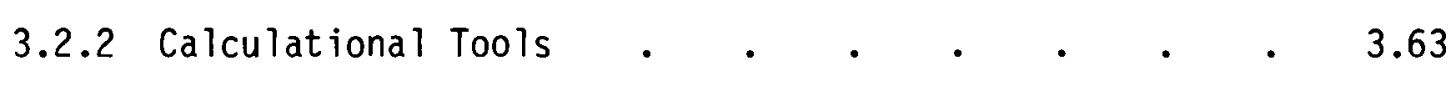

3.2.2.1 Detailed Computer Models • • • • • 3.63 
Lawrence Berkeley Laboratory DOE-2.1 • . . 3.64

National Center for Appropriate Technology SUNCAT • 3.66

3.2.2.2 Simplified Computer Models . . • • 3.67

California Energy Commission CALPAS . • • 3.68

Computerized Energy Audits, Inc.

Performance Energy Rating System . . . . 3.70

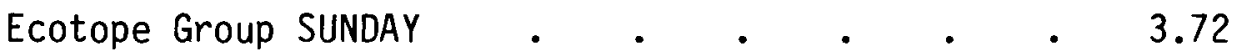

Enercom, Inc. The Enercom System . . . . 3.73

Energy Management Services REAC . • . . 3.75

Energyworks, Inc. RCS Audit . . . . . 3.76

Karpay Associates Residential Energy Analys is 3.77

Lawrence Berkeley Laboratory CIRA • . . . 3.78

National Bureau of Standards Variable Base

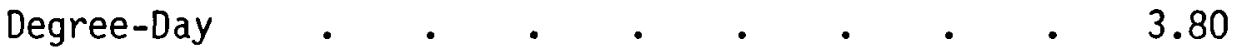

Ohio Department of Energy Home Energy

Analysis Audit . . . . . . . . 3.82

3.2.2.3 Hand Calculations . . . . . . 3.83

Carter Engineering, Inc. • . . • . . 3.84

Oak Ridge National Laboratory RCS Model Audit • 3.85

Owens-Corning Fiberglas Energy Performance

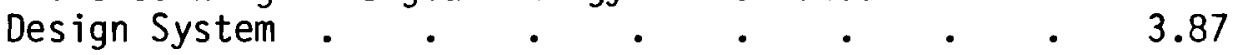

Pacific Northwest Laboratory Shell Thermal

Efficiency Index . . . • . . . 3.89

State of Florida Model Energy Efficiency Code $\quad$ - 3.91

State of Texas Energy Conservation Manual • • 3.92

State of Wisconsin Energy Worksheet . . . 3.94

U.S. Army Construction Engineering Research

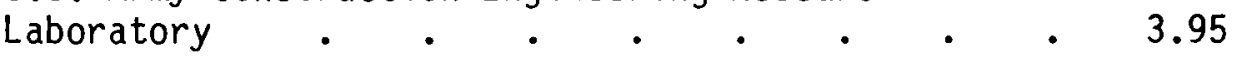


3.2.2.4 Slide Calculator . . . . . . . $\quad$. 3.97

Conservation Management Corporation Energy

Efficiency Appraiser . $. \quad . \quad . \quad . \quad 3.98$

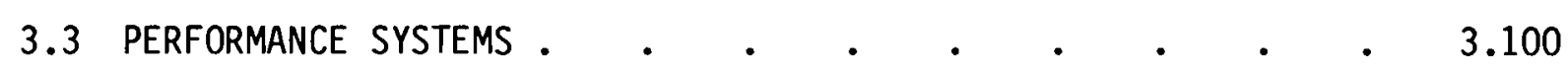

Energy Conservation Consultants Energy-Use Index . . . 3.101

University of Wiscons in Milwaukee County Extension

Service Thermal Proficiency . • . • . • • 3.102

National Association of Realtors Using Energy
Information to Sell Homes . . . . . . . 3.104

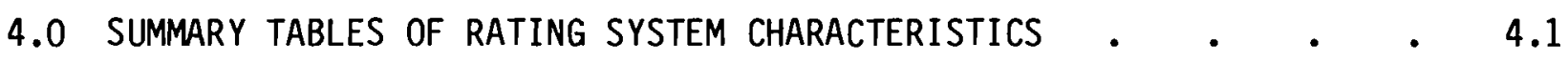

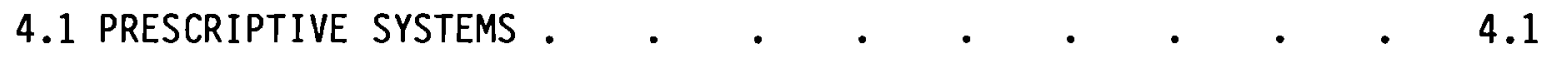

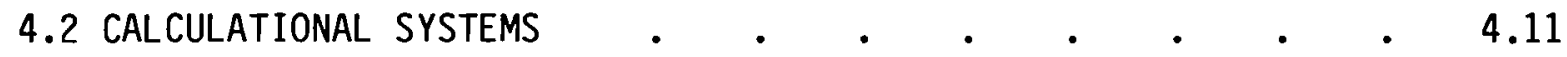

4.3 PERFORMANCE SYSTEMS . . . . . . . . . . . . . 4.19

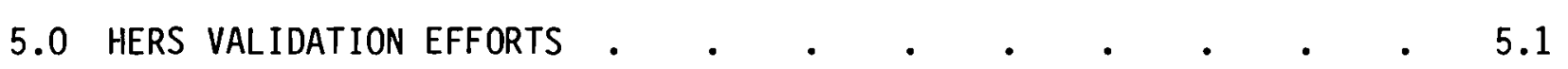

5.1 PRESCRIPTIVE SYSTEMS • • • • • • • • • • 5.2

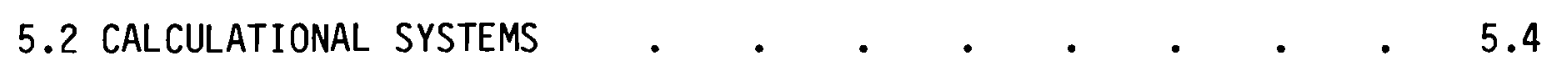

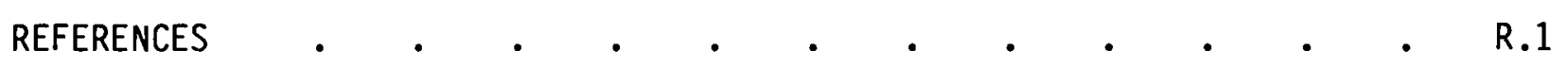

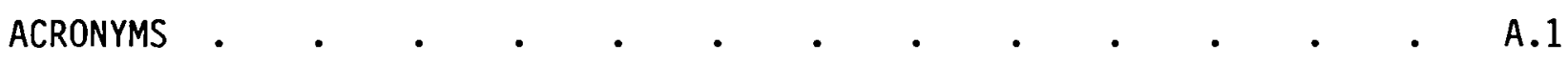

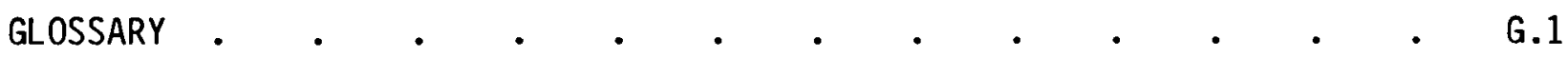

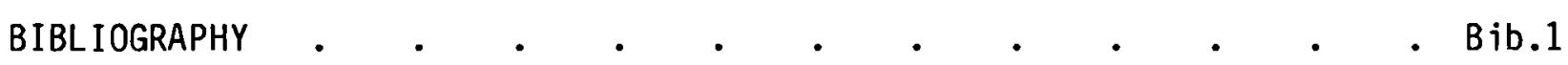

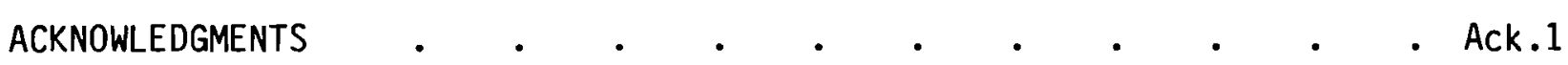

DISTRIBUTION 
4.1 Prescriptive Systems - Developer and Applicability $\quad$ • $\quad$ • $\quad 4.2$

4.2 Prescriptive Systems - Components Considered, Output,

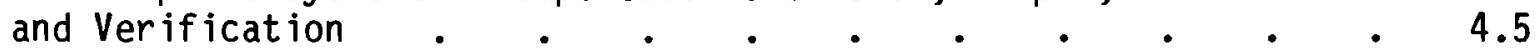

4.3 Prescriptive Systems - Implementation Information . . . . 4.9

4.4 Calculational Systems - Developer and Applicability $\quad$ • . 4.12

4.5 Calculational Systems - Components Considered and Input/Output Data $. \quad . \quad . \quad . \quad . \quad . \quad . \quad . \quad .4 .13$

4.6 Calculational Systems - Calculation Procedures and Verification . . . . . . . . . . . . . 4.16

4.7 Calculational Systems - Implementation Information $\quad$ - $\quad$ - 4.18

4.8 Performance Systems - Developer and Applicability $\quad$ • . $\quad 4.20$

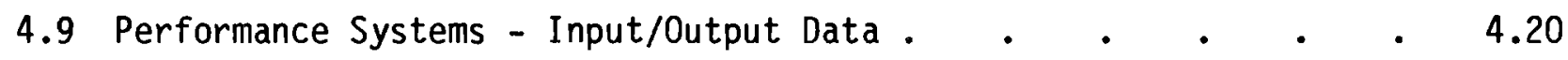

4.10 Performance Systems - User and Implementation Information 4.22 


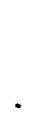




\subsection{INTRODUCTION}

A significant problem in encouraging conservation to its fullest potential in single-family residences is the relative lack of good information on the energy consumption of individual homes. Other than a prior home energy audit, which may or may not be available, home buyers have little information they can use to make intelligent decisions when trading off the initial cost of a home with its yearly energy bill. Likewise, lenders have difficulty making reasonable assessments of the impact of energy efficiency on loan risk since utility bills vary substantially between an energy-efficient home and an inefficient one. Rapidly escalating energy costs have contributed to the need for good information for home buyers and renters, primary and secondary mortgage lenders, and others.

One possible remedy for this problem is the implementation of a voluntary Home Energy Rating System (HERS) to assign an energy-efficiency rating to homes. The efficiency rating would enable home buyers/renters to make a reasonable consideration of home energy cost in their purchasing/leasing decisions. The rating should encourage potential sellers/landlords to improve the energy efficiency of their homes for two reasons. First is the satisfaction of owning a home with a higher rating and the ease of marketing such a home.

Second, the rating will make it more likely that energy-efficiency improvements will be reflected in the market value of the home. A HERS would enable the lending community to more accurately incorporate energy efficiency when assessing loan risks, with a probable result being a higher loan to income ratio for highly rated houses.

There are other potential benefits to implementing a HERS. A HERS should facilitate the marketing of energy-efficient homes by home builders and real estate brokers. Since a HERS would be voluntary, home builders would not face new mandatory construction requirements and home buyers will have no new restrictions on the energy conservation features of prospective homes. Real estate appraisers and assessors should also benefit from having a systematic way to compare and evaluate the energy efficiency of homes. The net result of 
a HERS would be to allow the free market system to adapt more readily to energy shortages and high prices by encouraging energy-efficient construction in new housing as well as conservation retrofits in existing housing.

The principal objectives of this report are to: 1) identify and categorize existing energy rating systems and tools that can be adapted as the basis for a rating system; 2) describe the technical basis of each system/tool, its developer, geographic area of use, type of users, and implementation experience; and 3) make an initial evaluation of the strengths and weaknesses of individual systems/tools and general categories of systems/tools.

This report consists of four major sections which follow this introductory material. Section 2.0 provides an overview of the three categories of rating systems and discusses the types of HERS included and their generic strengths and weaknesses. Section 3.0 is a compilation of information on the individual home energy rating methods and tools which has resulted from our literature reviews, telephone surveys, and other data collection techniques. Section 4.0 presents a tabulation of the characteristics of the various HERS identified. We feel this tabulation will be useful in efficiently assessing the application of each HERS. Section 5.0 discusses the technical validation efforts that have been undertaken for specific HERS.

\subsection{DISTINGUISHING CHARACTERISTICS OF HERS}

HERS may be classified into one of three generic categories based upon the methodology and inputs used to rate a home:

1. prescriptive systems

2. calculational systems

3. performance systems

The first type, prescriptive systems, assigns points to various design features of the home, and then rates the home on the basis of the total number of points scored. Prescriptive systems generally assign points to conservation features on the basis of how much energy is saved by each feature, with a certain number of points allowed for each unit of energy saved. Because the points must have some relationship to energy efficiency, prescriptive methods 
are always based on some type of calculational system (discussed below), although the basis may range from a very simple energy analys is to extensive computer modeling of homes. In practice, prescriptive systems tend to be used most often to make fairly broad comparisons of home thermal performance by assigning the home to a category, although some carefully designed prescriptive systems can actually predict home energy consumption as part of the rating.

The second category of systems, calculational systems, includes methodologies that use building characteristics and either assumptions or data on lifestyle and weather conditions to calculate an estimated energy use for the home. Calculational systems vary greatly in complexity, from simple hand calculation methods requiring few inputs to very large computer models requiring hundreds of inputs. Many calculational systems have been developed as research and design tools rather than being explicitly designed as rating systems, but the output from the systems can either be used directly for home rating or readily adapted to an energy-efficiency rating.

The final category, performance systems, consists of rating systems that evaluate the historical energy consumption of the household to assign a corresponding rating. This rating may be a simple average of energy use, may be normalized to the floor area of the home, and may also be adjusted for weather conditions. Aside from possibly requiring information on the floor area of the home for the rating, performance systems do not incorporate any part of the features of the home into the rating process.

In a previous, unpublished evaluation of HERS, the Solar Energy Research Institute (SERI) employed a somewhat different classification scheme of HERS. (a) In their work, SERI classified HERS into four generic categories:

1. site-specific simulation

2. component optimization

3. prescriptive

4. performance

(a) G. Sussman et a 1. June 16, 1981. (Draft). Finance and Incentives Task Summary, Solar Energy Research Institute, Golden, Colorado. 
The major differences between the SERI classification and the Pacific Northwest Laboratory (PNL) categories are in the site-specific simulation category and the component optimization category. The site-specific simulation type systems in the SERI classification included detailed computer models which predicted energy consumption for a specific building in a specific climate. These systems are roughly equivalent to PNL calculational systems, although the PNL category is somewhat broader since it includes methods that are not sitespecific and methods that do not require computers. SERI's component optimization type systems require an accurate energy appraisal of baseline homes, and then predict energy consumption for the home analyzed by comparing its features to the baseline home. In application, the most notable feature of component optimization systems is that they assign points to various home features during the rating of the home, and because of this are classified as prescriptive systems by PNL.

An additional distinction among alternative HERS is the type of information included in the energy-efficiency rating. The type of rating is important to home buyers, renters and the lending community since it needs to incorporate all information that users require in order to make informed decisions. Several pieces of information appear to be important. The projected energy consumption for the home and an estimate of the first year energy cost would be desirable information for both the buyer and the lender. Lenders in particular may be interested in some way to tie a dollar figure to a home energy rating that aids the overall assessment of loan risk. Additional information of value in a home energy rating would be a measure of how the energy consumption of the house compares to an "average" home in the area and to an "optimum" home in the area. This information would give the prospective home buyer and lessee a reference for interpreting how good a given home is compared to $h$ is other options. It may also provide an incentive to improve and enhance the energy conservation features of a home in order to obtain an aboveaverage or optimum rating. For this purpose, and in general, information on what specific features can be added to a home and the extent to which they would improve its rating would be valuable. 
The type of rating end product given to homes in the HERS examined to date are generally variations or combinations of four basic types. We have characterized the basic rating types as:

1. certification ratings

2. point score ratings

3. category ratings

4. energy-use ratings

Certification ratings simply indicate that the home has met standards for being an "energy-efficient home," but may not give any indication of how much better than the standard the home may be. Point score ratings give a point rating to the house, and are often used in conjunction with other types of ratings. Category ratings assign a home to one of only several possible categories. These categories may be letter grades, descriptors such as "very good", "good", or "poor", or other similar ordinal ranking schemes. A final rating type is an est imate of energy use or energy cost. This type of rating may or may not include a comparison to a standard or "optimal" energy use. An estimate of energy consumption and/or cost provides the most information of the four types of end product. The information can be used either directly or transformed to a relative energy-efficiency rating or index. Prescriptive systems usually use one of the first three rating types, since it is difficult to reliably predict actual energy consumption with prescriptive systems. Calculation and performance-based rating systems are generally based on estimates of energy use.

\subsection{RATING SYSTEM LIMITATIONS}

All of the potential systems/tools for development of an energy-efficiency rating system have limitations. Attempts at field validation of individual tools and rating systems have been extremely limited. This is true even for complex tools such as the DOE-2 code. More detailed information on this limitation is in Section 5.0. Most of the tools take limited account of air infiltration, a factor which can significantly affect energy consumption. With the exception of the generalized calculational systems, nearly all of the tools and systems will have to be adapted in some manner to take account of climate. Finally, the lifestyle of the home occupants will significantly affect energy 
consumption. Some of the calculational tools have a variable that can be qualitatively adjusted for lifestyle; however, most systems do not account for lifestyle variations. Whether or not inclusion of lifestyle is important depends on the use to be made of the rating and how accurate an estimate of energy cost and/or consumption is needed. In general, as rating system complexity increases, development and operational cost and expected accuracy will also increase (subject to the important question of validation).

\subsection{RELATIONSHIP BETWEEN HERS AND RCS AUDITS}

A home energy rating system can potentialy operate very synergistically with home energy audits performed under the Residential Conservation Service (RCS) program or otherwise. An energy audit offers a valuable cost-effective opportunity to gather data on home energy-efficiency characteristics that can be used for preparing a rating. It is quite possible that the same person who makes the audit can also calculate and assign an energy-efficiency rating at a small incremental cost. A pilot test of adding a HERS to RCS audits in Massachusetts is currently underway (see page 3.34).

Under Sections 210-225 of the National Energy Conservation Policy Act (NECPA) of 1978, utilities with annual natural gas sales of 10 billion cubic feet or more, or 750 million kilowatt-hours of electricity or more are required to offer home energy audits to the ir customers on request. ${ }^{(1)}$ The audits are to provide an estimate of installation cost and energy savings available from installation of alternative energy conservation measures. (2) The procedures used to make these determinations are largely based on the model audit procedure developed by Oak Ridge National Laboratory (ORNL) and SERI. These procedures have been computerized by several vendors (e.g., Enercom, Inc., Energy Management Services, Energyworks, Inc.) who prepare, for a fee, software specificaliy adapted for the climate of individual utilities. The model audit and the specific programs developed by certain vendors are discussed in Section 3.0.

As part of an RCS energy audit, the utility is not required to provide the homeowner with an estimate of the total energy load or consumption for the home. In the case of new homes, however, this calculation needs to be performed, in the absence of prior utility bills, as part of the process of estimating potential energy savings resulting from retrofitting energy conservation 
measures. The ORNL model audit provides a procedure for making this calculation that is largely based on America Society of Heating, Refrigerating and AirConditioning Engineers (ASHRAE) equations. ${ }^{(3)}$ Some of the vendors also include this capability in their software.

If the capability to estimate energy consumption is included in the RCS audit software, an energy-efficiency rating or index can be developed at little additional cost. It is also possible that alternative procedures for making the energy consumption estimate (such as those discussed in Section 3.0) can be added to existing audit software or substituted for the existing estimating procedure if they offer superior estimating capability. Whether or not the energy audit software or computational procedures are used to develop a rating, the audit process itse lf is a valuable opportunity to obtain data on a house that can be used as the basis for assigning a rating.

DOE has recently amended the RCS regulations. (4) The amendments generally simplify the RCS requirements to the minimum level required by NECPA. 


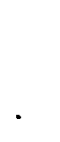




\subsection{OVERVIEW OF RAT ING SYSTEM CATEGORIES}

For the purposes of this report, HERS have been classified into three categories: prescriptive systems, calculational systems, and performance systems. The essential difference among the various types of systems is the method of rating the home. Prescriptive systems assign points to various conservation features in a home, and then rate the home on the basis of the total number of points scored. Calculational systems use data on home features as the input to calculational methodologies for predicting home energy consumption. Performance systems use the prior recorded energy consumption of the home as the basis for the home rating, and do not incorporate any information on conservation features of the home. Each of these types of system is discussed in more detail below.

\subsection{PRESCRIPTIVE SYSTEMS}

Prescriptive HERS are systems that assign point values to various conservation features of a home and then add the points to obtain a total point score. The point score forms the basis for assigning the house an energyefficiency rating. Prescriptive systems are designed to enable a home energy rating to be completed with no calculational tools, with the possible exception of a four-function hand calculator.

In previous work, SERI had broken prescriptive systems down into two categories, which they termed prescriptive systems and component optimization systems. SERI made this distinction based on how each system category was developed. Component optimization systems were identified as simplified versions of more detailed computer simulation programs, whereas prescriptive systems were identified as point systems developed with less rigor than component optimization systems. This definition was not used in the PNL categorization because it was felt that the important criteria were the way the system was used and the types of inputs it required, rather than how the system was developed.

Prescriptive systems form a rather broad category and vary significantly in the number of components considered in arriving at a rating, as well as the 
technical analysis and detail used in developing the systems. The more detailed prescriptive systems consider many factors in the home rating, including building shell characteristics, the hot water system, the heating, ventilation and air conditioning (HVAC) system, appliances, and the use of active and passive solar. Less detailed systems may consider only part of the building shell characteristics in assigning a rating, such as the type of glazing, amount of insulation, and type of infiltration controls. Development of prescriptive systems generally requires the use of an energy load model or calculational system to assign relative points to each energy conservation feature of a home. Some of the prescriptive systems reviewed were developed in great detail, using results from many computer simulations. Other prescriptive systems were developed in less detail, and were based upon hand calculations of energy savings.

As part of the review of prescriptive HERS, a number of users and developers of these systems were contacted. These contacts were not intended to cover every prescriptive HERS in existence, but rather to cover the major variations of prescriptive systems. By examining the range of possibilities, some generalized comments and observations on prescriptive systems as a class can be made.

A11 prescriptive systems involve summing points that can then be adapted to an energy-efficiency rating. The rating produced generally takes one of four forms: certification, point score, category, and energy use. These general rating types are described below.

Certification Ratings. Certification ratings are widely used, particularly by utilities participating in the National Energy Watch (NEW) program sponsored by Edison Electric Institute. Certification type ratings are yes/no propositions; the house either meets the certification requirements, or it does not. If the house meets the requirements, it is certified an "Energy-Efficient House," or some similar title. Possible certification criteria would be simply whether the house meets the DOE RCS program measures listed in Appendix I to 10 CFR 456, the National Association of Home Builders Thermal Performance Guidelines, or the ASHRAE 90-75 residential energy conservation standard. 
Point Score Ratings. Prescriptive systems by definition assign a total point score to a house during the rating process, so it would seem logical to use this point score as part of the rating itself. In practice, point scores are generally used only as supplementary information to one of the other primary ratings because of the difficulty in interpreting a point score without additional information. Point scores by themselves only show an ordinal ranking of homes relative to each other. Point scores are often reported as additional information with a certification rating or a category rating because of the desire of the homeowner to see exactly how many points the home scored.

Category Ratings. Category-type ratings are similar to certification ratings, only instead of two categories (certified and noncertified), a number of categories are used. Based on the point score, a home is assigned to a category such as poor, good, very good or excellent. Category-type ratings give more information on the performance of the home than certification ratings, but are not as common as certification ratings. A good example of a category rating is the Energy Rating System of Visalia, California, where the point score of the home is used to assign it to one of five categories. The lowest rated homes are zero-star homes and the highest rated are 4-star ( $\star \star \star \star)$ ) homes. Visalia also reports the total point score along with the category.

Energy-Use Ratings. A prediction of the total energy used by the house is an energy-use rating. The energy-use ratings for prescriptive systems are uncommon, primarily because of the difficulties in using prescriptive systems to accurately estimate energy use. Although prescriptive HERS add points based on the types of conservation features in a home, the energyefficiency effect of these conservation features is most often not additive, but rather intricately related. It is possible to relate the point score to energy consumption, but not without a substantial increase in the development cost of the system. A good example of a prescriptive system using an energy-use rating is the Minnesota Energy Conservation Rating System developed by Lawrence Berkeley Laboratory, which predicts home energy consumption as part of the rating. 
A large number of prescriptive HERS are currently in use by utilities across the nation, and a smaller number are in use by state and local governments. Many of the utility-sponsored programs are affiliated with the Edison Electric Institute's NEW program. The NEW program is a voluntary, loosely structured program for investor-owned utility systems aimed at encouraging energy conservation and reducing load growth through the use of HERS. Edison Electric Institute offers a prescriptive HERS system as part of the NEW program that is applicable to much of the U.S. Participating utilities may also develop their own standards and rating systems, provided that the utility standards are at least as strict as the national NEW system. Most utilities contacted by PNL for information on their HERS programs were affiliated with the NEW program, and most had made some modifications to the national NEW prescriptive system to tailor it more specifically to their region.

Development costs for prescriptive HERS depend on the detail, accuracy, and final rating desired from the system. A detailed system considers a larger number of components in the rating. Since point values must be calculated for each component (and sometimes combinations of components), increasing the detail in the system directly increases its development time. Similarly, as the desired accuracy increases, development time also increases. If a high degree of accuracy is not required, point values are often assigned based on hand calculations. Developing a highly accurate prescriptive HERS would require extensive simulation, and probably the use of a detailed computer model. Adapting existing systems for regional or national use would still require significant development if high accuracy were desired, since the point values would need to be developed for a number of geographic areas. Finally, if the rating desired for the system is an energy-use estimate, this will complicate development of the rating system. This problem is really related to accuracy considerations. Assigning points to conservation features to put a house in some sort of energy-use category generally requires less detail and accuracy than assigning points to predict energy consumption.

Development of prescriptive HERS capable of statewide or regional implementation could use existing systems as a basis, either adapting them directly 
or using their basic methodology. In either case, such a HERS would probably require breaking the country into a number of climatic regions and developing a point system for each region. The number of regions for which this would be done depends upon the desired accuracy of the system.

The ratings for most prescriptive HERS are done by raters employed by the utility. The rating usually requires a site visit that may require from 30 minutes to two hours. These ratings are generally done at no charge to the homeowner. Alternatively, the rating sheet may be filled in by the homeowner or builder and submitted to the utility. In the case of new houses, the rating may be completed by the utility on the basis of the house plans.

The major costs of rating a home with a prescriptive-type HERS are for collecting the required data. Going through the rating process itself is generally easy and can be done in a few minutes. Programs which use trained raters to collect the data generally cite a cost of approximately $\$ 100$ to $\$ 150 \mathrm{per}$ house rated. As a sidelight, utilities with both RCS programs and prescriptive HERS were nearly universal in saying that collecting the information for the prescriptive HERS rating added very little to the cost of an RCS audit.

Many of the prescriptive HERS programs operated by utilities have been in use for several years, and a substantial number of houses have been rated. By $f$ ar the largest class of users of any of the prescriptive systems are builders, and, of course, homeowners. Somewhat noticeable in their absence among the users is the lending cormunity. Several of the HERS developers indicated that the lending community had initially shown interest in using the systems, but never followed up with any significant use.

Only a very limited amount of field verification of prescriptive HERS has been performed by the developers and users who have been contacted to date. Verification that has been done has usually been aimed at determining if the programs really save energy, rather than determining the uncertainty in the results of the ratings systems. One of the more noteable verification programs is currently in progress by Central Power and Light in Corpus Christi, Texas. Central Power and Light has recently initiated a monitoring program for homes 
they have rated under their Energy Efficiency Award Program. The monitoring program will record heating and total electric consumption over 15-minute intervals, and will extend over a one-year period.

As a class, prescriptive systems have several advantages. They are easy to use thus minimizing rater training and rating costs. Including costs for a home visit to collect rating data increases the rating cost to a moderate leve1, generally in the $\$ 100$ price range. Prescriptive systems also provide for easy communication of the rating and the reason for the rating. Because the point score (and calculation procedure) is generally contained on one or two pages, the user of the rating can easily see where the home scored the most points, and why the house is rated as it is. In addition, the rating sheet indicates areas that are likely candidates for retrofitting conservation features. Finally, prescriptive systems have proved to be valuable to utilities in encouraging energy conservation. The majority of the utilities contacted indicated they were encouraged by the results of their HERS programs.

\subsection{CALCULAT IONAL SYSTEMS}

The calculational system classification encompasses a broad range of rating systems and tools that could be used to produce rating systems. Computer simulations and hand calculation methods are categorized together as "calculationa1." We have used this broader classification rather than the SERI classification of "site-specific simulations" because most of the simulation methods were neither site-specific (they use climatic data as an input variable), nor true computer simulations (many use hand calculations).

Calculational systems produce an estimated measure of the energy requirements of a building. Some of the calculational systems surveyed consider only the building shell design load, while others analyze the HVAC equipment to arrive at an annual energy-use for space conditioning. All of the calculational systems consider space heating, either by calculating the annual space heating load or by estimating energy used for space heating. Most of the calculational systems also analyze air conditioning loads or energy use. More detailed models also consider water heating and appliance uses of energy. 
Examples of some of the output from calculational systems are design load calculations (Btu/hr), annual energy usage (Btu), and annual cost of energy. Any of these measures could be used as a rating, or these figures could easily be transformed into an index if that is the preferred end product of a rating. Possible indices include: 1) the ratio of energy use to the average energy use for similar houses in the same location, 2) the ratio of design load, annual energy usage or energy cost to square footage of the conditioned space, 3) the ratio of design load, annual energy usage, or energy cost to annual degreedays, or 4) the ratio of design load, annual energy usage, or energy cost to both square footage and annual degree-days.

The calculational systems surveyed range from detailed hourly computer simulation models with hundreds of input variables to simple hand calculations requiring relatively few input variables. The calculational systems were further broken down into four generic types: 1) detailed computer models, 2) simplified computer models, 3) hand calculations, and 4) slide calculators.

of the calculational systems surveyed only one (the SOLCOM model) was developed specifically for use by the lending community. This simplified computer model provides life-cycle cost information as well as an estimate of principal, interest, taxes, insurance + energy (PITI $+E)$. The majority of calculational systems have been developed primarily: 1) as design or parametric analysis tools, 2) as a means of assessing compliance with an energy code or standard, or 3) as an RCS audit tool. Typically, the most complex methods were developed for parametric analyses. Those developed as design tools for sizing HVAC equipment range from simplified computer simulation models to simple hand calculations. The energy audit methods encountered in the survey include both hand calculation methods and simplified computer models. The methods developed to assess compliance of proposed buildings to energy codes or standards are typically the simplest of the calculational methods, requiring a few hand calculations.

Site-specific models, primarily the hand calculations and the computerized home energy audits, could require moderate to extensive modification to generalize them to regional or national adaptation. This could entail high front- 
end development costs. The advantage of the generalized computer models is that their development costs are already sunk; therefore the implementation cost would largely be for training.

In general, accuracy is likely sacrificed as the models are simplified; however, as a group, the accuracy of the calculational systems is generally considered greater than that of prescriptive systems. Typically, the simplified models assume constant values for parameters which are variable in the detailed models. For example, if weather data are implicit in the model, the model is site-specific. If building data are implicit, the model becomes applicable to only one housing type. Thus, calculational models tend to become less generalized as they are simplified. In choosing between a site-specific system or a more complex, generalized system for a nationally applicable HERS, the tradeoff is between the cost of generalizing the site-specific systems and the cost of more training and more time per rating for the more complex, generalized systems. The simplified computer models may provide a balance between accuracy and simplicity. If the model runs on a minicomputer rather than on a main-frame computer, the incremental data processing cost per rating becomes small as more ratings are performed.

In general, the advantages and disadvantages of using existing calculational methods as a basis for a HERS are:

Advantages: $\quad$ 1. flexible with respect to climate and housing type

2. potentially more accurate than other methods

3. sunk development costs

Disadvantages: 1 . may require more training

2. lack of adequate field verification

The advantages and disadvantages of specific calculational systems are presented below under their generic classification.

\subsubsection{Detailed Computer Models}

Two calculational systems were surveyed under the heading of detailed computer models: DOE-2.1 and SUNCAT. Other models (AXCESS, BLAST, BLDSIM, ECUBE, ESAS, TRACE) are available that perform essentially the same types of 
detailed calculations. BLAST, for example, is a program developed by the U.S. Army Construction Engineering Research Laboratory that is receiving use and continued development in the U.S. Department of Defense. Survey studies are available that compare a large number of models. (5) DOE-2.1 and SUNCAT were chosen to represent the field of detailed hourly simulation models because they have both been used as the basis for developing prescriptive rating systems or more simplified calculational systems.

Both of these programs use hourly weather data to simulate hourly energy performance of buildings. Typically the programs run on a main frame-computer, usually on a time-share basis. Although neither of these systems were developed specifically for use as a rating system, the types of output supplied by the codes can be used to construct a rating. Output includes building envelope energy loads, total annual energy use, or total annual energy cost.

The advantage of the complex simulation models is that they have the most potential for accurately predicting actual energy-use. Some attempt has been made or is being made to validate some of these models with field tests, although, to date, this effort has been less than adequate. Another significant advantage is that these calculational models can be used to simulate a broad range of building types in a wide range of climate types. This eliminates the development costs required to expand site-specific rating systems to other parts of the country. Since the development costs of these models are already sunk, the major cost of implementing a detailed simulation would be the cost of training personnel to use the model.

The disadvantages of these types of systems arise primarily from their complexity. Most of them require rather extensive, detailed data input. The complex input requirements will likely require a relatively high level of rater training. In addition, collecting and preparing the data for processing may be fairly time-consuming.

Although the models may be too complex and time-consuming in the ir present form for use as a rating system, these programs may serve as the technical basis for developing a simpler rating tool. Examples of this use of the detailed computer models include: 
1. development of a regression equation relating predicted annual energy use to a few easily measurable building parameters (see discussion of PNL's Shell Thermal Efficiency Index);

2. development of a slide calculator for quickly estimating annual energy use or cost (see CMC's slide calculators); or

3. development of a prescriptive system (see City of Boulder, the LBL Minnesota Energy Conservation System and the Western Resources Institute system as examples).

4. development of a simplified model (see Owens-Corning, EPDS model)

Other methods of easily implementing a rating based on a detailed computer model might include the development of nomographs or tables that would enable the rater to quickly and accurately determine a rating without the use of specialized equipment.

\subsubsection{Simplified Computer Models}

The majority of the calculational systems can be described as simplified computer models. These simplified models have a wide range of characteristics and capabilities. This category includes the computerized RCS audits as well as a number of models developed as tools for building design and analysis. The following systems are classified as simplified computer models:

1. Solar Computer Corporation--SOLCOM

2. Karpay Associates--Residential Energy Analysis Model

3. Lawrence Berkeley Laboratory--CIRA

4. Enercom, Inc.--The Enercom System

5. Energyworks, Inc.--RCS Audit

6. Energy Management Services--REAC

7. Public Service of New Hampshire--NEW Audit

8. Computerized Energy Audits, Inc.--Performance Energy Rating System

9. Ohio Department of Energy--Home Energy Analysis Audit

10. National Bureau of Standards--Variable Base Degree-Day 
11. California Energy Commission--CALPAS3

12. Ecotope Group--SUNDAY

13. Owens-Corning Fiberglas--EPDS

As a group, the simplified computer models potentially offer a balance between accuracy and simplicity not available with other systems. Generally, the input format is simpler and the data processing time is lower than that of the detailed computer models. This should aid implementation as well as lower the cost per rating if this type of system is used as a HERS. The major disadvantage of systems in this category is the lack of rigorous field testing. Specific advantages and disadvantages of particular systems are highlighted in the following paragraphs.

The SOLCOM model developed by the Solar Computer Corporation is the only rating system developed specifically for the use of the lending community. This model provides information that would be of interest to lenders, realtors, and appraisers. Only real estate brokers and appraisers, however, have had any involvement with the model up to this point. The advantage of this system is that it is already geared to the lending community. It provides both lifecycle energy cost information and an estimate of PITI + E. Little or no modification would be required to implement this as a HERS, assuming it is technically valid.

The Karpay model has been used by the City of Boulder to verify and expand the point system being implemented by the city. It is used to rate houses with uncommon design features that would not be adequately covered by the point system. Its main disadvantage is that it has not been technically proved. The City of Boulder and the developer feel that the model's simulation of passive solar building features is less than adequate.

The newly developed CIRA model may offer a good compromise between simplicity and accuracy. This model has an extremely simple, user-friendly input format, yet its estimates of energy load are reported to correspond closely with the more complex DOE-2.1 model predictions. The CIRA model has incorporated the best of the state-of-the-art energy analysis programs. It runs on a 
variety of microcomputers, making it less expensive to run than programs that run on a main-frame computer. The main disadvantage, again, is the lack of field testing.

The computerized home energy audits are all essentially the same (with the exception of the Ohio model) having been based largely on the Oak Ridge Model Audit. These models calculate annual energy usage and cost based either on past utility bills or on simplified load calculations. In some cases, the load calculation is not included in the audit software, but is performed by hand. Either the annual cost of energy or the annual energy usage could be used as the basis for a rating. To be implemented as a rating system, the load calculation would be done for both new and existing houses, rather than relying on billing data for the existing structures.

The Ohio model is a very simple computer model requiring few inputs. The limited input causes some difficulties for houses that vary markedly from the prototypes modeled in the code. The Ohio Department of Energy states that the code currently does not model uncommon housing designs adequately.

The biggest advantage of the computerized RCS audit systems is not necessarily the audit software, but rather the availability of input data for the rating model. A great deal of data on residential dwellings is being accrued on a national level through the RCS energy audit programs. Use of information available from these audits may avoid a duplication of effort by requiring only one trip to inspect a house. According to ORNL, the primary disadvantage of the RCS-type audits is that they tend to underestimate the annual energy usage in order to avoid overestimating energy savings of candidate conservation options.

Computerized Energy Audits, Inc. takes a unique approach in that they use actual performance measures as input to their energy-use analys is model. Air infiltration is measured by pressurizing the house. This technique allows determination of both the extent and the locations of the air leakage. The mechanical equipment is also tested to determine its steady-state efficiency. Using actual measured data will likely lead to more accurate results. 
The NBS/VBDD model is thought to be relatively accurate and it has the advantage of running on a common programmable calculator. Unfortunately, the data entry and processing are very time-consuming because of the limitations of the programable calculator. This would likely lead to a higher cost per rating if this system is used as a HERS.

CALPAS is probably the most complex of the simplified computer models. Because of the wide variety of input values, it is thought to be more accurate than some of the more simplified procedures. Again, accuracy is achieved at the expense of increasing the time and cost per rating.

SUNDAY has the advantage of running on a minicomputer, resulting in lower costs per rating. Its main disadvantages are that it is not in the public domain and it has not been field tested.

The EPDS system was developed based on Owens-Corning's hourly simulation model OCF-2. OCF-2 has been field validated with data from three test houses. EPDS, in turn, has been compared to OCF -2 for validation purposes. The EPDS system is available as a manual calculation and as a simplified computer system.

\subsubsection{Hand Calculations}

The hand calculation methods generally involve a steady-state load calculation based on ASHRAE equations. The complexity of the method is related to the number of variable input parameters versus the number of parameters that are assumed to be constant. The hand calculation systems include the following:

1. State of Texas

2. State of Florida

3. State of Wisconsin

4. Oak Ridge Model Audit

5. Carter Engineering Method

6. U.S. Army CERL

7. PNM-SMART Program.

8. PNL-Shell Thermal Efficiency

The systems adopted by the states vary in their level of complexity. They all calculate individual component loads on the basis of U-values, surface 
areas and temperatures and then aggregate the individual loads to obtain the total design load of the building. The Texas and Florida methods go beyond the design load calculation that is the end product of the Wisconsin calculation. Florida calculates the annual energy usage for space conditioning. The Texas method has the advantage of being more detailed than the other two. Texas considers appliance and hot water energy usage in addition to the space conditioning, thus providing a total energy consumption for the house. These sitespecific systems could be generalized for use as a HERS capable of nationwide implementation by providing location-specific tables of insolation, shading coefficients, degree-days, etc. Currently each of the state systems provides this type of information for regions within their state. Developing tables of site-specific parameter values may lead to high front-end development costs.

The Oak Ridge Model Audit was developed as a simple, noncomputerized baseline for the RCS program. The audit is based either on past utility bills or on a manual calculation of annual energy-use. The energy consumed by the previous occupants is not necessarily a good indicator of the future energy consumption of a new occupant. Therefore, to use the Oak Ridge Model Audit as a basis for a HERS, the load calculation that is currently performed for houses with no prior energy consumption records would have to be done for all houses. The Oak Ridge Model Audit has the advantage of being continuously modified to incorporate new technical information as experience in using the model is gained. The disadvantage of this model is that it purposely underestimates energy loads in order to achieve conservative estimates of potential conservation savings.

The Carter method involves very simple calculations, using values obtained from tables. The site-specific nature of this method would likely lead to high development costs. Extensive work would have to be done to determine heating equivalent full load hour/cooling equivalent full load hour (HEFLH/CEFLH) standards for each type of building, HVAC system and climate, based on past utility records for each location.

The algorithms developed by the U.S. Army CERL would be relatively easy to use. However, they would have to be tested to determine their applicability to the wide range of housing types encountered on a national level. Correction 
factors would have to be developed for each climatic region for a number of site-specific parameters. This would likely entail higher front-end development costs than many of the other systems.

The SMART program was developed over a number of years for the Public Service of New Mexico (PNM) service region. The energy-use calculations have evolved to become very accurate for this area; however, it would be difficult to generalize this system to a nationwide system without considerable cost.

The regression equation developed by PNL would be easy to use. The regression would require field testing to determine its applicability on a nationwide scale. If a predicted heat load, rather than the shell efficiency index, is the desired form of the rating, a regression equation would have to be developed for each climate region.

\subsubsection{Slide Calculators}

The slide calculator approach adopted by the Conservation Management Corporation is probably the simplest type of calculational system available. It requires relatively few inputs and a minimum of instruction to perform the calculations. While these factors would lower the cost per rating, the frontend development costs of a slide calculator could be moderately high, depending on the desired level of accuracy. Since each slide calculator is specific for an area and type of house, a family of slide calculators would have to be developed to account for different climatic regions and housing types. The number of parameters that could be offered on a slide calculator may be limited by the size of the slide calculator.

\subsection{PERFORMANCE SYSTEMS}

Performance systems refer to ratings that use past utility billing data as a basis for assigning a rating. In our review of rating systems, relatively few were found to be performance-based. This sparsity of performance systems is probably because most of the existing systems, prior to the RCS program, were developed for new houses either as an indicator of compliance with an energy code or standard, or as a method of sizing HVAC equipment. The performance classification includes the following systems: 
1. National Association of Realtors (NAR) - Using Energy Information to Sell Homes;

2. Energy Conservation Consultants - Energy Use Index; and

3. University of Wisconsin Milwaukee County Extension Service - Thermal Proficiency

Typically, performance systems calculate an index that is compared either with an average index for the particular type of house in the same area, or with indices calculated for the same house in previous years. Comparison with a local average provides information on how the energy-use in a house compares with other similar houses. Comparing the index to those of previous years provides information on trends in energy-use in that particular dwelling over time. Indices encountered in the survey of performance systems were either energy-use indices or energy-cost indices. Energy-use indices are a ratio of total annual energy consumption to annual heating degree-days (Btu/degree-day), or to square footage of the conditioned space (Btu/square foot), or both (Btu/square foot/degree-day). The energy-cost index is the ratio of annual energy cost to square footage of the conditioned space ( $\$ /$ square foot).

The main advantage of performance systems is their simplicity. They are perhaps the easiest systems to implement, since the primary data required for a rating is easily obtainable and calculations are simple. No special training is required to conduct a performance-based rating. With most existing performance systems, the rating was performed by the homeowner. The only measurement required is the square footage of the conditioned space.

There are several disadvantages to performance systems. First, they provide little information on how the energy loads are realized. Users of the rating would have no way to discern if the home achieved its rating based on the lifestyle of the occupants or on the energy conservation features of the house. The NAR system is the only one that attempts to resolve this issue. In addition to calculating an energy-use index, the real estate broker using this system modifies the rating by making a qualitative assessment of whether the rating is due to lifestyle or to the conservation features of the home, or 
both. The validity of the qualitative modifier, depends on the skill of the realtor in obtaining accurate information in an interview of the current occupants and a walk-through of the structure. Once the homeowner and the real estate industry become familiar with the rating system, they will perhaps have an incentive to manipulate responses to improve property sales.

Real estate brokers and homeowners would be more likely to attribute the energy use to lifestyle rather than to building features. This is advantageous from the seller's perspective because it implies that the lifestyle of the current occupants accounts for more energy consumption than an average family and not that the property itself is energy inefficient. In the event of manipulation, the qualitative modifier could become a liability in solving the lifestyle issue.

A second disadvantage of performance systems is that prior utility data may either be unavailable or inappropriate for rating a house. This occurs in the following cases:

- newly constructed house,

- newly remodeled house, or

- change in occupants.

In the case of newly constructed homes or homes in the planning stage, historical energy information is simply not available. Previous billing data may not accurately predict future energy consumption if the house has been remodeled or if there has been a change in the occupants. When they decide to se11, many property owners are motivated to make home improvements in order to enhance the sale. Some of these improvements could change the thermal characteristics of the building envelope. This improvement would not be reflected in prior utility bills. When a rating is performed at the time of sale, a change of occupants will always be a given. The energy consumption of the seller may not be a reliable predictor of future energy consumption, particularly if lifestyles are significantly different.

Other disadvantages are inherent in the utility data itself. Many utilities do not read meters on a regular basis, so monthly bills are often estimated. This could reduce the accuracy of the rating if estimated rather than 
actual consumption is considered. If the energy-used for heating and cooling is not metered separately from other uses of the fuel, such as water heating, an energy index with a degree-day denominator may not be a good indicator, since uses of energy other than heating and cooling are generally not a function of the weather.

The main advantages and disadvantages of performance systems are sumarized below.

Advantages: $\quad$ 1. data easily obtained

2. simple calculations

3. no special training required

4. easily implemented

5. few subjective measures

6. low cost.

Disadvantages: 1. No provisions are made for new houses, recently remodeled houses, or occupancy changes.

2. Does not provide information on where loads originate (e.g., lifestyle, structure, mechanical system efficiency).

3. Billing data may not be accurate if bills are estimated and if uses of energy that depend on degree-days are not metered separately from uses that are independent of degree-days.

4. Subject to possible manipulation by homeowners or real estate brokers. 


\subsection{DESCRIPTION OF INDIVIDUAL SYSTEMS}

This section contains descriptive information on rating systems and measuring tools for prescriptive, calculational, and performance systems. For each system, we have attempted to provide references to written material on the programs and individuals to contact for more information. Many of the characteristics of the systems are described in subjective terms, such as "low time per rating" and "moderate development time". The rationale and meaning of these subjective terms is described in Section 4.0, where the descriptors are used in sumary tables. The HERS rating systems/tools discussed in this section are not intended to be a complete list. The coverage is intended to provide a discussion of significant rating systems that our research has disclosed and to indicate the range of tools available than can be utilized for implementation of rating systems.

\subsection{PRESCRIPTIVE SYSTEMS}

Sections 3.1-3.3 describe the prescriptive systems surveyed. The systems have been grouped in the following way: 1) those affiliated with the Edison Electric Institute (EEI) National Energy Watch (NEW) program; 2) those currently in use, but not affiliated with EEI/NEW; and 3) those not currently in use but which could be easily adapted for use.

\subsubsection{Utility Programs Affiliated With the EEI/NEW Program}

This subsection describes the EEI/NEW program, and nine utility HERS that are affiliated with the NEW program. The utility programs were chosen to indicate the range of complexity and variety among NEW-affiliated programs. All of the utilities contacted offered the NEW rating to customers at no charge. 


\section{EDISON ELECTRIC INSTITUTE \\ NATIONAL ENERGY WATCH}

The National Energy Watch (NEW) program was structured by Edison Electric Institute as a voluntary, umbrella type program for investor-owned electric utilities. The NEW rating system was developed as a general guideline which could be used for national implementation. Member utilities are free to expand the system, or substitute their own system, provided that the modified system is at least as stringent as the standard NEW program. The most important criterion for NEW membership is not the substance of the rating procedure, but whether the rating procedure will provide a means of meeting the objectives of the NEW program, which are:

At the national level: to help reduce the drain on the fossil fuels that are in short supply.

At the utility level: to help reduce the requirement for new and costly generating facilities.

At the customer level: to help keep the customer's monthly energy bills as low as possible.

Edison Electric Institute began the NEW program in 1978. Over 170 investorowned utilities nationwide are currently members of the NEW program.

In developing the NEW system, points were assigned to various home features based on thermal comfort design guidelines that had been previously developed by EEI for new all-electric home construction. The NEW program can be used to rate new and old single-family homes and mobile homes. Considered in the home rating are building shell characteristics, HVAC systems, some appliances, and active solar systems. The information required to rate the home is shown on the following page.

Rating a home with the NEW system is a simple matter of going through a checklist of conservation features, verifying the features that are applicable to the home, and tallying the points accrued. The output from the rating system is the certification of the house as a NEW home, and a total point score. An 80-point minimum is required for certification of new homes, while 
existing homes may be certified by either meeting the 80-point requirement or by upgrading the point score of the home by 20 percent over a prior rating. Allowing two ways to qualify existing homes for the NEW certification provides an incentive to make some modifications even in older homes where retrofitting difficulties preclude achieving an 80-point score.

\section{Information Required for Rating}

\begin{tabular}{ll}
\hline$\frac{\text { Item }}{\text { Insulation }}$ & Wall, ceiling and floor insulation values. \\
Windows and Doors & Glazing type and use of insulated doors. \\
Weather Stripping & Whether house is weather stripped. \\
Attic Ventilation & Type and size of attic ventilation \\
HVAC System & $\begin{array}{l}\text { Type of equipment, insulation on ductwork, } \\
\text { setback thermostat. }\end{array}$ \\
Appliances & EER Ratings. \\
Active Solar & Existence of solar equipment.
\end{tabular}

Developing the standard NEW rating system is judged to have been moderately expensive, but implementing the system for a specific utility can be done very cheaply. The cost of the rating for the standard system is low to moderate, depending on how the information on the energy conservation features of the home is verified. A detailed inspection of the house to perform the rating can generally be done in under two hours. The technical training required in order to rate the homes is low to moderate.

Edison Electric Institute believes that one of the best features of the NEW program is the marketing program which encourages consumers to participate. As part of the marketing for the NEW program, certificates, decals, door knockers, pen sets, and other awards are offered to homes which meet the certification requirements. Giving the homeowner some kind of visible recognition for conserving energy is felt to greatly increase participation in the NEW program. 
Additional

Information: National Energy Watch - Residential

Program Guide, Operating Manual and

Promotions Catalog, November, 1980.

Contact: Bob Griffin

Edison Electric Institute

1111 19th Street, N.W.

Washington, D.C. 20036

202-828-7514 
CENTRAL POWER AND LIGHT

ENERGY EFFICIENCY AWARD PROGRAM

The Energy Efficiency Award (EEA) Program was developed by Central Power and Light (CPL) for the ir service area in southwest Texas to help reduce future peak power demands and to conserve energy. The rating system was adopted in its present form in 1978, and applies to both new and used single-family residences.

Components considered in awarding the EEA certification include building she 11 characteristics, the HVAC system, the hot water system, some appliances, and a simple passive solar treatment. The rating system is simple in application, with relatively few items to be considered in the points score in each category. The information required to complete the rating is shown below.

Information Required for Rating

\begin{tabular}{|c|c|}
\hline Item & Information \\
\hline Insulation & Wall, ceiling and floor insulation values. \\
\hline Windows and Doors & Type of glazing, whether doors are insulated. \\
\hline Infiltration & $\begin{array}{l}\text { Whether house is weather stripped, use of } \\
\text { storm windows. }\end{array}$ \\
\hline Attic Ventilation & Type of vent, amount of vent area. \\
\hline HVAC System & $\begin{array}{l}\text { Efficiency of heating and cooling systems, } \\
\text { fireplace damper, insulation of ductwork. }\end{array}$ \\
\hline Hot Water System & Location of water heater $(s)$, heat trap. \\
\hline Appliances & $\begin{array}{l}\text { Laundry outside conditioned space, use of } \\
\text { outside range exhaust. }\end{array}$ \\
\hline Passive Solar & Amount of roof overhang. \\
\hline
\end{tabular}

Home ratings are conducted by CPL personnel. To obtain a Energy Efficiency Award, a home must have a number of required features, such as minimum insulation levels and weather stripping, and must also achieve a point score of 150 points or more. 
The EEA Program is judged to be relatively easy to implement. CPL indicated that the costs for rater training were low. The average home rating generally takes several hours, with a total cost to CPL of roughly $\$ 100-$ $\$ 125 /$ house.

CPL has been very happy with the results of the EEA Program. The program has had a good reception from builders and the utility customers, and a total of 10,000 to 12,000 homes have been rated. CPL has estimated that a new EEA certified house can cut the peak home electric demand by an average of 1-2 kW over an average noncertified new home. They view this as being very costeffective, since a $\mathrm{kW}$ of demand avoided at a cost to the utility of roughly $\$ 75$ (\$100-125/1-2 kW) is much less expensive than adding a $\mathrm{kW}$ of new generating capacity. To further quantify the savings from the EEA program, CPL is currently operating a monitoring program recording the electricity use and power demands over 15-minute intervals for 120 EEA-certified homes.

During the development and implementation of the EEA program, CPL met with local savings and loan institutions to discuss ways the program could be incorporated into lending decisions. This discussion never came to anything, however, and current users of the system are builders and homeowners.

In CPL's opinion, the inability of the EEA program to actually predict home energy consumption is a slight drawback of the rating system, which is, of course, compensated for by the simplicity of the system. They believe that a HERS program is an important way to reduce electrical demand and conserve energy.

Additiona 1

CPL Information: "Your Door to Energy Savings."

"Energy Efficient Award Home

Special Instructions and Rating Form."

Contact: $\quad$ Bruce Miller

Central Power and Light Company

P.0. Box 2121

Corpus Christi, Texas, 78403

512-881-5300 


\section{DALLAS POWER AND LIGHT}

\section{E-OK-PROGRAM}

The E-OK program is offered by Dallas Power and Light (DP\&L), Texas Power \& Light (TP\&L), and several other Texas utilities to their customers, although the details of the program differ slightly among utilities. The program was developed to conserve energy and reduce growing demands for electricity; it was adapted directly from the Edison Electric Institute National Energy Watch program, with modifications made to tailor it more specifically for the Texas area. In addition to the E-OK program, DP\&L offers a less stringent certification as a NEW home for existing homes which do not meet E-OK standards. The E-OK program is a new undertaking for DP\&L.

New and old single-family residences are eligible for E-OK certification. The E-OK rating is based on building shell characteristics, HVAC systems, water heating systems, and active solar hot water systems. A summary of the information required to rate the home is shown below.

\section{Information Required for Rating}

\begin{tabular}{ll}
\hline \multicolumn{1}{c}{ Item } & \multicolumn{1}{c}{ Information } \\
$\begin{array}{ll}\text { Windows and Doors } & \begin{array}{l}\text { Glass area and type of glazing, use of insulated } \\
\text { doors. }\end{array} \\
\text { Infiltration } & \text { Type of weather sealing. } \\
\text { Fireplace } & \begin{array}{l}\text { Existence of damper, glass screen, and out- } \\
\text { side air intake. }\end{array} \\
\text { Attic Ventilation } & \begin{array}{l}\text { Vent area. } \\
\text { HVAC System }\end{array} \\
\text { Doct insulation, air handler location, heatingand } \\
\text { cooling unit efficiencies. }\end{array}$ \\
Solar Water Heater System & $\begin{array}{l}\text { Location of water heater, type of circulation } \\
\text { system, insulation of pipes. }\end{array}$
\end{tabular}


Qualifying for the E-OK certification requires a minimum of 135 points, of which at least 90 must be scored in the insulation, windows, infiltration, fireplace and attic ventilation areas. Existing homes which do not meet E-OK standards may be certified as a NEW home provided that they make improvements sufficient to upgrade their score in the first 5 categories by 35 points.

Development costs of the E-OK program are judged to be low to medium, since it was largely adapted from NEW standards. DP\&L raters conduct the rating, which requires at least one and possibly two or more site visits for new housing. Moderately trained raters are required for the program. The average time required for a rating is judged to be moderate.

The principal users of the DP\&L E-OK program are area builders. The builders are in favor of the program since it gives them a selling tool and because the DP\&L inspections help the builder ensure that subcontractors have adequately performed the ir tasks.

Additional

DP\&L Information: "E-OK - The N.E.W. Way to an Energy-Efficient Home"

Contact: $\quad$ Marilyn Harris

Dallas Power and Light Company

Dallas, Texas

$214-698-7000$ 


\section{GULF STATES UTILITIES \\ NATIONAL ENERGY WATCH PROGRAM}

Gulf States Utilities (GSU) developed their National Energy watch (NEW) program in an effort to reduce their summer cooling load and slow the growth in electricity demand. The GSU NEW program was developed specifically for the GSU service area, which stretches roughly from Houston to Baton Rouge along the Gulf Coast. The program is broad in the types of homes covered; it applies to new and used single-family residences, apartments, condominiums, townhouses, mobile homes, and manufactured housing.

The GSU NEW program uses building shell characteristics, HVAC systems, hot water systems, and passive and active solar systems as components in the rating procedure. The specific information required in the rating varies somewhat between housing types, since mobile homes have decidedly different energy characteristics than apartments or townhouses. A generalized description of the information required is shown in the table below.

Information Required for Rating

\begin{tabular}{ll}
\hline \multicolumn{1}{c}{ Item } & \multicolumn{1}{c}{ Information } \\
Winsulation & $\begin{array}{l}\text { Insulation values for walls, ceilings, floors, } \\
\text { basements. }\end{array}$ \\
Glass area, type of glazing. & $\begin{array}{l}\text { Caulking and weather stripping, fireplace } \\
\text { construction, use of insulated doors or storm } \\
\text { doors. }\end{array}$ \\
Attic Ventilation & $\begin{array}{l}\text { Type of ventilation supplied, vent area, } \\
\text { location of air handler and ductwork. }\end{array}$ \\
Hot Water System & $\begin{array}{l}\text { Type of water heater, use of insulation } \\
\text { blanket use of flow restrictors. }\end{array}$ \\
HVAC System & $\begin{array}{l}\text { Insulation of ductwork, type of heating and } \\
\text { air conditioner efficiency, heat recovery } \\
\text { systems, setback thermostats. }\end{array}$ \\
Active Solar & $\begin{array}{l}\text { Use of solar-assist heating and water heating } \\
\text { systems. }\end{array}$ \\
Passive Solar & Glass orientation and area, exterior shading.
\end{tabular}


Rating forms are tailored to be specific to the type of dwelling being rated. GSU raters inspect the homes, check off the conservation features on the forms, and calculate the total number of points earned. To qualify for the NEW certification, the home must meet a minimum point score (which varies for different dwelling types) and must not have certain features which result in automatic disqualification. Examples of disqualifying features include large living areas with east-west exposures and no exterior shading, and less than minimum insulation levels.

Deve lopment costs for the GSU NEW program are judged to be moderate. A moderate amount of rater training is also required. A one-week training session is given to new GSU raters, with on-the-job training allowed for as the raters gain proficiency. GSU also regularly schedules 4 days of training per year for all raters as a refresher course and to discuss new information. In application, rating a home typically takes 2 to 2.5 hours for the GSU raters. Like most other utility programs, the rating is performed without charge to the homeowner. An approximate cost to GSU for a normal rating is $\$ 100$.

Roughly 15,000 homes have been certified in the GSU NEW program since its inception in 1978. The primary users of the system have been homeowners and builders. These groups seems to be very happy with the program. The only aspect of the GSU'S program that the utility is not completely happy with is the rating system for mobile homes, which is currently under revision. GSU would like to have the rating system adopted by the manufacturers of mobile homes rather than just the purchaser. Because retrofitting problems can be quite difficult for mobile homes, maximum energy saving features would need to be incorporated in the original design.

Surveys conducted by GSU have indicated that the ir NEW program is saving energy and reducing peak load. GSU calculations indicate that homes meeting their NEW standards can reduce the peak load for cooling by up to $2 \mathrm{~kW}$ compared to average homes in their area. They view the program as being very costeffective, since the marginal capital cost of new electric capacity for GSU is currently about $\$ 1400 / \mathrm{kW}$. 
To verify that the NEW program was saving energy, GSU conducted a field survey in 1980 of 712 homes in their service region. The surveyed homes were built in 1978 and 1979, and included homes which did and did not qualify for the NEW program. Survey results for homes using electricity for heating and cooling are shown in the following table.

Annual Energy Consumption By NEW Point Score in $\mathrm{kWh} / \mathrm{ft}^{2}$ of Living Area

\begin{tabular}{|c|c|c|c|c|c|c|}
\hline \multirow[b]{2}{*}{ NEW Point Score } & \multicolumn{3}{|c|}{ Heat Pump Heating/Cooling } & \multicolumn{3}{|c|}{$\begin{array}{c}\text { Electric } \\
\text { Resistance Heating } \\
\text { Electric Cooling } \\
\end{array}$} \\
\hline & Low & High & Average & Low & High & Average \\
\hline Below 75 & 10.04 & 15.45 & 13.88 & 12.46 & 15.09 & 13.76 \\
\hline $75-85$ & 7.01 & 15.14 & 11.78 & 10.79 & 16.99 & 12.69 \\
\hline 86 and above & 9.36 & 15.34 & 10.93 & 10.07 & 17.45 & 12.50 \\
\hline
\end{tabular}

While there is a wide range within each category due to differences in house styles and sizes, family sizes, and lifestyles; the average energy consumption figures indicate that homes with higher NEW scores use less energy. Similar survey results applied to homes using gas heat with electric cooling.

Additional

GSU Information: Payback Analysis Handbook

Contact:

J. B. Bishop

Gulf States Utilities Company

P.0. Box 2951

Beaumont, Texas 77704

713-838-6631 


\section{ILLIOIS POWER COMPANY \\ NATIONAL ENERGY WATCH PROGRAM}

Illinois Power Company (IP) implemented its National Energy Watch (NEW) program in 1977 to reduce the growth of electrical demand and conserve energy in the residential sector. The NEW program applies to new and used singlefamily residences.

Components included in the IP NEW rating system include the building shell, HVAC system, water heater, and active solar. General information requirements to conduct the rating are shown below.

Information Required for Rating

\begin{tabular}{ll}
\hline \multicolumn{1}{c}{ Item } & Wall, ceiling, and floor insulation values. \\
Windows and Doors & Type of glazing, whether doors are insulated. \\
Weather Stripping & Amount and quality of weather stripping. \\
Attic Ventilation & Type of ventilation, amount of vent area. \\
Fireplace & $\begin{array}{l}\text { Use of dampers, glass doors, outside com- } \\
\text { bustion air, heat exchangers. }\end{array}$ \\
HVAC System & $\begin{array}{l}\text { Types of controls, heat pump, insulated } \\
\text { ducts, EER of air conditioner. }\end{array}$ \\
Hot Water System & $\begin{array}{l}\text { Water heater blanket, thermostat setting. } \\
\text { Active Solar }\end{array}$ \\
$\begin{array}{l}\text { Use of active solar for space or water } \\
\text { heating. }\end{array}$
\end{tabular}

Homes are rated at the homeowner's request by IP raters, who are also responsible for doing the RCS audits for the utility. As is the case for many of the utility-operated HERS, performing an RCS audit may be conducted at the same time as the NEW rating. If the NEW rating is conducted in conjunction with an RCS audit, a computerized calculation of home energy use and potential savings is performed. The NEW rating by itse if requires only the use of a point checklist. New homes qualify for the NEW certification if their point 
score is at least 80 percent of a maximum point score. The maximum point score varies for different home types. Existing homes can qualify under the IP NEW program by meeting the 80 percent requirement or by adding conservation features to upgrade their initial score by 20 percent.

Developing the IP NEW program was simple and low cost, since it was largely adapted fom the Edison Electric Institute NEW program. IP typically provides new raters with roughly two weeks of training, which is about average for prescriptive HERS. The average time for IP raters to rate a home is approximately one hour, which is also about average for prescriptive systems.

The primary users of the IP NEW program are builders and homeowners. Acceptance of the program by these users has been very positive. IP has had a high percentage of reply cards sent in after the NEW inspection has been completed, and these generally contain praise for the program. An important aspect of the NEW program for IP is that using regular employees as raters allows an additional way to communicate with customers and facilitates improved customer relations. Since 1977 roughly 80,000 NEW inspections have been carried out.

Contact: E. G. Galassi

Illinois Power Company 500 South 27th Street Decatur, Illinois 62525 217-424-6896 


\section{KANSAS CITY POWER AND LIGHT}

\section{PLUS PROGRAM}

Kansas City Power and Light (KCPL) has operated several home energy rating systems in the past, the latest being the 150 Plus program. This program was developed specifically for the Kansas City area to conserve energy and reduce the growing demand for power. Because energy use for KCPL's service area is dominated by summer cooling loads, the program focused on reducing air conditioning requirements. The 150 plus program was aimed at new single-family residences only, but is being discontinued in favor of a revised program.

The 150 Plus program was comprehensive in the components that were considered. It included building shell characteristics, HVAC systems, hot water systems, appliances, active solar and passive solar in the rating process. A generalized list of the information required in the rating process is shown below.

Information Required for Rating

\begin{tabular}{|c|c|}
\hline Item & - \\
\hline Insulation & $\begin{array}{l}\text { Insulation values for walls, ceilings, floors, } \\
\text { basements, and crawl spaces. }\end{array}$ \\
\hline Windows & $\begin{array}{l}\text { Glass area, shading factor for glass, type of } \\
\text { glazing, thermal breaks. }\end{array}$ \\
\hline Doors & $\begin{array}{l}\text { Use of insulated doors, existence of sliding } \\
\text { glass doors. }\end{array}$ \\
\hline Infiltration & $\begin{array}{l}\text { Use of vapor barriers, caulking and weather } \\
\text { stripping. }\end{array}$ \\
\hline Attic Ventilation & Type of ventilation supplied, vent area. \\
\hline Hot Water System & $\begin{array}{l}\text { Type of water heater, use of insulation blanket, } \\
\text { pipe insulation, low-flow shower heads. }\end{array}$ \\
\hline HVAC System & $\begin{array}{l}\text { Location and insulation of ductwork, type of } \\
\text { heating/cooling equipment, heat pump and air } \\
\text { conditioner efficiency, humidifier, system } \\
\text { controls, fireplace options. }\end{array}$ \\
\hline
\end{tabular}


Information Required for Rating

\begin{tabular}{ll}
\hline Item & \multicolumn{1}{c}{ Information } \\
\cline { 2 - 2 } Appliances & $\begin{array}{l}\text { Use of fluorescent lighting, light controls, } \\
\text { construction of recessed lighting. }\end{array}$ \\
Solar Heating & $\begin{array}{l}\text { Use of active and passive solar to provide } \\
\text { heating. }\end{array}$
\end{tabular}

Homes were rated by KCPL on the basis of plans provided by the builder. In order to be certified for the 150 Plus program, the house had to have been built according to the plans. To qualify for certification, the home had to have a number of required features, and had to meet a minimum point score of 150 .

The 150 Plus program is judged to be moderately difficult to implement. Rater training and the time required to complete a rating are also judged to be moderate.

The primary users of the 150 Plus system were builders in the KCPL area. The system is being discontinued in favor of a revised program which will be developed and operated in conjunction with local builders. The revised program will be more detailed, and should have more credibility with builders than did the 150 Plus program. One reason the 150 Plus program is being discontinued is that its stringent requirements made it relatively difficult for a house to be certified under the program. Only 200-300 houses achieved the 150 Plus certification over the three years of program operation.

An area of concern for KCPL home rating systems is that they adequately consider passive solar homes. Poorly designed passive solar homes may actually increase the already high air conditioning demand for KCPL. The new rating program under development will have a more detailed treatment of passive solar, and solar heat gains.

Additional

KCPL Information: "150 Plus Energy Conserving New Home"

Contact: Jerry Shaw

Kansas City Power and Light Company

P.0. Box 679

Kansas City, Missouri 64141

816-556-2178 
PACIF IC GAS AND ELECTRIC

ENERGY CONSERVATION HOME PROGRAM

Pacific Gas and Electric Co. (PG\&E) began their Energy Conservation Home (ECH) program across the entire PG\&E service area in 1976 in an attempt to conserve energy. The ECH program was developed by PG\&E personnel with assistance from Lawrence Berkeley Laboratory. The ECH program applied to new singlefamily residences, and was affiliated with the Edison Electric Institute's National Energy watch program. PG\&E recently discontinued the ECH program because of tighter energy conservation requirements in the California building code.

Points for house features in the ECH program were based on actual or potential energy savings. Savings of either natural gas or electricity were allowed. Because electricity use is only about $30 \%$ efficient when the conversion in the power plant from primary fuels is included, and natural gas is about $97 \%$ efficient delivered to an end use, saving a Btu of electricity results in a higher net energy savings than saving a Btu of natural gas. For this reason, the point system was structured so that saving 3 Btu's of natural gas gave an equivalent point score to saving 1 Btu of electricity. The relationship used in calculating point scores was:

1 Point $=3$ therms natural gas savings per year

$=30 \mathrm{kWh}$ electricity savings per year

(1 Therm $=30 \mathrm{kWh}$ )

The ECH program was comprehensive in the components it included in the rating process, giving consideration to the building she11, HVAC system, hot water system, appliances, and use of active and passive solar systems. A generalized list of the information required in the rating follows.

Information Required for Rating

$\begin{array}{ll}\frac{\text { Item }}{\text { Insulation }} & \begin{array}{l}\text { Insulation values for walls, ceilings, floors. } \\ \text { Windows }\end{array} \\ \text { Doors } & \text { Glass area, type of glazing, use of reflective } \\ \text { treatment. } & \text { Use of insulated doors. }\end{array}$


Information Required for Rating

\begin{tabular}{ll}
\hline \multicolumn{1}{c}{ Item } & \multicolumn{1}{c}{ Information } \\
\cline { 2 - 3 } Infiltration & $\begin{array}{l}\text { Type and amount of caulking and weather } \\
\text { stripping. }\end{array}$ \\
Hot Water System & $\begin{array}{l}\text { Use of insulation blanket, pipe insulation, } \\
\text { low-flow shower heads. }\end{array}$ \\
Fireplace & $\begin{array}{l}\text { Use of damper, glass doors, heat exhanger, } \\
\text { outside combustion air, use of central space } \\
\text { heating ducts. }\end{array}$ \\
HVAC System & $\begin{array}{l}\text { Use of setback thermostat and clogged filter } \\
\text { indicator. }\end{array}$ \\
Appliances & $\begin{array}{l}\text { Use of fluorescent lighting, gas range, } \\
\text { microwave oven, controlled drying dishwasher, }\end{array}$ \\
gas dryer outlet, construction of recessed \\
lighting.
\end{tabular}

Builders requesting a home rating supplied PG\&E with home specifications. PG\&E then rated the home, using field auditors to verify conservation features. Builders were allowed to challenge the point basis of any specific conservation option, but were required to show calculations supporting higher than standard point values. A home qualified as an ECH home if it scored a minimum of 50 points. The output of the rating program was the total point score and an ECH certification for the home. As an incentive to builders to participate in the program, PG\&E offered cash awards of \$2.00/point for every point scored over the 50 point minimum, up to a maximum of $\$ 150$ per home and $\$ 15,000$ per subdivision. 
PG\&E was able to implement and operate the ir ECH program very inexpensively because of in-house expertise among the system developers and the home raters. Similar rating systems are judged to be moderately expensive to implement and operate. The average time per rating ranged from 1 to 2 hours per home.

The ECH program was developed by PG\&E to encourage conservation over and above that was required by regulatory standards. Surveys and statistical studies by PG\&E indicated that the program was indeed acomplishing this. Approximately 300,000 homes were rated under the program. The adoption by Californa of the revised Residential Buildings Standards has caused PG\&E to discontinue their ECH program, since the Residential Buildings Standards will have the same effect.

Additional Information: "Energy Conservation Home Requirements and Agreement"

Energy Conservation Home ProgramPoint Justification for Revised Home Requirements and Agreement January 1980.

Parti, M., and J. M. Harris. 1982.

Energy Conservation Home Comparative Analysis. MR-79-27. Pacific Gas and Electric Company, Energy Conservation and Services Department San Francisco, California

Contact: John Hailey Pacific Gas and Electric Company 77 Beale Street San Francisco, California 94106 415-781-4211 
TEXAS POWER AND LIGHT

E-OK PROGRAM

The E-OK program is offered by Texas Power and Light (TP\&L), Dallas Power and Light (DP\&L), and several other Texas utilities to their customers, although the details of the program differ slightly among utilities. The program was developed to conserve energy and reduce growing demand for electricity. It was adopted directly from the Edison Electric Institute NEW program, with modifications made to tailor it more specifically for the Texas area. In addition to the E-OK program, TP\&L offers a less stringent certification as a NEW home for existing homes which do not meet E-OK standards. TP\&L has offered the E-OK program since 1974 .

Both new and old single-family homes are eligible for E-OK certification. The E-OK rating is based on building shell characteristics, HVAC systems, water heating systems, and active solar hot water systems. A sumary of the information required to rate the home is shown below.

\section{Information Required for Rating}

\begin{tabular}{ll}
\hline Insulation & \multicolumn{1}{c}{$\begin{array}{c}\text { Information } \\
\text { Windows and Doors }\end{array}$} \\
Infiltrations & $\begin{array}{l}\text { Glass area and type of glazing, use of } \\
\text { insulated doors. }\end{array}$ \\
Fireplace & $\begin{array}{l}\text { Type of weather sealing. } \\
\text { air intake. }\end{array}$ \\
Energy Ratio & $\begin{array}{l}\text { Ratio of installed capacity of A/C to } \\
\text { conditioned floor area. }\end{array}$ \\
HVAC System & $\begin{array}{l}\text { Duct insulation, heating unit location, } \\
\text { heating and cooling unit efficiencies. }\end{array}$ \\
Hot Water Heater & $\begin{array}{l}\text { Location of water heater, type of } \\
\text { circulation system, insulation of pipes. }\end{array}$ \\
Solar Water Heater & Existence of solar water heater.
\end{tabular}


Under the E-OK program, points are allocated to the home on the basis of the features described above. To qualify for the program, homes must score a minimum of 135 points, and at least 90 of these points must be from categories 1 through 5 in the above table. Existing homes that cannot qualify for the EOK program can be certified as an NEW home provided they increase their initial score in categories 1 through 5 by a minimum of 35 points.

Deve lopment costs of the E-OK program are judged to be low to medium, since the program was largely adopted from NEW standards. TP\&L raters do the actual rating of the home, which requires a visit and approximately one hour of time; the overall cost per rating is judged to be medium. Only moderate training of the raters is required.

TP\&L's experience to date with the E-OK program has been good. The principal users of the program are TP\&L's customers and builders. Roughly 20,000 houses have been rated since the program began.

Additional

Information: E-OK Energy Efficient Rating Sheet

Contact: David Patterson

Texas Power \& Light Company

Box 226331

Dallas, Texas 75266

214-748-5411 


\section{UNION ELECTRIC COMPANY \\ NATIONAL ENERGY WATCH PROGRAM}

The Union Electric home energy rating system was developed based on National Energy Watch (NEW) guidelines. The program is used in the St. Lou is area and nearby regions. The program was enacted by the utility in an attempt to conserve energy.

The Union Electric program is applicable to new and used single-family residences. It considers the building shell characteristics and HVAC systems. The system is simple in application, as is shown by the information requirements listed below.

$\frac{\text { Information Required for Rating }}{\text { Item }}$
$\begin{aligned} & \text { Insulation } \\ & \text { Windows and Doors ceiling, and floor insulation values. }\end{aligned}$
Weather Stripping
Attic Ventilation of glazing, whether doors are insulated.
HVAC System

Union Electric provides homeowners and builders with the home rating form. The owner or builder completes the rating and mails the form to Union Electric, which then certifies the house as a NEW home (subject to verification of the rating by Union Electric at its option). New homes qualify for the NEW certification when they achieve 80 points or more. Homes built after April 1977 can qualify for the certification by adding thermal improvements to increase their point score by $20 \%$ or more.

Developing the Union Electric program was inexpensive since it was largely adopted from the NEW program. In operation, the program is inexpensive, since the primary rating is completed by the builder or homeowner. While all ratings are subject to verification by Union Electric, no attempt is made to verify each home's rating. 
The Union Electric NEW program is primarily used by builders and homeowners. Roughly 3800 homes have been qualified under the program since its inception. Union Electric has done some qualitative field tests on another conservation program operated by the utility to determine whether the program actualiy saved energy. The results, which are believed to be applicable to Union Electric's NEW program, showed that thermal improvements in the conservation program did result in energy savings in each house, but that these energy savings were difficult to quantitatively predict.

Union Electric had several comments on the operation of their NEW program. One aspect they particularly liked was the recognition given to homes that achieved the NEW certification. Owners of certified homes receive certificates. Union Electric believes that this recognition, along with the energy savings, encourage consumer participation. A drawback of the Union Electric NEW program is that it is difficult to predict energy consumption from the total point score. Union Electric also commented that in developing the program, it was difficult to allocate points correctly between alternative conservation options.

Additional

Information: National Energy Watch Program Membership Application

Contact: Norman L. Raab

Union Electric Company

P.0. Box 149

St. Louis, Missouri 63166

314-554-2186 


\subsubsection{Prescriptive Systems Unaffiliated with EEI/NEW}

The following prescriptive systems are in use, but are presented separately because they are not affiliated with the EEI/NEW program. 


\section{CITY OF BOULDER \\ ENERGY CONSERVATION POINT SYSTEM}

The City of Boulder, Colorado, requires all new housing to meet certain minimum standards to conserve nonrenewable resources. The Energy Conservation Point System (ECPS) is applied as part of the review process for building permits. It is not currently being used as a HERS, but could be readily adapted as a rating system. ECPS is heavily weighted toward considerations of solar energy, since many other attributes are covered under the city's energy code. Components considered in the ECPS include the building she11, HVAC system, hot water system, and active and passive solar. A summary of the information considered in the homes rating is shown below.

Information Required for Rating

\begin{tabular}{|c|c|}
\hline Item & Information \\
\hline Windows & Use of triple-glazing on nonsouth windows. \\
\hline Insulation & $\begin{array}{l}\text { Use of insulation with R-value } 25 \text { percent } \\
\text { greater than minimums specified in the } \\
\text { city's energy code. }\end{array}$ \\
\hline
\end{tabular}

HVAC System

Use of demand meters for electrically heated buildings, flow meters for hydronic centralized heating, vent dampers and electronic ignition for natural gas furnaces, efficiency of gas furnace, setback thermostat.

Hot Water System Use of insulating blanket, flow restrictors and pipe insulation.

Active Solar Orientation of house and roof, legally binding solar access agreements, preplumbed solar hot water system, installed solar hot water system.

Passive Solar Reduced area of nonsouth glazing, use of shading and natural cooling, moveable insulation. 
Obtaining the point score for the home is a simple matter of checking off design features that apply to the home, and totaling the point score. The total points scored for energy conservation are added to points scored in other areas of the review process, which include location and urban facilities, provision for moderate income housing, development standards, and whether it involves a phased development. A total of 140 points is possible in the review process, of which a maximum of 32 points may be from energy conservation features. The home rating is done by the builder.

The cost of developing the ECPS is judged to be moderate, similar to other prescriptive systems. Because the builders fill out the rating sheet, there are no costs for rater training.

The ECPS was revised in December 1981 to make the point system more accurately reflect actual energy savings. Revisions were based in part on analyses made with the Karpay Associates Residential Energy Analysis Model (see Section 3.3). Currently, the primary users of the ECPS are builders.

Additional

Information: Chapter 6, Residential Growth Management System

Land Use Regulation,

City of Boulder, Colorado

Contact: Nancy Schalch

City of Boulder Energy Office

P.0. Box 791

Boulder, Colorado 80306

303-441-3270 
CITY OF VISALIA

ENERGY RATING SYSTEM

Visalia is a rapidly growing community in California, approximately 30 miles southeast of Fresno. Visalia's current population of 52,000 is projected to reach 142,000 by the year 2000 . Because of concern with rapidly rising energy costs and the prospects of future energy shortages, the Visalia City Council formed the Visalia Citizens Energy Committee (VCEC) in August of 1980. The VCEC concentrated on residential energy consumption. Because newer homes tend to be constructed with more energy conservation features, and because most of Visalia's housing consists of units built prior to 1975, the VCEC felt the major thrust of a residential conservation program should encourage retrofitting conservation features to existing homes. Towards this end, the VCEC developed the Visalia Energy Rating (VER) System.

The VER system is a voluntary HERS for new and old single-family homes. It is designed to encourage energy conservation by informing the community of the relative energy and dollar savings possible through the use of various conservation measures. The system has been used in Visalia since December 1981. Homes are rated on the basis of the building shell, HVAC system, hot water system, appliances, active solar systems and passive solar design. A summary of the information required to rate the house is shown in the table below.

\begin{tabular}{|c|c|}
\hline Item & Information \\
\hline Insulation & Insulation values for walls, ceilings, floors. \\
\hline Windows & $\begin{array}{l}\text { Glass area, type of glazing, use of reflective } \\
\text { treatment. }\end{array}$ \\
\hline Doors & Use of insulated doors. \\
\hline Infiltration & $\begin{array}{l}\text { Type and amount of caulking and weather } \\
\text { stripping. }\end{array}$ \\
\hline Attic Ventilation & Type of ventilation supplied. \\
\hline
\end{tabular}




\section{Information Required for Rating}

\begin{tabular}{ll}
\hline Item & \multicolumn{1}{c}{ Information } \\
Hot Water System & $\begin{array}{l}\text { Use of insulation blanket, pipe insulation, } \\
\text { low-flow shower heads. }\end{array}$ \\
& $\begin{array}{l}\text { Use of damper, glass doors, heat exhanger, } \\
\text { outside combustion air, use of central space } \\
\text { heating ducts. }\end{array}$ \\
HVAC System & $\begin{array}{l}\text { Use of setback thermostat and clogged filter } \\
\text { indicator, intermittent ignition device on gas } \\
\text { furnace. }\end{array}$ \\
Appliances & $\begin{array}{l}\text { Use of fluorescent lighting, gas range, } \\
\text { micowave oven, controlled drying dishwasher, } \\
\text { gas dryer outlet, surface-mounted lighting. }\end{array}$ \\
Passive Solar & $\begin{array}{l}\text { Square feet collectors for space and water } \\
\text { heating. }\end{array}$ \\
& $\begin{array}{l}\text { House-to-lot orientation, south-facing glass } \\
\text { area, use of trees for windbreaks and shade, } \\
\text { roof overhang. }\end{array}$
\end{tabular}

The VER system was originally intended to use RCS audit forms as the input for rating the homes. It was later determined that a rater from the VCEC would visit each home to conduct the rating since the information needed for the rating was not being totally supplied by the RCS audit forms. During the rating, points are allocated on an easy to use checklist. The output rating is a point score and an efficiency rating expressed in star values. The possible efficiency ratings are:

0 Stars Point score less than 125

1 Star $(*) \quad$ Point score of 125-249

2 Star (**) Point score of 250-374

3 Star ( $* \star \star)$ Point score of $375-499$

4 Star $(\star \star \star \star)$ Point score of over 500

In addition to the efficiency ratings, the VER system offers a special energy-efficiency technique award. This award is given to homes that go beyond the use of conventional conservation measures, and obtain at least 25 percent of their energy from renewable energy sources. 
The VER system is judged to be of medium development time and require a medium amount of rater training, both average characteristics for most prescriptive systems. In practice, rating a home requires roughly 30 minutes of time for the VCEC rater, making the cost per rating low to moderate.

The VER program was intended for use by homeowners, builders and developers, the real estate community, and the local lending community. It is too early to tell the extent to which these groups will utilize the system, since the program has only been operational since December 1981. Roughly 225 homes were rated under the program during its first 6 months of operation.

Additional

Information: Visalia Energy Rating System Review

Technical Report

March 1981

Contact: Diana Metzler

City of Visalia

$707 \mathrm{~W}$. Acequia St.

Visalia, California 93291

209-625-6295 


\section{DUKE POWER COMPANY \\ ENERGY EFFICIENT STRUCTURE PROGRAM}

Duke Power Company developed their Energy Efficient Structure (EES) program in an attempt to reduce the rate of growth of their peak demand and to help their customers conserve energy. The EES program is somewhat unique in that Duke Power offers some significant economic incentives (beyond savings from the energy conservation features themselves) to encourage customer participation. Residential customers who have an EES-certified home are entitled to utility rates that are approximately 17 percent lower than standard residential rates.

The rating in the EES program is a certification-type rating; either the home qualifies for the EES program or it does not. Homes can qualify for the EES certification in either of two ways (unlike most prescriptive systems, neither qualification procedure requires the home to meet a set point score). The primary means of qualifying for the EES program is by complying with a list of required conservation features. Alternatively, if the home does not have all the prescribed conservation features, it can still qualify by a calculational procedure. To qualify under the calculational method, calculated energy consumption must be less than or equal to calculated energy consumption for a similar home meeting all of the prescribed conservation features. The calculational qualifying procedure is provided by the utility to allow flexibility in meeting the energy budget desired for home qualification. Most homes qualifying for the program do so by complying with the required conservation features. These required features are sumarized in the table below.

\section{Features Required for EES Certification}

\begin{tabular}{lll}
\hline Ceiling Insulation & & R-30 \\
Sidewall Insulation & $R-16$ \\
Floor Insulation & $R-19$ \\
Window Area & No more than $12 \%$ gross wall area.
\end{tabular}


Features Required for EES Certification

\begin{tabular}{ll}
\hline \multicolumn{1}{c}{ Item } & \multicolumn{1}{c}{ Features } \\
Vuct Insulation & $\begin{array}{l}\text { Warm air ducts require } 2 \text { inches duct } \\
\text { insulation. }\end{array}$ \\
Attic Ventilation & $\begin{array}{l}1 \mathrm{ft}^{2} \text { ventilation area per } 150 \mathrm{ft}^{2} \\
\text { attic area. }\end{array}$ \\
Slab Insulation & $\begin{array}{l}2 \text { inches perimeter insulation for slab } \\
\text { construction. }\end{array}$ \\
Fireplace & Fireplace must have damper.
\end{tabular}

For houses that do not require an energy-use calculation, the rating is done very quickly by a utility rater, with only a few minutes time required to verify home conservation features. Qualifying homes through the calculational procedure requires more rater time. In either case, the home rating is performed without charge to the customer.

Deve lopment costs of the EES program are judged to be low to medium. The time and cost to do the rating when the home qualifies by meeting the compliance features is judged to be low. Time and cost for performing a rating using the calculational method are judged to be moderate.

Duke Power has had good results with the program since its inception in 1975. Homeowners, home buyers, builders and lenders have all participated in the program. The most significant lender participation has come from Home Federal Savings and Loan, where buyers of homes qualifying for the EES certification are offered a $1 / 8$ of $1 \%$ reduction on home mortgages. As mentioned previously, one of Duke Power's reasons for implementing the program was to slow the growth of peak demand and forestall the purchase of expensive new generating capacity. Duke Power has estimated that homes qualifying for the EES program have peak electricity use betwen 1 and $5 \mathrm{~kW}$ less than average homes in the area, which represents significant savings. Over 43,000 homes have qualified for the EES certification. 


\section{Contact: Bob Taylor \\ Duke Power Company \\ $422 \mathrm{~S}$. Church Street \\ Charlotte, NC 28242 \\ 704-373-7382}


NATIONAL HOMES CORPORATION

ENERGY PERFORMANCE RATING

National Homes Corporation (NHC) instituted their Energy Performance Rating (EPR) system in October 1978 to give home buyers a tool for comparing the relative energy efficiency of homes as they shopped for a home. The EPR system is described in a simple booklet form for the consumer to use in rating alternative homes, and is distributed through participating NHC builders.

The EPR system was developed with a separate point scale for each of 4 home styles in 5 different climate areas, and is applicable to the entire United States. A separate book let is prepared for each climate region that gives the home buyer information on how to rate homes, and contains rating sheets for each of the four home types. The home rating is based on building shell characteristics, the HVAC system, hot water system, and use of active solar water heating. Information used in rating the home is sumarized in the table below.

Information Required for Rating

\begin{tabular}{|c|c|}
\hline Item & Information \\
\hline Insulation & Ceiling, wall, and floor insulation values. \\
\hline Windows and Doors & $\begin{array}{l}\text { Type of glazing, type of doors, use of storm } \\
\text { windows and storm doors. }\end{array}$ \\
\hline Infiltration & Number of air changes per hour. \\
\hline HVAC System & $\begin{array}{l}\text { Type of heating system, location of heating } \\
\text { system, EER of air conditioner, use of duct } \\
\text { insulation, use of setback thermostat or } \\
\text { individual room controls. }\end{array}$ \\
\hline Fireplace & Use of glass screen, outside combustion air. \\
\hline Hot Water System & Use of water-saving fixtures. \\
\hline Solar Water Heater & Use of solar water heater. \\
\hline
\end{tabular}

In rating the home, the home buyer checks off applicable conservation features to determine raw point scores in several areas. The point score for 
building shell characteristics is used to obtain a multiplicative factor, which is multiplied by the point score for the HVAC system and fireplace to obtain a composite point score. Point scores for the water heating system and solar water heater are then added to the composite point score to obtain the Energy Performance Rating, which indicates the relative energy efficiency of the home compared to other homes of the same type.

Development time for the EPR system is judged to have been moderate, although it should be noted that the system is not limited to a single geographic area. Questions of rater training do not apply, since the rating is performed by the home buyer. After covering development costs, the cost per rating is quite low, essentially consisting of only the costs of publishing the rating pamphlets. A technical back-up report on the EPR system was prepared by Technology and Economics, Inc. of Cambridge, Massachusetts.

NHC feels that there is tremendous interest on the part of the home-buying public in some sort of rating tool, and has received very good feedback from users of their rating system prior to the current slowdown in the housing market. Because NHC only makes the rating system available and is not involved in the rating process, they have no estimates on the number of homes that have been rated with the EPR system.

Contact: Ken Schmid

National Homes Corporation

Earl Avenue and Wallace Street

Lafayette, Indiana 47903

$317-448-2000$ 
ENERGYWORKS, INC.

MASS-SAVE PILOT PROJECT

Energyworks, Inc. (EWI) is under contract to PNL in a study funded by the U.S. Department of Energy to design and field test the addition of a HERS to the RCS audit used by a consortium of Massachusetts utilities, Mass-Save. Rather then developing a new rating system, EWI adapted an existing system for use, the residential energy evaluation (REE) methodology developed by Western Resources Institute (WRI) (discussed later in section 3.1.2). Because of the similarities between the Energyworks, Inc., HERS and the REE methodology, only the significant differences between the two systems are discussed here.

The Massachusetts climate varies significantly enough from that of western Washington that a different point scale is required in Massachusetts to reflect different priorities for conservation options. EWI used the calculation mode 1 CIRA (discussed in Section 3.2.2) to model a number of building configurations and conservation options, using the results of the simulation to assign points to different conservation figures. The categories and descriptors of conservation options used by EWI are the same as in the REE methodology.

In addition to changing point values to reflect climate differences, EWI has also modified the charts used in the REE methodology to differentiate between home types. The Massachusetts housing stock is quite varied, and it was felt important to be able to capture the effects of wall vs. ceiling heat loss for a wide variety of home types. Consequently, where the REE methodology uses point assignment charts for seven different types of homes, the EWI HERS point charts differentiate between homes on the basis of the number of floors, floor area, and length-to-width ratio. EWI felt that this approach could capture more precisely the essential differences in housing design. 


\section{Additional}

Information: Eric Tarini, "A Methodology for Adding a Home Energy Rating to an Existing RCS Audit Program." Presented at the 1982 Summer Study on Energy-Efficient Buildings, Santa Cruz, California; sponsored by the American Council for an Energy-Efficient Economy, 305 Massachusetts Ave. N.E., Washington, D.C. 20002

Contact: Katherine Cox Energyworks, Inc. 45 Border Street West Newton, MA 02165 $617-332-3600$ 


\section{PUBLIC SERVICE COMPANY OF COLORADO $\mathrm{ECH}_{2}$ ONERGY PROGRAM}

To stimulate the use of energy conservation and water conservation features in Colorado housing, Public Service Company of Colorado (PSC) developed the $\mathrm{ECH}_{2}$ ONERGY program in conjunction with the Denver Water Board and the Home Builders Association of Metropoliton Denver. In addition to developing the $\mathrm{ECH}_{2}$ ONERGY HERS system, PSC has also participated with builders in constructing state-of-the-art conservation homes to demonstrate the potential for energy and water conservation. The $\mathrm{ECH}_{2} \mathrm{ONERGY}$ program was developed during 1978-79 and applies to new and existing single-family houses.

The $\mathrm{ECH}_{2}$ ONERGY rating system applies to both energy and water consumption. To be consistent with descriptions of other systems, only the portion dealing with energy consumption is discussed here. Six different point systems are used to rate various house types. The types of home construction considered are: ranch with crawlspace, ranch with basement, two story with basement, bi-level, tri-level with crawlspace, and tri-level with basement. The energy rating of the home is based on building shell characteristics, the use of active solar systems, and ductwork insulation of the HVAC system. General information requirements for the energy rating are shown in the table below.

\section{Information Required for Rating}

\begin{tabular}{ll}
\hline \multicolumn{1}{c}{ Item } & \multicolumn{1}{c}{ Information } \\
Winsulation & $\begin{array}{l}\text { Insulation values for walls, ceilings, floors, } \\
\text { Wasements. }\end{array}$ \\
Infiltration & $\begin{array}{l}\text { Type of glazing, use of thermal breaks, use } \\
\text { of insulated or storm doors. } \\
\text { Caulking and weather stripping, fireplace } \\
\text { of vapor barrier, use of outside air. }\end{array}$ \\
HVAC System & $\begin{array}{l}\text { Insulation of ductwork. } \\
\text { Active Solar }\end{array}$
\end{tabular}


The $\mathrm{ECH}_{2}$ ONERGY rating system is used by the potential buyer (or owner) of a home; PSC is not involved with the rating. Using the system requires only checking off appropriate features on a form, and adding points to arrive at a total score. The point score is designed so that a rating of zero represents a home with no insulation, single pane windows, and no energy-saving devices or techniques. Higher point scores indicate more energy-efficient homes.

Deve lopment time for the $\mathrm{ECH}_{2} \mathrm{ONERGY}$ program is judged to be moderate, similar to most other prescriptive systems. Because the rating is completed by the purchaser or home owner, questions of rater training do not apply. The cost per rating is quite low, since the utility is not involved in actually conducting the ratings.

Originally, the users of the $\mathrm{ECH}_{2}$ ONERGY program were targeted to be the lending community, home builders, home purchasers, and homeowners. All of these groups have made substantial use of the $\mathrm{ECH}_{2}$ ONERGY program with the exception of the lending community. PSC is not aware of any lenders who have used the system significantly. The reason for this lack of participation is not clear. Lenders were initally quite interested in using the system in qualifying people for loans for energy efficient homes. PSC worked with lenders during the development of the $\mathrm{ECH}_{2}$ ONERGY program, and developed suggested loan payment to income ratios for various rating system point scores. Additional Information: $\mathrm{ECH}_{2}$ ONERGY Verification Form

Contact: David Davia

Public Service Company of Colorado 550 15th Street Denver, Colorado 80202 303-571-7338 


\section{TENNESSEE VALLEY AUTHORITY}

ENERGY SAVER HOMES PROGRAM

As part of the Energy Saver Homes (ESH) program, the Tennessee Valley Authority (TVA) developed a point system for rating the energy efficiency of new single-family and duplex residences. The basic ESH rating is a certification type rating, which states that the house has conservation features that qualify it for the ESH program. The point system is applicable for houses with solar and conservation-type features beyond those required for the basic ESH certifica-tion. The point system is designed to provide builders with a general guide to designing residences, and provide home buyers and the lending community with information on the projected energy use of new homes rated with the system.

Ratings using the ESH point system are applicable only to homes that have met basic requirements for ESH certification, since the ESH home energy consumption is the baseline from which the point system measures improvement. The basic certification can be achieved either by meeting a list of required conservation options, or through tradeoffs that allow substitution of a higher value of one conservation feature in exchange for a lower value on another.

The ESH point system is oriented primarily toward solar considerations, but does include points for conservation features that go beyond the minimum levels required for the ESH certification. Point assignments depend on the floor area of the home, and whether it is one or two stories. Information required to use the rating system is summarized in the table below.

Information Required for Rating

\begin{tabular}{ll}
\hline Item & \multicolumn{1}{c}{ Information } \\
Insulation & $\begin{array}{l}\text { Insulation levels for walls, ceiling and floor } \\
\text { beyond those used to meet certification } \\
\text { requirements, use of moveable insulation on } \\
\text { windows. }\end{array}$ \\
Glazing & $\begin{array}{l}\text { Use of triple glazing (when not part of } \\
\text { certification rating tradeoffs). }\end{array}$ \\
Active Solar & Collector area for active solar hot water system.
\end{tabular}


Information Required for Rating

\begin{tabular}{ll}
\hline Item & \multicolumn{1}{c}{ Information } \\
Passive Solar & $\begin{array}{l}\text { Direct gain glazing area and orientation, Trombe } \\
\text { wall and water wall glazed area and orientation, } \\
\text { area and orientation of thermosiphoning air } \\
\text { panels, area and orientation of sun space. }\end{array}$
\end{tabular}

Each point allowed in the system is approximately equivalent to a 1 percent reduction in the annual energy use for heating, cooling, and domestic hot water compared to a house of similar size and design that meets ESH certification requirements. The point allowances for solar options were developed using the computer programs f-Chart, f-Chart SLR, and TEASOL, which are described more fully in the technical support document listed below. Cooling considerations in point allocations are based on cooling load calculations using the National Association of Home Builders method.

In rating the home, points are sumed for insulation, solar hot water heating, and solar space heating, and are combined with home size information to obtain an energy-savings factor. The energy-savings factor is then used with information on fuel costs to obtain estimates of yearly fuel savings for the home.

Home ratings are performed by builders, with the rating forms sent to TVA and made available to home buyers and the lending cumunity. Local building inspectors will be involved in verifying the proper construction of the energy conservation features of the home. According to TVA, the Federal Home Loan Mortgage Corporation allows banks in TVA's region that sell loans to the Corporation to use results of the ESH program to qualify home buyers for loans in circumstances where the borrower would not otherwise meet the Corporation's loan/income requirements. The ESH program is just beginning, so experience with the program is limited.

Development costs of the ESH program are judged to be moderate. The time and cost to perform a rating are low, since the rating is conducted by the builder using a simple checklist. 
Additional

Information: Residential Energy Evaluation Point System - Technical Support Document, prepared for TVA by Total Enviromental Action, Inc. Harrisville, New Hampshire. May 1981.

Energy Saver Homes - Point Rating System for Solar and Conservation Options

Contact: Ira Birnbaum

TVA Solar Applications Branch

310 TVA Credit Union Building

Chattanooga, TN 37401

$615-751-5153$ 
WESTERN RESOURCES INSTITUTE

RES IDENTIAL ENERGY EVALUATION METHODOLOGY

Western Resources Institute (WRI) has developed the Residential Energy Evaluation (REE) methodology, a prescriptive HERS, as part of the Washington State Energy Evaluation Program. One goal of the Washington program is to provide a consistent energy evalution and rating system that can be used by the entire shelter industry, including appraisers, primary and secondary lenders, home buyers, builders and realtors. WRI has developed the REE methodology with support and input from all of these groups. Although much of the methodology has been developed, the system is not yet finished, and several features are currently under development. The REE methodology currently applies to new and used single-family residences, although it may be expanded in the future to include multifamily dwellings. Initial work on the REE methodology was conducted under the sponsorship of the State of Washington office of the Western Solar Utilization Network.

The REE methodology is intended to be an easy-to-use tool that is appropriate for assessing the energy efficiency of 95 percent of the housing stock. WRI is now considering methodologies that can be used in conjunction with the REE methodology to assess the performance of nonstandard, custom houses that may make up 5 percent of the housing stock.

The REE methodology currently considers only factors affecting space heating and water heating. The addition of cooling considerations to the methodology is under study. Five different point scales are used to rate various house types. The types of home construction considered are: one story, split entry, split level, two-story, and one and one-half story. Total point scores range between 0 and 100 points. A zero point score is equivalent to a home with absolutely no conservation features and a 100 point home is equivalent to a home with the highest levels of climatically optimum conservation options, including an energy efficient building shell, solar options, and energy efficient water heating options.

The energy rating is based upon building she 11 characteristics, the HVAC system, water heating features, the use of active solar water heating and 
passive solar considerations. The basic rating can also be modified by qualitative considerations such as the potential for summer overheating, the use of a setback thermostat, and other energy conserving features. General information requirements for rating the house are shown in the table below.

\section{Information Required for Rating}

\begin{tabular}{ll}
\hline \multicolumn{1}{c}{ Item } & \multicolumn{1}{c}{ Information } \\
\hline Insulation & $\begin{array}{l}\text { Insulation values for ceiling, walls, floors, } \\
\text { basement. }\end{array}$ \\
Windows & $\begin{array}{l}\text { Type of glazing, use of thermal break, storm } \\
\text { windows, movable insulation. }\end{array}$ \\
Infiltration & $\begin{array}{l}\text { Use of caulking and weather stripping, fire- } \\
\text { place construction, use of vapor barrier and } \\
\text { double entry porch. }\end{array}$ \\
Water Heating & $\begin{array}{l}\text { Hot water temperature, use of flow restrictors, } \\
\text { heater wrap, insulated pipes, heat trap, and } \\
\text { heat pump water heater. }\end{array}$ \\
Active Solar & $\begin{array}{l}\text { Use of active or thermosiphon solar water } \\
\text { heating system. }\end{array}$ \\
Passive Solar & $\begin{array}{l}\text { South-facing glass area (50 or } 100 \text { square } \\
\text { feet), light (wood frame) or heavy (masonry) } \\
\text { construction, envelope efficiency } \\
\text { score. }\end{array}$ \\
HVAC System & $\begin{array}{l}\text { Type of heating equipment, efficiency of } \\
\text { combustion, use of flue dampers and ignition } \\
\text { devices, duct insulation, setback thermostat. }\end{array}$
\end{tabular}

An interesting aspect of the REE methodology is the way that points are assigned for passive solar benefits. Passive solar points depend not only on the amount of south glazing and thermal mass in the house, but also on the thermal efficiency of the home, as judged by its envelope efficiency score. Low-efficiency homes, with their higher demand for space heating, are allowed higher point scores for passive solar than are high-efficiency homes, which cannot use the solar gain as completely. 
The REE methodology is intended for use by appraisers during normal home appraisal. Appraisers would check off point scores on a sheet for the appropriate housing types, and then add the scores to obtain a total point score. The total point score is not reported as a rating, but is used to assign the home to one of five categories. The possible categories are poor, fair, good, efficient, and very efficient. A separate part of the REE methodology is a calculational methodology that can be used to convert the category-type rating into a projection of the annual energy consumption for the home, along with an estimate of the annual energy cost.

The package to estimate energy consumption and cost is intended for use primarily by the secondary mortgage market participants as a means of evaluating relative energy performance of residential dwellings. In order to involve all shelter industry concerns, similar energy evaluation manuals for consumers, builders and others are expected to be developed.

Appraisers familiar with the REE methodology have indicated that rating a home would involve little incremental time in the appraisal process, on the order of 15 minutes, making the cost per rating low. Development of the system for other climate regions is judged to be of moderate difficulty. A moderate amount of training for appraisers would be required.

A field application of the REE methodology is currently being developed as part of the Washington program. This field application will be cosponsored by relevant shelter industry groups, and will attempt to demonstrate the rating concept on a large scale in metropolitan areas throughout the Puget Sound region.

Additional

Information: J. Luboff, "The Washington Program - A Shelter Industry Integrated Residential Energy Evaluation Process." Presented at the 1982 Sumer Study on Energy-Efficient Buildings, Santa Cruz, California, sponsored by the American Council for an Energy-Efficient Economy, 305 Massachusetts Avenue, N.E., Washington, D.C. 20002.

Contact: Jay Luboff or Evan Brown Western Resources Institute Box 5477

Seatt le, Washington 98105 206-543-1249 


\subsubsection{Other Potential Prescriptive Systems}

The following section describes energy-efficiency tools which have potential as home energy rating systems. The building codes of both Florida and California require that certain energy features be included and scored in all new residential construction; Lawrence Berkeley Laboratory has prepared a draft HERS for Minnesota; and Owens-Corning Fiberglas Corp. has prepared an energy appraisal package. In all cases, these codes or systems measure factors affecting home energy consumption and could thus be adapted for use as home energy rating systems. 


\section{STATE OF CALIFORNIA}

\section{RESIDENTIAL BUILDING STANDARDS}

The State of California has recently adopted energy-efficiency standards for new residential buildings. The standards establish energy budgets for new residential construction for 16 different climatic zones within California, and require certain features. Mandatory features include:

- minimum levels of wall and ceiling insulation,

- infiltration control measures,

- vapor barriers (in certain climate zones),

- duct and pipe insulation,

- proper sizing of space conditioning equipment,

- setback thermostats,

- efficient lighting.

The standards apply to all new residential construction if the proposed construction was not approved by an advisory agency or other appropriate local agency before June 15, 1982.

Builders are allowed two methods to comply with the energy budget requirements. A prescriptive approach specifies lists of measures which have been predetermined to meet the budget requirements. The builder can comply by simply installing all specific components in the home. Note that this approach is somewhat different from the other prescriptive systems discussed in this paper since it does not allow free selection of conservation options. The second way a builder can comply with the energy budget requirements is by showing through performance calculations that the building will meet the requirements. Two performance calculation approaches are allowed. The first is a point system approach, and the second is a choice of computer calculational systems. The point system is similar to other systems classified by PNL in this report as prescriptive rating systems, and is the topic of this discussion. While the point system is not currently being used as a rating system, it could easily be adapted to this function. The calculational systems are discussed in Section 3.2 . 
The California Residential Buildings Standards point system is a comprehensive system that includes building shell characteristics, HVAC systems, hot water systems, active solar and passive solar in the consideration of the buildings energy budget. The amount of information required in each category is limited by the fact that mandatory housing features do not need to be included in the point system. A condensed list of the information required to complete the rating is shown below.

\begin{tabular}{|c|c|}
\hline Item & $\frac{\text { rmation Required for Rating }}{\text { Information }}$ \\
\hline Insulation & $\begin{array}{l}\text { Insulation values for walls, ceilings, } \\
\text { floors, basements. }\end{array}$ \\
\hline Windows & Glass area, skylight area, type of glazing. \\
\hline Infiltration & Degree of infiltration control. \\
\hline Hot Water System & Type of water heater. \\
\hline HVAC System & $\begin{array}{l}\text { Type of heating/cooling equipment, heating and } \\
\text { air conditioner efficiency, system controls. }\end{array}$ \\
\hline Active Solar & $\begin{array}{l}\text { Active solar fraction for water heating and } \\
\text { space heating. }\end{array}$ \\
\hline Passive Solar & $\begin{array}{l}\text { Shading coeficients for windows and skylights, } \\
\text { thermal mass, south overhang length, amount of } \\
\text { movable insulation. }\end{array}$ \\
\hline
\end{tabular}

Point calculations for each category are well documented in New Residential Building Standards Energy Conservation Manual by the California Energy Commission. Points are assigned positive values for desirable features, and negative values for undesirable features. To meet the energy budget requirements, the home must have a total point score of zero or more. Scores of less than zero require a reworking of the building plans.

Compared to other prescriptive-type systems, the California Residential Buildings Standards point calculation system is judged to have a high development time. Rater training for operating this type of system is judged to be moderate, and time to complete a rating is also judged to be moderate. 
Additional

Information: New Residential Building Standards

Energy Conservation Manual,

January 1982, California Energy Commission.

Tit le 24, Part 2, Chapter 2-53

Title 20, Sections 1401-1410

California Administrative Code

Contact: Kevin Smith

California Energy Comission

1111 Howe Avenue

Sacramento, California 95825

916-920-6421 


\section{STATE OF FLORIDA \\ MODEL ENERGY EFFICIENCY CODE}

In an effort to conserve energy used by residential housing, Florida adopted in 0ctober 1980 an energy code for new houses that utilizes a prescriptive point system as one alternative for determining compliance. Adoption of the Model Energy Efficiency Code (MEEC) point system was intended to save energy in two ways. First, the MEEC code will save energy by requiring new houses to be built with more energy conservation features. Second, the MEEC point system will provide consumers with information on the energy efficiency of homes prior to purchase, which should encourage builders to market more energy-efficient housing. Individual point systems have been developed for nine climatic zones within Florida.

Factors included in the MEEC point system include building shell characteristics, the HVAC system, the hot water system, active solar systems, passive solar considerations, and a limited consideration of appliances. The basic information required in using the MEEC point system is summarized in the table below.

\section{Information Required for Rating}

\begin{tabular}{ll}
\hline \multicolumn{1}{c}{ Item } & \multicolumn{1}{c}{ Information } \\
Winsulation & $\begin{array}{l}\text { Insulation values for walls, ceilings, floors. } \\
\text { Glass area, skylight area, type of glazing, } \\
\text { use of operable windows. }\end{array}$ \\
Hot Water System & $\begin{array}{l}\text { Type of water heater, capacity of A/C heat } \\
\text { recovery unit. }\end{array}$ \\
HVAC System & $\begin{array}{l}\text { Type of heating/cooling equipment, heating and } \\
\text { air conditioner efficiency, duct insulation, } \\
\text { multizone A/C, use of ceiling fans. }\end{array}$ \\
Appliances & $\begin{array}{l}\text { Use of washer/dryer in conditioned space - } \\
\text { penalty points. }\end{array}$ \\
Active Solar & $\begin{array}{l}\text { Certified daily collection rate for solar water } \\
\text { heating, storage tank size. }\end{array}$ \\
Passive Solar & $\begin{array}{l}\text { Roof overhang distance for each wall, use of } \\
\text { tinted glass, orientation of windows. }\end{array}$
\end{tabular}


Passive solar considerations in the MEEC point system are aimed primarily at estimating the amount of summer insolation avoided through proper design techniques.

Under the MEEC point system, low scores are preferable to high scores. A point score of 100 or less is required to pass the code requirements. Obtaining the point score for a home requires assessing the conservation feature of the home on the rating sheet, and going through a simple but somewhat lengthy (compared to other prescriptive systems) calculation. The point calculation procedure requires multiplying point values by the appropriate unit areas of floors, walls and windows. Window areas must also be multiplied by an overhang factor to account for shading. Point values are kept separately for sumer and winter benefits, and are multiplied by efficiency values for ductwork and the heating and cooling system, then divided by the total floor area to obtain winter points and summer points. To arrive at the total point score, winter and summer points are added, penalty points are added, and credit points for hot water systems and special features are subtracted. Hot water credit points are accrued for the use of gas water heaters, solar water heaters, and air conditioning heat-recovery units.

The MEEC point system was developed with the intent of using point values to make reasonable predictions about energy consumption of the home. Costs of developing the MEEC point system are judged to be moderate to high compared to other prescriptive systems. The rater in the MEEC point system is the homeowner or builder, who completes the rating form prior to application for a building permit. The instructions for rating the home are included with the rating form, and no formal training is required to use the rating system. Enforcement of the energy code is done at the local level by building inspectors.

The primary users of the MEEC point system are, of course, builders who must use the system to determine compliance with the code requirements. There is currently no hard information on the number of residences rated under the MEEC point system, because of the short period of time it has been in use and because of the fluctuation of housing construction during that period. 
Several revisions to the MEEC point system are currently being made. The two largest revisions are to the point calculation procedure and the minimum points required to meet the code. The method of determining compliance to the code is being modified and streamlined so that the calculations required to obtain the point score of the house are simpler and easier. The point score required to meet the code is also being revised. The new point requirement will be a sliding value which varies according to the size of the house, and will range from 80 points to 120 points. The old requirement of 100 points for all houses had been criticized for being unfair to smaller houses where fixed energy consumption becomes disproportionate to the low square footage of floor space.

Additional

Information: State of Florida, October 1980, "1980 Instruction Manual for Sections 8, 9, and $9 H$, Zones 1, 2, 3, for the Model Energy Efficiency Code for Building Construction."

Feldman, W., Harbridge House, Inc. A Survey of Existing Programs that are Potential Vehicles for Improving Energy Efficiency in New Buildings, Department of Energy, April 1981.

Contact: $\quad$ Bill Bower Department of Community Affairs Howard Building 2571 Executive Center Circle East Tallahassee, Florida 32301 904-487-1822 


\section{LAWRENCE BERKELEY LABORATORY \\ MINNESOTA ENERGY CONSERVATION SYSTEM}

Under sponsorship of the U.S. Department of Energy, Lawrence Berkeley Laboratory (LBL) developed a HERS for new single-family residences in the Minnesota region. The Minnnesota Energy Conservation (MEC) system is a good example of a HERS that could be used to inform builders and home buyers of the importance and cost-effectiveness of conservation features.

Components considered by the MEC system in rating homes include the building she11, HVAC system, and passive solar design considerations. The generalized information required to rate the home is shown in the table below.

Information Required for Rating

\begin{tabular}{|c|c|}
\hline Item & Information \\
\hline Insulation & $\begin{array}{l}\text { Wall, ceiling, and floor insulation values, } \\
\text { use of earth-sheltered construction } \\
\text { techniques. }\end{array}$ \\
\hline Windows & Glass area, type of glazing. \\
\hline Infiltration & $\begin{array}{l}\text { Amount and quality of weather striping, use of } \\
\text { vapor barrier, other infiltration controls. }\end{array}$ \\
\hline Attic Ventilation & Type of ventilation, amount of vent area. \\
\hline HVAC System & $\begin{array}{l}\text { Heating and cooling efficiencies, amount of } \\
\text { wood burned in wood stove, insulated ducts, } \\
\text { EER of air conditioner. }\end{array}$ \\
\hline Passive Solar & $\begin{array}{l}\text { Area of south-facing glass, movable insula- } \\
\text { tion } R \text { value, use of thermal mass for } \\
\text { storage, use of sun space. }\end{array}$ \\
\hline
\end{tabular}

Rating the home requires checkoff of conservation features on a form and a few simple calculations. Both positive and negative points are possible. Positive points indicate an increase in energy consumption, so lower scores are preferable to high scores. A home with a score of 0 meets proposed energyefficiency guidelines which were used in developing the system. Homes with scores less than zero use even less energy. Separate rating forms are used 
depending on whether the house is heated by gas or 011 , a heat pump, or electric resistance heating. The MEC system was designed to be simple to use, and to allow for easy presentation of the results (all rating calculations are contained on two sheets).

A rather unique aspect of the MEC system is that the output of the system is both a point score and an estimation of the home's annual energy consumption for space conditioning. Estimating actual energy consumption is something most prescriptive systems avoid, since the effect on energy consumption of adding various conservation features is not strictly additive. The MEC system is able to predict energy consumption by carefully selecting point values and by providing a simple calculational procedure to translate point values into energy consumption.

The MEC system was developed using the DOE-2 computer model as an analysis tool to model the effect of various conservation options on the thermal performance of a home. Results of the MEC system have been verified against the DOE-2 model with good results.

Developers of the MEC system believe that including energy required for water heating and possibly other appliances may be desirable. This would give a more thorough treatment of the total energy consumption in the house, rather than simply analyzing space conditioning requirements, and would add little complexity to the system. They also mentioned that another possible change to the system would be to make the desirable point values positive rather than negative and perhaps to give some sort of summary rating such as a letter grade. While the latter changes are cosmetic rather than technical considerations, they may have some impact on how easy it is for consumers to relate to the output from the system.

The expense of developing similar rating systems for other portions of the U.S. would be directly proportional to the accuracy desired in the systems, particularly with regard to passive solar considerations. Rather than a stateby-state approach, it may be possible to develop systems for perhaps 12 regions which would cover the entire country. An approach like this could cost in the neighborhood of $\$ 50-60 \mathrm{~K}$ per region, in the judgement of LBL personnel. Rater training for using the system is judged to be moderate. The cost for rating a 
home under the MEC system is also judged to be moderate, although this would depend on how the program was implemented. If RCS audit data were used to rate the home, the rating could be completed quickly at low cost. Cost per rating would be moderate if a site visit were required.

The MEC system is not currently being used.

Additional

Information: Energy Conservation Rating System for New Single Family Detached Residences in Minnesota, April 1981 Draft Report, Lawrence Berkeley Laboratory.

Contact: Mark Levine

Lawrence Berkeley Laboratory

University of California

Berkeley, California 94720

FTS 451-5238

415-486-5238 


\section{OWENS-CORNING FIBERGLAS CORPORATION \\ HOME ENERGY APPRAISER}

The Home Energy Appraiser was developed by Owens-Corning Fiberglas Corporation to provide a tool for mortgage lenders, appraisers, utilities, and any other group interested in assessing the energy rating of a home. The Home Energy Appraiser is a device similar to a slide rule. It includes a list of points for various conservation options and also keeps a running tally of the total score. The Home Energy Appraiser allows for easy interpretation of suggested thermal improvements because the user can readily see how the point score would be improved by various conservation measures. Unlike many prescriptive systems that are tailored for a specific area, the Home Energy Appraiser is applicable across the United States. The Home Energy Appraiser applies to both new and used single-family homes. It can be purchased from the developer.

Only building shell characteristics are considered in rating the home. Information required to rate the home is shown in the table below.

Information Required for Rating

\begin{tabular}{|c|c|}
\hline Item & Information \\
\hline Insulation & $\begin{array}{l}\text { Insulation values for ceiling, floor and } \\
\text { basement, wall area. }\end{array}$ \\
\hline Windows & $\begin{array}{l}\text { Window area, type of glazing, type of sash, } \\
\text { use of storm windows. }\end{array}$ \\
\hline Infiltration & Qualitative judgement of house tightness. \\
\hline
\end{tabular}

The rater adjusts the scales of the Home Energy Appraiser to the appropriate insulation levels, window areas, etc., for the home being rated, and reads the point score for that feature from the slide rule. A separate scale is used to keep track of the total points scored. Points scored for ceiling and floor insulation depend on both the total insulating value and whether the house is single-story, two-story, or split-level construction. The total score for the house is then compared to a suggested score. The suggested score depends on the type of house construction (single floor, two floor, or split entry) and which geographic region of the country the home is in ( 8 regions total). A 
separate scale compares the scored points to the suggested points and calculates an energy-efficiency rating, ranging from 12 to 150 . The energyefficiency ratings are themselves categorized in three groups; very good, fair, and poor.

An additional feature of the Home Energy Appraiser is that after the home has been rated, additional scales on the back of the Appraiser allow easy calculation of how the point score could be improved by various thermal upgrading options. This feature allows a quick assessment of which retrofitting projects could most easily improve the rating.

The Home Energy Appraiser is judged to have been moderately difficult to develop, which of course is tempered by the fact that it is not limited in use to a specific geographic area. Training required for raters to be able to use the Appraiser is low. The time and cost to rate a home will depend greatly on how the Home Energy Appraiser was implemented in a rating process. If the rating required a site visit to measure window area and estimate insulation values, the time and cost per rating would be moderate. If the rating was done using information from plans or another source that did not require a site visit, the time and cost per rating would be low. The cost of the Home Energy Appraiser itself is nominal at around $\$ 3.00$.

The Home Energy Appraiser has been available for nearly two years. OwensCorning Fiberglas does not have information on how the Appraiser has been used, since they only supply it as a tool rather than rate the homes themselves. Owens-Corning Fiberglas feels that the Home Energy Appraiser is a very costeffective tool for use as a simplified estimating guide. It is not intended to be a definitive instrument for exact energy-loss calculation.

Additional

Information: Home Energy Appraiser

Owens-Corning Fiberglas Corporation

Contact: $\quad$ Tim Grether Owens-Corning Fiberglas Corporation

Fiberglas Tower

Toledo, Oh io 43659

419-248-8000 


\subsection{CALCULATIONAL SYSTEMS}

This section presents brief write-ups of a sample of the calculational systems surveyed. The systems are grouped according to whether they are currently in use or whether they are tools that could be used to produce a rating.

\subsubsection{Calculational Rating Systems}

This subsection describes the calculational systems that are currently in use as home energy rating systems. Rating is distinguished from auditing in that an audit does not compare a home's energy use relative to other houses or to a baseline whereas a rating provides this information. 


\section{PUBLIC SERVICE COMPANY OF NEW HAMPSHIRE}

NEW AUDIT

Product: Computerized NEW Audit

The Public Service Company of New Hampshire (PSNH) uses a computerized audit for analyzing home energy use and the cost and savings of applicable conservation measures. The computer code is copyrighted by Cornerstones Energy Group of Brunswick, Maine.

The computerized audit has been in use since March of 1978. Since that time, approximately 8000 single-family residences have been audited.

The following data is provided as input to the model from the inspection of the home:

- volume of heated space

- estimated air changes per hour

- daytime and nighttime thermostat settings

- areas of envelope surfaces

- type of heating surface

- occupant behavior (e.g., number of showers, baths, loads of wash per week)

Other input to the model includes heating degree-days and local fuel prices.

From this information, the estimated annual costs of space heating and water heating are calculated. Then, using local prices of contract labor and materials, the net cost, the first year energy savings, and the years to payback are calculated for twenty conservation options. Although the annual energy usage is not included with the output, it can be easily obtained by dividing the annual energy cost by the local fuel price.

The home energy audits are performed by a trained utility representative at the request of the customer. Data collected during the audit is transmitted to a cental computer from a portable terminal. A typical rating takes from one to two and one-half hours. This includes time for a visual inspection of the home, interview with the occupants, processing of data, and presentation of 
results. The cost of an average rating is estimated by PSNH to be about $\$ 100$ considering personnel and computer time. The audit is provided free of charge to the customer.

Contact: Bob Fournier

Public Service Company of New Hampshire $100 \mathrm{EIm}$ Street

Manchester, NH 03105

603-669-4000 


\section{PUBLIC SERVICE OF NEW MEXICO \\ SMART PROGRAM}

Product: Hand Calculation of Heat Loss

The SMART program was developed by Public Service of New Mexico (PNM) to encourage conservation and reduce electrical demands. The program actually grew out of an older program operated by PNM that was instituted in 1964 to encourage the use of electicity in new homes. The old program performed heatloss calculations for houses in order to help builders size electrical heating and cooling equipment. As the emphasis of PNM changed in the 1970 s from increasing sales to slowing growth and encouraging conservation, the heat-loss calculations developed for the old program become the basis of the SMART program. The SMART program is affiliated with the EEI National Energy watch program.

The SMART program is designed specifically for new single-family homes, since PNM feels that retrofitting problems do not allow any significant savings to be made in most existing homes in their area. A home qualifies for the SMART certification by meeting a calculated heat loss of 6.5 watts per hour per square foot. The heat-loss calculations are based on modified ASHRAE methods.

Beginning in 1964, PMN began installing two electric meters on all new electric houses. One meter monitors the total electric consumption, while the other meter monitors electricity used by the heating system. Using the data collected by the heating meter, PNM has compared predicted heat losses to actual heat loss. Over the years, the differences between the predicted values and the actual values have been used to modify the ASHRAE multiplying factors, resulting in a simple and accurate calculational system tailored specifically for the PNM area.

Heat-loss calculations focus on the construction of the building shell. The rating is done without charge by PNM at the request of the home builder. The builder supplies PMN with the plans for the home. PNM then rates the home and supplies the builder with the calculated heat loss. PNM will then size and 
design the HVAC equipment for the home. During construction of the home, PNM attempts to inspect the home at various stages of completion to verify that energy conservation features are as indicated in the plans.

An advantage of the PNM system is that it supplies accurate estimates of heat loss very quickly and easily. The average rating for a home generally requires about 45 minutes. A fair amount of technical training is required to enable the rater to make the heat-loss calculations and to design the HVAC systems. As mentioned previously, the PNM system was developed over a long period of time as field test were used to refine the heat-loss calculations. Initial implementation of the program was moderately difficult.

While some slight interest has been shown at times by area lenders, the primary users of the system are the utility and builders. Acceptance by the building community has been good, and PNM indicates that the general public seems to like the program. PNM feels that the SMART program has been effective in saving energy and has reduced the rate of growth of electrical demand. Contact: Bill Gillmore Public Service Company of New Mexico Alvarado Square Abuquerque, New Mexico 87158 $505-848-2760$ 
SOLAR COMPUTER CORPORATION

SOLCOM

Product: Simplified Computer Energy Use Calculation Model

SOLCOM is a real estate energy evaluation program developed by the Solar Computer Corporation that is designed to be accessed by real estate brokers, appraisers and lenders. Although the code has specific output of interest to lenders, up to this point, they have not significantly utilized the program.

The program is currently being field tested by appraisers in the Denver area. The objective of the test is to determine whether the computer predicts essentially the same results given the subjective measures provided by each of the appraisers for the same house. That is, how sensitive is the code to the inputs for the user.

The SOLCOM code accepts input data such as water usage, building construction characteristics, type of heating and cooling system, and occupant behavior. This information is collected by the appraiser during the appraisal process or by the real estate broker for multiple listing service information.

SOLCOM provides an annual energy demand profile. Energy use is disaggregated by end-use such as hot water, appliances, and space heating or cooling. Within each of the categories, the energy use is further broken down for each specific appliance or heat-loss component both in Btu's and on a percentage basis. A statement of annual energy usage provides the net energy demand for the house, identifies contributors to the energy demand, and identifies gains made by active and passive solar systems and by internal heat generated by occupants and appliances. Other reports generated by the code include: a graph of projected energy costs for a twenty-year period, an analys is of state and federal tax credits, and a lenders' summary of financial data. The lenders' summary includes an estimate of the first year energy cost as well as an energy index in terms of Btu/square foot/year. The lenders' summary also provides the ratio of the PITI + average monthly energy cost to the purchaser's income. A PITI + E to Income ratio is provided for the first 
year and is also projected for subsequent years based on assumptions of fue 1 escalation rates and of the potential increase in the purchaser's income.

The average cost of analyzing a house is expected to be on the order of $\$ 50$ per house. Gathering data for use in the SOLCOM mode 1 is expected to take an appraiser or realtor an additional 45 minutes to one hour beyond his normal house inspection.

Contacts: Charles R. Booz Solar Computer Corp. 1580 Gaylord

Denver, Colorado 80205

$303-320-7707$
Don Boyson

Appraisal Department

Columbia Savings and Loan

Littleton, Colorado

303-795-3069 


\subsubsection{Calculational Tools}

This subsection describes calculational tools that have not yet been used to perform home energy ratings, but that could be used.

\subsubsection{Detailed Computer Models}

This section describes two detailed calculational tools, DOE-2.1 and SUNCAT, that are potentially applicable to a HERS. 


\section{LAWRENCE BERKELEY LABORATORY}

DOE-2.1

Product: Detailed Hourly Computer Simulation.

DOE-2.1 is a public domain computer program developed for the use of architects and engineers in analyzing energy use in residential and commercial buildings. Development of the code has been an evolutionary process. There have been several earlier versions including DOE-2. The current version of the code is DOE-2.1(a). DOE-2.1(b) will be available soon. Non-DOE predecessors of DOE2.1 in the public domain include a program developed for the U.S. Post Office by General American Transportation Corporation; NBSLD, developed by the National Bureau of Standards; and NECAP, developed for the National Aeronautics and Space Administration. DOE-2.1 load calculations are based on the Post Office and NECAP program.

DOE-2.1 has been verified on a software-software basis with other simulation models and in field tests on houses in Davis, California. It was found to predict within $10 \%$ to $15 \%$ of actual energy-use figures. The code is continually updated as additional information becomes available.

DOE-2.1 calculates the hourly energy use in a building and its life-cycle cost of operation, given information on location, orientation, construction, operation, and HVAC systems. The program is capable of analyzing multizone buildings.

The program features a four-step analysis. The first step is the calculation of building heating and cooling loads based on ASHRAE procedures. Second, the actual heat added or extracted by the HVAC systems in order to meet temperature setpoints is calculated. The third step determines the fuel required by the primary HVAC system and the energy collected by solar systems. The fourth step evaluates the life-cycle, capital, and operating costs of the building, and the cost of fuel and electricity.

DOE-2.1 runs on a main-frame computer. About $120 \mathrm{~K}$ core is required for the program. Computer costs vary with the complexity of the building and computer system on which the program is run. Typically, the costs range from 
about $\$ 5$ to $\$ 50$ per run, with an analysis of a single-family residence expected to be at the low end. The cost of preparing the building input data must be added to the cost of computer time. A fair amount of training is required to become proficient in using the code.

DOE-2.1 program tapes are available through the National Technical Information Service (NTIS) along with a comprehensive documentation package. DOE contractors may access the program through the LBL remote access users' network. Individuals in the private sector can access the program through a number of private computer service bureaus.

Program Documentation:

1. User's Guide (LBL-8689)

2. Reference Manual (LBL-8706, LA-7689-M)

3. Program Manual (LBL-8705, LA-7688-M)

4. Sample Run Book (LBL-8678)

5. BDL (Building Design Language) Summary (LBL-8688)

Additional

Information: Lokmanhekim, F. W., et al. 1979. "DOE-2: A New State-of-the-Art Computer Program for the Analys is of Buildings." Presented at the Second International CIB Symposium on Energy Conservation in the Built Environment, Copenhagen, Denmark, May 28-June 1, 1979.

Diamond, SC, BD Hunn and CC Cappiello. April 1981. DOE-2

Verification Project: Phase I Interim Report. LA-8295-MS. Los Alamos Scientific Laboratory, Los ATamos, New Mexico.

Contact: James Hirsch

Lawrence Berkeley Laboratory

Building 90-3147

University of California

Berkeley, CA 94720

415-486-5711

FTS $451-5711$ 
NATIONAL CENTER FOR APPROPRIATE TECHNOLOGY

SUNCAT

Product: Detailed Hourly Computer Simulation.

SUNCAT is a public domain computer program, developed by the National Center for Appropriate Technology to analyze building energy use. This model was developed primarily as a design and parametric analysis tool for use by architects, engineers, and R\&D personnel. This model has been verified on a software-software basis with other simulation models.

SUNCAT can be used to analyze energy use in multizone buildings. Typical input parameters include building description data and orientation. The program uses hourly SOLMET weather tapes. SUNCAT estimates building design energy loads, but does not model the HVAC system. SUNCAT runs on a main-frame computer.

SUNCAT was used as the basis for developing the Western Resources Institute prescriptive rating system.

A proprietary version of the SUNCAT program called SUNCODE has been developed by the Ecotope Group. SUNCODE has the added capability of simulating passive solar features, common heating and cooling systems, and occupant behavior patterns. SUNCODE is available from the Ecotope Group for about $\$ 1500$ under a single-user license agreement and is designed to be implemented on most general-purpose minicomputer systems.

Contact: John McBride

National Center for Appropriate Technology

Butte, Montana

406-494-4572

Larry Palmiter or David Baylon

Ecotope Group

2328 East Madison

Seattle, WA 98112

206-322-3753 


\subsubsection{Simplified Computer Models}

This section contains information on simplified computer models that can potentially be adapted for use in a HERS. 


\section{CALIFORNIA ENERGY COMMISSION}

CALPAS

Product: Simplified Hourly Simulation Model.

CALPAS was developed as a simplified design and parametric analys is tool for architects and engineers. The CALPAS1 program was developed at California Polytechnic State University at San Luis Obispo. CALPASI was certified by the California Energy Commission (CEC) in January of 1982 for use in demonstrating building compliance with state-adopted energy budgets for new buildings.

CALPAS1 was used extensively to develop performance data on passive heating and cooling sytems for the Passive Solar Handbook for California (Pub. No. 500-80032), published by the CEC.

In 1979, Berkeley Solar Group (BSG) undertook major revision of the original program, producing CALPAS3. CALPAS3 results have been validated with test cell data from LoS Alamos Scientific Laboratory, and with measured energy consumption in monitored buildings.

The input data required to run the code is only slightly more detailed than the building description required for a standard heat-loss calculation. CALPAS1 and CALPAS 3 can model any of the following features:

- unlimited number of walls with any orientation and absorptivity;

- an unlimited number of windows, each with its unique orientation, shading, movable insulation, and glazing system;

- thermal masses, such as mass wall, water wall, slab and under slab rockbed;

- night setback thermostats;

- internal gains;

- passive configurations, such as Trombe walls, direct gain, attached sun spaces, and envelope;

- natural or forced ventilation with optional evaporative cooling. 
The model uses a simplified input language to describe the building. Hourly weather data are called from a program file.

The program calculates the hourly solar heat gains through windows, and gains and losses through the building shell to determine the total building heating and cooling load. It also handles internal heat generation according to one of several profiles selected by the user to model the type of residential building. Although CALPAS1 does not produce an estimate of annual energy consumption, the CEC provides simple hand calculation methods for converting heating and cooling energy loads into an estimate of total annual energy consumption from the energy load figures. The CALPAS 3 version does estimate the annual energy consumption as well as the annual cost of electricity and fuel for heating and cooling.

CALPAS1 will be made available to the public through the CEC Publications Office in Sacramento, California. CALPAS3 is run on a time-share basis on BSG computers. The average cost of a typical run made at high-priority is about $\$ 7$. The most expensive high-priority runs should not exceed more than $\$ 18$. Off-peak analysis can save about $60 \%$, making the average run cost about $\$ 3$ and the most expensive run about $\$ 7$. In addition, it costs about $\$ 125$ to sign on to use CALPAS3 and this includes a one-day training class. There is a monthly maintenance charge of $\$ 20$.

Reference: New Residential Building Standards Energy Conservation Manua 1. P400-82-013. January 1982. California

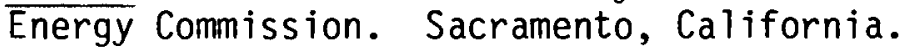

Contact: $\quad$ Berkeley Solar Group 3140 Grove Street Berkeley, California 94703 415-843-7600

Kevin Smith Cal ifornia Energy Commission 1111 Howe Avenue, MS-50

Sacramento, California 95825 916-920-7361 
COMPUTERIZED ENERGY AUDITS, INC.

PERFORMANCE ENERGY RATING SYSTEM

Product: Energy Use Simulation Model Using Test Data.

Computerized Energy Audits, Inc. (CEA) of Boulder, Colorado has developed a rating system that uses actual performance test results as input data to an energy-use analysis computer model. The model currently provides an estimate of annual energy usage (Btu/yr) and annual energy cost; however, the model can readily be modified to provide an index such as Btu/square foot/degree-day.

The model incorporates the following:

- extensive air infiltration testing which determines the location and severity of air leaks;

- mechanical system testing to establish steady state and seasonal efficiencies of gas or oil systems, coefficient of performance (COP) ratings of electric systems and reliability tests of solar systems;

- comprehensive lifestyle survey of current residents;

- measuring and recording of thermal properties, including insulation values, construction techniques, siting, landscaping and design;

- daily weather data for the site; and

- a validation procedure which compares actual energy usage with projected usage.

The Performance Energy Rating System model first calculates the shell load using the U-values and accounting for infiltration. Internal gains caused by appliances and occupants and load reductions attributable to passive and active solar are subtracted from the shell load. The resulting load is divided by the efficiency of the mechanical system to derive an annual energy use for heating. Hot water heating energy use derived from system efficiency and from the occupant survey is added to yield a total annual energy use. This is converted to an annual energy cost by multiplying by the fuel cost. 
The model also projects the value of energy-saving retrofits and sets the order in which they should be adopted. This analysis provides the following information for the improvement: 1) cost, 2) first year utility bill savings, and 3) years to payback. This capability can provide the lending institution or the homeowner with information on the cost of attaining a given level of energy efficiency.

CEA's experience with the system indicates that the projected energy usage is within $\pm 10 \%$ of actual usage. The cost of the rating is approximately $\$ 200$. This includes on-site testing and measurement as well as the computer analysis.

CEA is currently involved in the formation of a real-market testing and demonstration program in the Denver area. The goal is to standardize testing, measurement and analysis procedures to ensure consistent results in rating properties.

Additional

Information: Walsh, James P. April 21, 1982. Performance Test as a Basis for a Home Energy Rating System. Presented to the National Institute of Building Sciences, Washington, D.C.

Contact: James P. Walsh

Computerized Energy Audits, Inc.

2330 Broadway

Boulder, Colorado 80302

$303-449-3346$ 


\section{ECOTOPE GROUP}

SUNDAY

Product: Simplified Computer Load Calculation Model.

SUNDAY is a proprietary code developed by the Ecotope Group as a simplified version of SUNCODE, which is the proprietary version of the SUNCAT model. The model was developed primarily as a simplified design tool for use by architects and engineers. The model is useful in sizing HVAC equipment for a given building. SUNDAY has been software-software verified with SUNCODE and was found to predict within $5 \%$ of the SUNCODE predictions.

SUNDAY has been developed to run on several types of personal computer systems, such as an Apple computer. The program prompts the user to enter the relevent data, such as building orientation, glazing area, thermostat setpoints, and expected contributions of appliances and occupants to internal heat gain. SUNDAY reads weather data previously stored in the computer's memory. National Oceanic and Atmospheric Administration (NOAA) typical meteorological year (TMY) weather data have been preprocessed by the Ecotope Group to match the format required by the SUNDAY program.

The model is used to predict monthly and annual heating and cooling loads of single-zone buildings. Since the model does not simulate the HVAC systems, actual heating and cooling energy consumption is not predicted. That is, the actual energy consumption may be higher or lower than the energy load depending on the efficiency of the HVAC equipment. The model can simulate passive solar features.

The SUNDAY program is available on tape from the Ecotope Group for about $\$ 500$ on a single-user license basis. Preprocessed weather data tapes are available for about 230 sites for about $\$ 75$ each.

Contact: David Baylon

Ecotope Group

2328 East Madison

Seattle, Washington 98112

206-322-3753 
ENERCOM, INC.

THE ENERCOM SYSTEM

Product: Computerized RCS Audit.

The Enercom System is a residential audit package designed by Enercom, Inc. It is sold to individual utilities for use in the RCS energy audit program. The Enercom System is currently being used by 150 utilities in 43 states. Enercom, Inc. estimates that approximately 500,000 houses have been audited using their system.

Each custom-designed utility package includes site-specific cost and weather data for each zone with in the utility's service region. The program accomodates 80 to 100 input variables including past utility bills, building features, solar access data, efficiencies of HVAC equipment and local fuel prices. Data are processed on a time-share basis with the computer service of General Electric Information Services. The following modes of entering data and receiving results are available with the Enercom System:

1. Voice Response. Data is transmitted to the computer using telephone touch tone signals from the audit site. The computer transmits results via a synthesized voice.

2. Interactive Terminal. Data is transmitted to the computer using a portable terminal from the audit site and results are printed at the site.

3. Batch Processing. Homeowner submits form to audit of fice. Data is processed and results are presented at a later date.

The basic Enercom software package was designed with feedback from utilities, customers, and auditors. Enercom, Inc. estimates that their program predicts results that are accurate to within 5\% of actual energy use and savings. In general, the program first estimates an annual energy usage and cost based either on past utility bills for existing houses, or on theoretical load calculations for new houses. The theoretical calculations are based on ASHRAE techniques for heat-loss calculation. The program then calculates the 
estimated cost and the payback period of implementing various energy conserving retrofits. The estimated first-year energy savings for each retrofit is also calculated.

The cost of developing each utility package varies, depending on the options desired by the utility. However, since the basic software package has already been developed, the incremental cost of modifying the program to fit the needs of a particular utility is thought to be moderate. Packages are typically prepared on a time-and-materials basis.

Typical costs of computer time for a single rating range from $\$ 2$ to $\$ 12$. A typical in-house audit takes from one to two hours. This includes the time for data collection and processing as well as time for presenting information on energy conserving ideas. The data processing equipment ranges from $\$ 70$ for the voice response modem to about $\$ 4000$ for a "smart" terminal. The level of training required for auditors varies from as little as two days to as much as three weeks depending on the preference of the utility implementing the Enercom system.

Contact: Jim Marquardt

Enercom, Inc.

2323 South Hardy Drive

Tempe, Arizona 85282

$602-894-2279$ 


\section{ENERGY MANAGEMENT SERVICES}

REAC

Product: Computerized RCS Audit.

The REAC (Residential Energy Analysis for Conservation) program was developed by Energy Management Service (EMS) as a computerized RCS audit for utility use. The program has been used by two Northwest utilities over a one and one-half year period. Snohomish County PUD located in Everett, Washington, reports having used the model to audit over 10,000 residences including singlefamily and multifamily residences, as well as mobile homes. The Bonneville Power Administration (BPA) is currently beginning to implement a modified version of the REAC model. The BPA version of the model has been field and simulation tested.

The model uses past utility billing data to compute an annual energy usage and cost. In the absence of past billing data, the model is used to estimate annual energy cost based on U-values, building component areas, local fuel prices, degree-days, and estimates of HVAC system efficiency and air leakage rate. The marginal savings of specific conservation options are calculated, along with the percentage energy savings expected with each option.

The program runs on a portable minicomputer. The program can store data for up to four audits, which can later be dumped to a centralized data base on a main-frame computer. A typical audit takes about two hours. Of that time, about 15 minutes are used to enter data and about four minutes are required to process the data.

Contact: Bob Helm

EMS

0434 SW Iowa

Portland, Oregon 97201

1-800-547-4232

Carol Thompson

Snohomish County PUD

Everett, Washington

206-258-8211
Bruce Batson

BPA

P0 Box 3621

Portland, Oregon 97208

FTS 429-4082 
ENERGYWORKS, INC.

RCS AUDIT

Product: Computerized RCS Audit.

Energyworks, Inc. (EWI) has developed computerized residential audit systems for both Massachusetts and Pennsylvania for use under the RCS program. In its one year of use in Massachusetts, this audit methodology has been used on about 60,000 houses. This system has been validated by the U.S. Department of Energy and the appropriate state energy offices as required by law.

Starting with the previous year's energy bills, the audit program projects the total annual cost of heating/cooling. If prior billing data are not available, such as with new houses, a worksheet and a hand calculator are used to determine the annual heat load and the cost of heating. The program uses inputs on occupant behavior obtained during the interview of the residents. These inputs include hot water usage and thermostat settings. From inspection of the house, the auditor obtains information on insulation levels, heating system performance and solar measures. Data is entered into a main-frame computer through a portable data terminal. Climate data are available in the program by zip code. In addition to the total annual heating cost, expected costs and savings that can be realized by implementing various conservation options are generated.

A typical audit takes about two and one-half hours. This time includes the occupant interview, inspection of the residence and data collection, data input and processing, and presentation of results.

EWI estimates that the total actual cost of a typical audit ranges from $\$ 90$ to $\$ 140$. This includes both the startup costs for the audit service and the cost of the computer time. EWI states its costs as:

start-up fees: $\quad \$ 5000-\$ 20,000$

computer cost: $\quad \$ 1-20$ per audit (depending on type of delivery, batch-interactive)

Contact: John Schimpf

Energyworks, Inc.

45 Border Street

West Newton, MA 02165

617-332-3600 
KARPAY ASSOCIATES

RESIDENTIAL ENERGY ANALYSIS MODEL

Product: Simplified Computer Model.

This model, developed by Karpay Associates, is based on the NBS variable based degree-day mode1. The Karpay model has the added capabilities of modeling active and passive solar systems.

The development of the program was financed by the Colorado Office of Energy Conservation for implementation in Boulder and Fort Collins. The program has been used to revise and expand the City of Boulder's energy conservation point system (see Section 3.1.2). The program will be used to audit atypical building designs that cannot be adequately audited with the point system.

The model is based on standard ASHRAE equations and allows over 100 data inputs. Types of input values needed include building dimensions, orientation, U-values, and infiltration. Occupant behavior is also considered on the model through inputs such as average occupancy and thermostat setpoints. Program capabilities include monthly and annual calculations for space heating and cooling energy use, domestic hot water energy requirements, and solar contributions for the building's energy needs. Active solar calculations are based on the F-Chart methodology. F-Chart is a computer program developed at the University of Wisconsin for sizing solar domestic hot water, space heating, and industrial process heating systems. Future plans include implementing the SLR methodology for passive solar analyses.

The Karpay program has reportedly shown good agreement in a software verification with the DOE-2.1 mode1. The program is designed to run on a microcomputer.

Contact: Burton Karpay

12116 Greenleaf Ave. Potomac, MD 20854 $301-279-9430$
David Ford

Colorado Office of Energy Conservation 1525 Sherman Street, 4th Floor Denver, CO 80203

$303-866-2508$ 


\section{LAWRENCY BERKELEY LABORATORY}

\section{CIRA}

Product: Simplified Computer Energy Use Model.

The Computerized Instrumented Residential Audit (CIRA) model was developed by LBL to run on a wide variety of microcomputers. CIRA is a user-friendly program, designed to simplify the detailed description of house characteristics required by more complex models for energy analyses.

CIRA is a collection of programs related to building energy analysis designed to run interactively on a wide variety of microcomputers. CIRA has been verified on a software-software basis with DOE-2.1. Discrepancies between the two programs were found to be on the order of about $\pm 10 \%$.

CIRA energy-use calculations are based on a simplified monthly load estimation method. The method is based on monthly calculations of degree-days and degree-nights for both heating and cooling seasons. Base temperatures used to calculate degree-days and degree-nights are derived from thermostat settings, solar and internal gains, sky radiation losses, and thermal characteristics of the building envelope. Correlation curves based on experimental data are used to account for performance variations of HVAC equipment under part-load and ambient conditions.

CIRA accepts a wide variety of inputs including: building component information, features of the surrounding terrain, active and passive solar features, heating and cooling systems, occupant behavior characteristics, and fuel prices. The CIRA model facilitates the process of entering building data by prompting the user for each input, providing detailed explanations of input requirements with examples, providing a list of possible answers, and providing dynamic default values based on other input parameters.

CIRA displays monthly values and yearly totals of:

- daily and nighly heating and cooling energy consumption

- daily and nightly heating and cooling loads 
- air infiltration

- solar gain

- dollar expenditures for heating and cooling.

Results can be presented in tabular form or graphically.

One unique feature of the CIRA model is its ability to automatically determine the most cost-effective package of retrofits for an existing house, given the homeowner's budget constraints. CIRA contains an extensive file of retrofit options, costs and relative thermal merit. Only those items appropriate to the structure in question are considered. Dollar and energy savings are calculated for each retrofit based on the expected period of occupancy of the current resident.

The cost of the equipment needed to run CIRA is in the range of $\$ 4000$. The program will be available soon at a cost of approximately $\$ 240$. This amount includes 3 disks and a comprehensive reference manual.

Additional

Information: Sonderegger, R. C., J. Y. Garnier and J. D. Dixon. November 1981. Computerized, Instrumented, Residential Analysis. PUB-425, Lawrence Berkeley Laboratory, Berkeley, California.

Sonderegger, R. C. and J. Y. Garnier. October 1981. "A Simplified Method for Calculating Heating and Cooling Energy in Residential Buildings." LBL-13508. Presented at the Third International Symposium on Energy Conservation in the Built Environment, Dublin, Ireland, March 30-April 1, 1982.

Contact: Robert Sonderegger

Bldg. 90-3074

University of California

Lawerence Berkeley Laboratory

Berkeley, CA 94720

415-486-4029

FTS $451-4029$ 
NATIONAL BUREAU OF STANDARDS

VARIABLE BASE DEGREE-DAY

Product: Simplified Load Calculation Model.

The NBS Variable Base Degree-Day (VBDD) program was developed as an alternative to the larger and more complex DOE-2 computer program. The program can run on a TI-59, Radio Shack PC-1 or HP-41C programmable calculator; or a Northstar Horizon microcomputer. The VBDD program has been simulation verified with DOE-2.1. VBDD load and energy calculations were found to fall with in $\pm 10 \%$ of those computed by the DOE-2.1 model.

The input data describes the building in terms of the following:

- area of roof, floors, walls, windows and doors

- thermal conductances of the preceding components

- internal heat gains from people, lights and appliances

- temperature requirements

- average outdoor temperature

- average outdoor absolute humidity

- horizontal surface and wall insolation.

- heating/cooling equipment capacity and efficiency

- duct/pipe insulation solar collector efficieny data

The model is thought to perform particularly well in analyzing window orientation. This capability makes the model particularly useful for analyzing some of the passive features of residential buildings, such as attached greenhouses.

Component heating and cooling losses are calculated by multiplying the component $U$-value and surface area by the degree-days. The degree-day base is not the conventional $65^{\circ} \mathrm{F}$ value. The variable temperature base is obtained from the balance temperature for the specific house. The balance temperature is defined as the outdoor temperature at which internal heat source plus solar heat gain exactly offset the envelope heat loss due to conduction and air leakage. 
The VBDD model calculates annual heating and cooling loads by aggregating conduction losses, infiltration losses and internal gains. The VBDD model uses an air change rate specific to each location, average wind speed, and average temperature to calculate infiltration losses.

The program takes a long time to run ( 30 minutes) once the data are entered on the desk-top calculator. Entering data is rather tedious since it requires a great deal of button pushing. The draft documentation for the program is now available. The final documentation and program cards will be disseminated through the Department of Energy, Office of Conservation and Renewable Energy.

Additional

Information: Kusuda, T., Ish Sud and Taghi Alereza, "Comparison of DOE2-Generated Residential Design Energy Budgets with Those Calculated by the Degree-Day and Bin Methods." ASHRAE Transactions 1981. V.87, PT.1.

Kusuda, T. and Taghi Alereza. June 1982. "Development of Seasonal Performance Models for Equipment for Simplified Energy Analysis Methods." ASHRAE Transactions 1982. Presented at ASHRAE Toronto meeting, June 1982.

Dickens, H. Brian. September 1981, Report to Canadian Standards Association on the Evaluation and Labelling of Energy Conservation Features of a House, Misc. 017-1981. Canadian Standards Association, 178 Rexdale Blvd., Rexdale, Ontario, Canada.

Contact: Tamami Kusuda National Bureau of Standards Department of Commerce Washington, D.C. 20234

FTS $921-1000$ 


\section{OHIO DEPARTMENT OF ENERGY}

HOME ENERGY ANALYSIS AUDIT

Product: Simplified Computer Model.

The Ohio Department of Energy developed a computerized residential energy audit program early in 1979. About 13,000 homes have been audited since its implementation in 1979. Although the audit is still available on demand, Ohio no longer promotes it because of the availability of RCS energy audits.

The model uses the ASHRAE modified degree-day method to calculate the design heat loss. Because of the limited number of choices available on the questionnaire for building component information, problems have been encountered when analyzing atypical house designs. Ohio is currently working to resolve this problem.

The homeowner completes a multiple-choice questionnaire including questions on fuel type, house construction, thermostat settings, and region of Ohio in which the home is located. Weather and cost data are stored within the model for each region in Ohio.

The model estimates a total heating bill and indicates what percentage of the bill is due to heat losses through each building component. The model provides an hourly design heat-loss estimate as well as annual savings, years to payback, and return on investment of several conservation options.

Processing the data requires only a few minutes. Data is typed on a portable terminal that is connected via telephone to a main-frame computer. Computer time is inexpensive because of the short program execution time. Additional

Information: Ventresca, J.A. June 1979. "Ohio's Home Energy Analysis Experience." Presented at a joint meeting of the American Society of Agricultural Engineers and the Canadian Society of Agricultural Engineering, June 24-27, 1979, Winnipeg, Canada.

Contact: Tom Crown

Ohio Department of Energy

30 East Broad Street

Columbus, Ohio 43215

614-466-6081 


\subsubsection{Hand Calculations}

This section describes calculational tools potentially adaptable to a HERS where all calculations can be performed on a hand-held calculator. 
CARTER ENGINEERING, INC.

Product: Simplified Hand Calculation of Energy Use.

A simplified method for use in building energy labelling was proposed by Donald G. Carter of Carter Engineering, Inc. during his testimony before the U.S. House of Representatives Subcommittee on Energy Conservation and Power, in July of 1981 .

The Carter method is used to develop a distinct label for winter and for summer. The same calculation is used to derive each label. The Carter method first uses the ASHRAE long form to calculate heating and cooling energy loads. The loads are calculated using information on building dimensions, insulation thicknesses, and indoor and outdoor temperatures. Building passive solar heat gains are accounted for as well as internal gains from occupants and appliances. The method then uses the concept of Heating/Cooling Equivalent Full Load Hours (HEFLH/CEFLH) to relate an envelope heat-loss figure to annual heating estimates. This requires prior determination of HEFLH/CEFLH factors for each type of building and heating/cooling system in each locality. The standards are based on local records of energy consumption as obtained from utilities and suppliers. The heating/cooling load is simply multiplied by the standard HEFLH/CEFLH for the location and type of building to estimate the annual fue 1 requirement. Conversion to dollars is direct with knowledge of local fuel prices.

Additional

Information: Carter, D.G. Testimony from Hearing on Energy Efficiency Labels for Buildings before the U.S. House of Representatives Subcomittee on Energy Conservation and Power, July 21, 1981. Serial No. 97-65.

Dickens, H. Brian. September 1981. Report to Canadian Standards Association on the Evaluation and Labelling of Energy Conservation Features of a House. Misc. 017-1981. Canadian Standards Association, Ontario, Canada.

Contact: Donald G. Carter

Carter Engineering, Inc.

1107 Spring Street

Silver Spring, Maryland 20910

$301-588-3230$ 
OAK RIDGE NATIONAL LABORATORY

RCS MODEL AUDIT

Product: Noncomputerized RCS Audit.

The RCS Model Audit was developed by ORNL as a simple, noncomputerized baseline for the RCS program. The model audit is intended to provide free technical assistance for voluntary use by utilities. It contains procedures for customer interviews, residence inspections, and energy load, cost and savings calculations. Several private firms (e.g., Enercom, Inc.) have computerized the model audit calculation procedures.

ORNL has performed a few field tests for verification purposes. Additional work is planned on audit validation. This effort includes field testing with instrumented houses to determine accuracy of load calculations and savings estimates. ORNL believes that the model audit may tend to underestimate energy loads. This is a conservative approach inherent in the model which prevents overestimation of the conservation potential of various energy saving alternatives.

The model audit uses past building data and degree-day information to construct a graph to determine the energy supply rate in terms of units of energy used per degree-day. This energy supply rate is multiplied by heating (cooling) season degree-days and the local fuel price to determine an annual heating (cooling) season cost of energy. With knowledge of the efficiency of the furnace (air conditioner), the heating (cooling) energy load in $\mathrm{Btu} / \mathrm{hr} \mathrm{O}^{\mathrm{F}}$ can be determined.

In the following instances prior billing data is either unavailable or inappropriate for calculating energy loads:

1. newly constructed house with no prior billing history;

2. recent modification to existing house; or

3. change in occupancy of existing house.

If prior building data cannot be used for any of these reasons, the conductive energy load is calculated using $U$-values for each building component, 
areas of components, and degree-days. The infiltration load is calculated based on an estimate of the number of air changes per hour. The model audit provides information on how to estimate air changes. The total building heating and cooling load is obtained by aggregating these two loads. Then, the annual seasonal heating and cooling cost is obtained by multiplying the building load by the degree-days and the local fuel price, and dividing by the efficiency of the HVAC equipment. Either the total load or the total cost could be used as rating.

With knowledge of how each individual building component contributes to the energy load, cost and savings for various conservation methods can be calculated.

ORNL indicates that the average residential audit requires about two and one-half hours to complete.

Additional

Information: Residential Conservation Service Auditor Training Manual. August 1980. Prepared by Oak Ridge National Laboratory, University of Massachusetts, and Solar Energy Research Institute for the U.S. Department of Energy.

Contact: Michael Karnitz

P.0. Box X Oak Ridge National Laboratory

Oak Ridge, Tennessee 37830

$615-574-4826$

FTS $624-4826$ 


\section{OWENS-CORNING F IBERGLAS \\ ENERGY PERFORMANCE DESIGN SYSTEM}

Product: Simplified Computer Model or Manual Calculation.

The Owens-Corning Fiberglas Energy Performance Design System (EPDS) was developed to allow builders to predict heating and cooling requirements of homes in the planning stage. With EPDS the builder can obtain an energy performance rating of any house plan and determine how the rating can be improved. Builders can substitute various building components, such as more wall or ceiling insulation, and calculate the impact on the overall energy consumption of the house. The model gives an estimate in normalized energy units, such as $\mathrm{kWhr} / \mathrm{ft} \mathrm{t}^{2}$ or $B t u / f t^{2}$, and the annual cost of energy at the local rate.

The EPDS model was developed as a manual calculation based on OwensCorning's hourly simulation model OCF-2. Owens-Corning has tested the OCF -2 model on three test houses at their Granville, Ohio, research facility. These tests were thought to provide strong validation of the model. The EPDS manual calculation was verified through comparisons with OCF-2 for a variety of houses and locations. To provide calculational speed, the EPDS model was then computerized.

The builder has the option of either working through the manual calculations with the aid of a workbook, or requesting a trained OCF representative with a portable terminal to perform the energy analysis. The terminal connects via phone lines to OCF's main-frame system. Using data on the dimensions, shape, and location of the home, EPDS computes an energy target for the design at a given location. Analysis of individual building components allows the builder to determine the proximity of the predicted energy use of his planned house to the energy target. The basis of the energy target in EPDS is a 1200-square-foot house that could be heated and cooled for less than $\$ 300$ in any city. A heat pump and a cost of electricity of $5 \phi / \mathrm{kWh}$ are assumed.

The model is limited to the analysis of new, single-family dwellings in the planning stage. Owens-Corning is already working to expand the program to 
include evaluation of retrofitting plans for existing houses. The model uses weather data available for 208 locations across the United States.

Owens-Corning sponsors a one-day training seminar on the EPDS model. It plans to make EPDS available to all professional builders free of charge beginning in the summer of 1982 .

Additional

Information: "Design-for-Energy System to Preview." Housing. McGraw-Hill, January 1982, page 30.

"Energy: Manufacturers Preview Systems." Housing. McGrawHill, February 1982, page 32.

Energy Performance Design System. 1981. Owens-Corning Fiberglass Corp., Toledo, Ohio.

Contact: Tim Grether

Insulation Division

Owens-Corning Fiberglas Corp.

Toledo, Ohio 43659

419-248-8000 


\section{PACIF IC NORTHWEST LABORATORY}

SHELL THERMAL EFFICIENCY INDEX

Product: Hand Calculation.

As part of a study to determine the impact of improved building thermal efficiency on residential energy demand, PNL developed a method of calculating a shell thermal efficiency index. The index is the ratio of predicted Btu/square foot to the sample mean Btu/square foot.

The DOE-2.1 model was used to develop the simplified procedure for calculating the shell efficiency index. A random sample of 250 hours was selected from the National Interim Energy Consumption Survey (NIECS) data base. The characteristics of each of these residences were analyzed with DOE2.1 to estimate heating energy requirements for the structure based on St. Louis, Missouri, climate data.

The natural $\log$ of the estimated Btu requirement was then regressed on a number of building characteristics to obtain a simplified equation that could be used to predict energy consumption. The equation was in the form:

$$
\ln (\text { MBtu })=C+A 1(X 1)+A 2(x 2)+A 3(x 3)+A 4(X 4)+\ldots
$$

where, the $X$ values are various building features such as floor area, glazing area, inches of attic insulation, number of doors, etc. The $A$ values are coefficients arising from the regression analysis. The R-Square value for the regression was $85.1 \%$, indicating a reasonably good fit of the data.

The regression equation was used to predict the heat load (Btu/hr) of the she 11 for each residence. The measure of the structure's she 11 energy efficiency was then computed by dividing the predicted Btu requirement per square foot of floor area into the overall sample mean Btu per square foot. Thus, a residence that is twice as efficient as the average structure would have an index of 2.0, and a residence that is one-half as efficient as the average structure would have a value of 0.5 .

If the heat load is used for the rating, it would be necessary to develop a separate regression equation for each climate zone; whereas a single equation 
could be sufficient if the rating is the shell thermal efficiency index. Although the development time may be large, implementing the model would be facilitated by its simplicity. Little training would be required to use the regression equations, and no specialized equipment would be needed. Greater accuracy could be achieved by using a nonlinear equation or by increasing the number of independent variables in the equation.

Additional

Information: Adams, R. C. and A. D. Rockwood. October 1981. Impact of Improved Building Thermal Efficiency on Residential Energy Demand. PNL-3733. Pac if ic Northwest Laboratory, Richland, Washington.

Contact: $\quad$ Rich Adams

Pacific Northwest Laboratory

P.0. Box 999

Richland, Washington 99352

509-376-4254

FTS $444-4254$ 
STATE OF FLORIDA

MODEL ENERGY EFFICIENCY CODE

Product: Hand Calculation of Annual Energy Use.

In an effort to conserve energy used in residential housing, the State of Florida adopted an energy code for new houses in 0ctober of 1980. Contractors and architects must show that proposed new residential dwellings comply with the state energy standards in order to obtain a building permit. The State of Florida provides guidelines for architects and contractors to use to determine compliance of proposed new buildings with the Florida Model Energy Efficiency Code for Building Construction.

One way of determining compliance involves a hand calculation of annual energy loads. The Florida Energy Efficiency Code book provides equations and tabulated information for calculating energy loads. Tabulated data includes Uvalues, shading coefficients, and solar orientation factors by $\mathrm{climate}$ zone with in Florida. The state has been subdivided into nine climatic regions.

Calculations of energy use are based on ASHRAE equations. The energy use calculations consider climate data, operational charachteristics, mechanical equipment, and internal loads. A form is provided to tabulate monthly energy use, which is then aggregated to obtain annual energy useage. The annual usage is divided by the square footage of the building to obtain an energy use index. This index is compared to an energy budget specified for each building type by climate zone within Florida. In order to obtain a building permit, the calculated energy index must be less than the energy budget.

Additional

Information: Model Energy Efficiency Code for Building Construction. October 1980. Published by the Governor's Energy Office for the Department of Community Affairs, Bureau of Codes and Standards. Tallahassee, Florida.

Contact: $\quad$ Bill Bower

Department of Veteran and Community Affairs

Howard Building

2571 Executive Center Circle East

Tallahassee, Florida 32301

904-487-1822 


\section{STATE OF TEXAS \\ ENERGY CONSERVATION MANUAL}

Product: Hand Calculation.

Section 7 of the Texas Energy Conservation in Buildings Act requires the State Building Commission to publish an energy conservation manual for potential use by designers, builders and contractors of residential and nonresidential buildings. The guidelines presented in the manual are not mandatory; the manual is intended to encourage and promote the construction of energy conserving residences. The manual, which is intended for use with dwellings in the planning stage, has been available since late 1977 . The manual contains a stepwise procedure for calculating energy use of buildings and appliances. Separate forms are included for calculating total building energy use for various types of HVAC systems.

Inputs required for building energy calculations include:

- areas of building envelope surfaces

- U-values of components

- shading coefficients

- energy efficiency ratios (EER) of HVAC equipment

- number of occupants

The manual provides tabular data on typical U-values, shading coefficients, and EERs for Texas. Areas and occupant information are provided by the builder or contractor.

The manual provides a simple format for calculating building envelope loads and building environmental loads (i.e., solar gain and infiltration). Data on building envelope surface areas, U-values and shading coefficients are entered in the appropriate boxes on the form. The form indicates the type of operation (addition, multiplication, etc.) to use on the data in the boxes to obtain heat losses for each building component. The individual calculated heat losses are recorded in the appropriate boxes on the form. The annual heating and cooling loads are then determined by aggregating the individual heat losses and multiplying by the degree-days for the specific location. The manual 
provides tables of heating and cooling degree-days for major cities in Texas. The total building energy load is the sum of the heating and cooling loads. This total is divided by the square footage of the building to obtain the envelope energy index in Btu/sq.ft./yr. The calculated index is compared to a maximum recommended index for similar size dwellings in the same location.

An estimate of the actual energy used for heating and cooling is calculated by dividing the annual heating and cooling energy loads by the EER of the furnace and air conditioner, respectively. A table of typical annual appliance energy use is provided based on the type of appliance and the use rate. Total building energy use (Btu/yr) is obtained by aggregating heating, cooling and appliance energy use. Dividing by the square footage yields an energy use index (EUI), aga in in Btu/sq.ft./yr.

Total annual energy use could easily be converted to dollars with knowledge of local fuel prices. Tables of U-values, climate data, and shading coefficients are specific to the State of Texas. They would have to be expanded to generalize the procedure for use on a national scale.

Additional

Information: Energy Conservation Manual Part I: Residential Buildings. November 1977. Facilities Planning and Construction Division, Austin, Texas.

Texas Civil Statutes, article $678 i$.

Contact: $\quad$ Facilities Planning and Construction Division State of Texas

P.0. Box 13047

Austin, Texas

512-475-2941 
STATE OF WISCONSIN

ENERGY WORKSHEET

Product: Hand Calculation of Heat Loss.

Wisconsin has had energy conservation standards as part of their uniform dwelling code since 1978. New homes must comply. About 20,000 new home designs have been processed.

A worksheet provided by the state contains a step-by-step procedure for determining heat loss through each building component. These heat losses are then aggregated to obtain the total building heat loss. Specifically, the procedure first calls for calculating the area of various building components, such as walls, windows, doors, etc. Then using tables in the Uniform Dwelling Code book, $U$ and $R$ values are calculated for each building component. The design heat loss (Btu/hr) is calculated for each building component as the product of the area, U-value, and the design temperature.

Building design heat-loss calculations are performed by local building inspectors and require about 15 minutes to complete. About 16 hours of training are required to familiarize the inspectors with the heat-loss estimation procedure.

Additional

Information: Wisconsin Uniform Dwelling Code. May 1978. Department of Industry, Labor and Human Relations, Madison, Wisconsin.

Halverson, Terry and Del Blasde1. October 1979. Wiscons in Uniform Dwelling Code: Energy Conservation Workshop. Published by the Department of Industry, Labor and Human Relations.

Contact: John Egan

Department of Industry, Labor and Human Relations Safety and Buildings Division Madison, Wiscons in 53707

608-366-1748 


\section{U.S. ARMY CONSTRUCTION ENGINEERING RESEARCH LABORATORY}

Product: Hand Calculation of Energy Use.

The U.S. Army Construction Engineering Research Laboratory (CERL) developed a simple, noncomputerized procedure for determining energy use in army buildings. The methodology was tested on a single, private residence and was found to predict within five percent of the metered consumption for one season's heating energy use.

Algorithms were developed that will calculate the annual heating and cooling energy use of five characteristic building types. Building types include single-family residences, townhouses, administration/office buildings, barracks, and commissaries. Algorithms were developed by first calculating monthly heating and cooling loads using a revised version of the U.S. Postal Service Computer Program (a predecessor to DOE-2). The computer model considers factors such as building structure, surroundings, weather, and solar access. The model is capable of disaggregating heating and cooling loads to the contributing building elements. Using St. Louis weather data as a base case, parametric studies were performed to generalize the algorithms to other climates.

Algorithms were developed that calculate the following building component loads:

- building envelope

- infiltration

- solar radiation

- floor and underground walls

- internal loads.

Each component load is corrected for parameters that differ from the base parameters. Tables are available that provide factors to correct component loads based on the following parameters:

- envelope conductance, or U-value

- inside setpoint temperature

- underground wall and floor conductance 
- ground temperature

- latitude

- lighting energy use

- climate variables

- envelope area

- air change (infiltration) rate

- underground wall and floor area

- incident solar radiation

- window area

- number of occupants

- equipment/applicance energy use

- HVAC system efficiencies.

The corrected component loads are aggregated to obtain the total annual heating and cooling energy loads. Using estimates of furnace and air conditioning efficiencies, total annual heating and cooling energy use can be predicted.

To generalize this model for use as a rating system, the five characteristic building types would have to be analyzed to determine the ir applicability to the wide range of housing types enountered on a national or regional level. Correction factors may have to be expanded to encompass the range of applicable weather zones.

Additional

Information: Alereza, T., et al., Development of a Noncomputerized Method to Determine Energy Utilization in Residential and Commercial Buildings. Prepared by Hittman Associates for the U.S. Army Construction Engineering Research Laboratory, Champaign, Illinois.

Contact: Douglas C. Hittle P.0. Box 4005

U.S. Army Construction Engineering Research Laboratory Champaign, I1linois 61820 $217-352-6511$ 
3.2.2.4 Slide Calculator

This section describes the Conservation Management Corp. slide calculator that is potentially adaptable to a HERS. 


\section{CONSERVATION MANAGEMENT CORPORATION \\ ENERGY EFFICIENCY APPRAISER}

Product: Preprogrammed Slide Rule.

Conservation Management Corporation (CMC) has developed a number of different types of energy analyzing slide calculators. Among these are the Fuelomizer, which is designed to provide the layman with a variety of residential energy factors, and the Complete Energy Audit Kit which was developed for Basin Electric Power Cooperative to comply with the RCS program in Ohio. Over 100,000 residents have used the Fuelomizer during the past four years. The Audit $k i t$ is being used by about 600 auditors.

The CMC slide calculator that is most relevent to the HERS program is the Energy Efficiency Appraiser. This slide calculator provides an approximation of the Btu's per square foot per degree-day consumed for heating and cooling. These values range from 2 for a super-efficient house to 50 for a house with no energy-conserving features.

Input variables include ceiling, wall and floor insulation, window glazing, infiltration, efficiency of heating and cooling systems, and orientation of the house with respect to sun and wind. The Btu/square foot/degree-day figure provides a rating for the basic house. Variations due to occupant behavior as well as inexpensive changes, such as duct insulation or flow restrictors, are excluded. CMC indicates that in their experience with the Audit Kit, these 10 parameters account for over 90 percent of the variation in energy requirements of a house. Energy Efficiency Appraisers are designed for cold, moderate, and warm climates.

The unit cost of the Energy Efficiency Appraiser would be about $50 \$$, assuming a demand for 100,000. This includes all of the front-end development costs. A booklet describing why and where houses lose heat and how this heat loss can be reduced is available for about $\$ 1$. CMC estimates that an untrained person could rate the energy efficiency of a house in about 15 minutes with this slide calculator. 
Contact: Doris M. Ikle

Conservation Management Corporation

7010 Glenbrook Road

Washington, D.C. 20014

301-951-0279 


\subsection{PERFORMANCE SYSTEMS}

This section describes the three performance-based systems we found. None are currently functioning as HERS, but they potentially can be adapted to this use. 
Product: Energy Index Calculated from Utility Bills

Energy Conservation Consultants has developed a simple computerized procedure for determining Energy Use Indices. No attempt is made to determine where loads are occurring. This procedure is being used primarily in commercial buildings, such as banks and retail stores, to track energy consumption over time and to evaluate the effect of modifications made to reduce consumption.

Inputs to the code include monthly consumption and cost figures for each fuel type, square footage of the building, and monthly heating and cooling degree-days. The code provides two energy use indices: 1) Btu/square foot, and 2) Btu/square foot/degree-day. Also provided is an energy cost index in terms of $\$ /$ square foot. Energy-use indices can be compared from year to year to analyze the effectiveness of conservation measures.

The cost of running this computerized procedure with 12 months of utility data is about $\$ 12$ per building.

Contact: H.S. Hanson Energy Conservation Consultants

P.0. Box 20996

1629 Avenue D

Billings, Montana 59104

$406-259-7300$ 


\section{UNIVERSITY OF WISCONSIN MILWAUKEE COUNTY EXTENTION SERVICE \\ THERMAL PROFICIENCY}

\section{Product: Energy Index Calculated from Utility Bills}

The Thermal Proficiency calculation was developed by the Milwaukee County Office of the University of Wisconsin Extension Service as a way for homeowners to determine how their home energy use compares to the average use for an equivalent size home in their area. The method was made available to the public in 1977. The calculation is performed entirely by the homeowner according to guidelines in a two-page flyer.

The information needed to compute the Thermal Proficiency rating includes:

- annual heating degree-days;

- annual heating energy consumption;

- square footage of conditioned space; and

- average degree-day/energy use for similar homes in area.

The homeowner obtains annual degree-days from the weather bureau and his annual energy consumption from past bills or from his utility. The flyer has guidelines for estimating the amount of energy used for heating if the utility bill includes other uses of the fuel, such as clothes drying or water heating. The owner then determines the square footage of the conditioned living space of $h$ is house based on a few simple measurements. The first step of the Thermal Proficiency calculation is to divide the annual degree-days by the annual fuel use. Next, this figure is divided by the average degree-day per energy use figure for houses of equivalent size in the area to obtain a percentage called the Thermal Proficiency. The average figures are available from the utility for various square footages.

A rating of $100 \%$ is average. Above $100 \%$ indicates that the house uses fuel more efficiently than average and below $100 \%$ indicates more than average usage.

The two-page flyer is made available at county fairs, energy symposiums and through the extension office. Since the procedure is implemented entirely by the homeowner, no figures on the number of homes rated are available. 
To implement this system on a regional scale, average use figures would have to be made available for each locality. These average figures would need to be updated periodically to reflect trends in conservation.

\section{Additional}

Information: Schroeder, Howard M. and Dave Sharpe.

Brochure: "Thermal Proficiency: How Does Your Home Rate?"

Available from the Milwaukee County University Extension Office

929 N. 6th Street

Milwaukee, Wisconsin 53203

Contact: Dave Sharpe

Milwaukee County University Extension Office

929 North 6th Street

Milwaukee, Wiscons in 53203

414-224-4277 


\section{NATIONAL ASSOCIATION OF REALTORS}

USING ENERGY INFORMATION TO SELL HOMES

Product: Energy Index Calculated from Utility Bills

The National Association of Realtors (NAR) has developed a training program to educate realtors in the use of energy information as a selling tool. NAR has trained approximately 15,000 realtors under this program.

The method used to classify homes includes a simple hand calculation based on previous energy bills. The first step is to obtain the energy bills from the homeowner or the utility for a one-year period. Next, the annual energy cost is divided by the square footage of the conditioned living space. The energy cost per square footage figure is compared to figures for other similiar houses in the same market area. Then a visual inspection of the house is made and building features, HVAC system, and lifestyle characteristics are noted. This information along with the $\$ /$ square foot figure is used to classify the house into one of four basic property energy types. These types are shown in the following matrix.

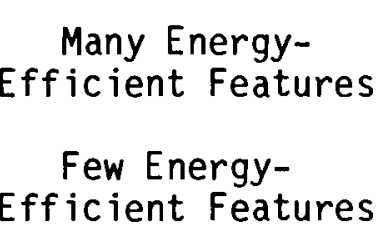

Lower $\$ /$ Square Foot

\begin{tabular}{|l|l|}
\hline 1. Efficient & $\begin{array}{l}\text { 2. Lifestyle? } \\
\text { Design? }\end{array}$ \\
\hline $\begin{array}{l}\text { 3. Lifestyle? } \\
\text { Design? }\end{array}$ & 4. Upgrade \\
\hline
\end{tabular}

The training course recommends different sales strategies for each type of energy property.

The NAR training program is available on four 90-minute videotape segments. Training is geared toward understanding how a house uses energy; recognizing energy features, including renewables; and using the appropriate sales strategy based on the type of energy property.

A great deal of interest has been shown in the training program, particularly by realtors in the frost belt. 
Additiona 1

Information: Using Energy Information to Sell Homes. January 1981. Prepared for the U.S. Department of Energy by Berkeley Planning Associates, California, and Energyworks, Inc. of West Newton, Massachusetts. 



\subsection{SUMMARY TABLES OF RATING SYSTEM CHARACTERISTICS}

The tables contained in this section summarize the pertinent characteristics of each of the rating systems tools identified in Section 3.0. Tables are grouped according to the type of rating system: prescriptive, calculational or performance.

\subsection{PRESCRIPTIVE SYSTEMS}

Table 4.1 contains information on the developer of each prescriptive system and how generally applicable the system is. The developer information includes the type of organization that developed the rating system, and whether the rating system is proprietary or is publically available. Information is also given on the adaptability of the system to various types of houses and geographic regions. Adapting site-specific systems for use in other regions may entail a significant amount of work. Similarly, adapting a prescriptive system to apply to types of housing which differ from those for which it was originally developed may also take a significant effort.

Table 4.2 indicates the building components considered in the rating, the type of output from the system, and the type of verification of the technical accuracy of the system. The types of building components listed in the table are fairly specific, with the exception of the building shell category. A large number of factors are included in building shell characteristics such as amount of floor, ceiling and wall insulation, types of infiltration control, types of glazing used, and many other factors. The system descriptions in Section 3.1 should be consulted for a complete description of the items each system includes under building shell characteristics. The output section of Table 4.2 indicates the type of rating(s) that is the end product of the system, either a point score, a subjective category, or an estimate of the home's annual energy consumption. The final section of Table 4.2 gives a general indication of the type of verification that was performed on the technical basis of the rating systems. Verification by hand calculations or computer simulation was generally done by the developers as part of the initial 
TABLE 4.1. Prescriptive Systems - Developer and Applicability

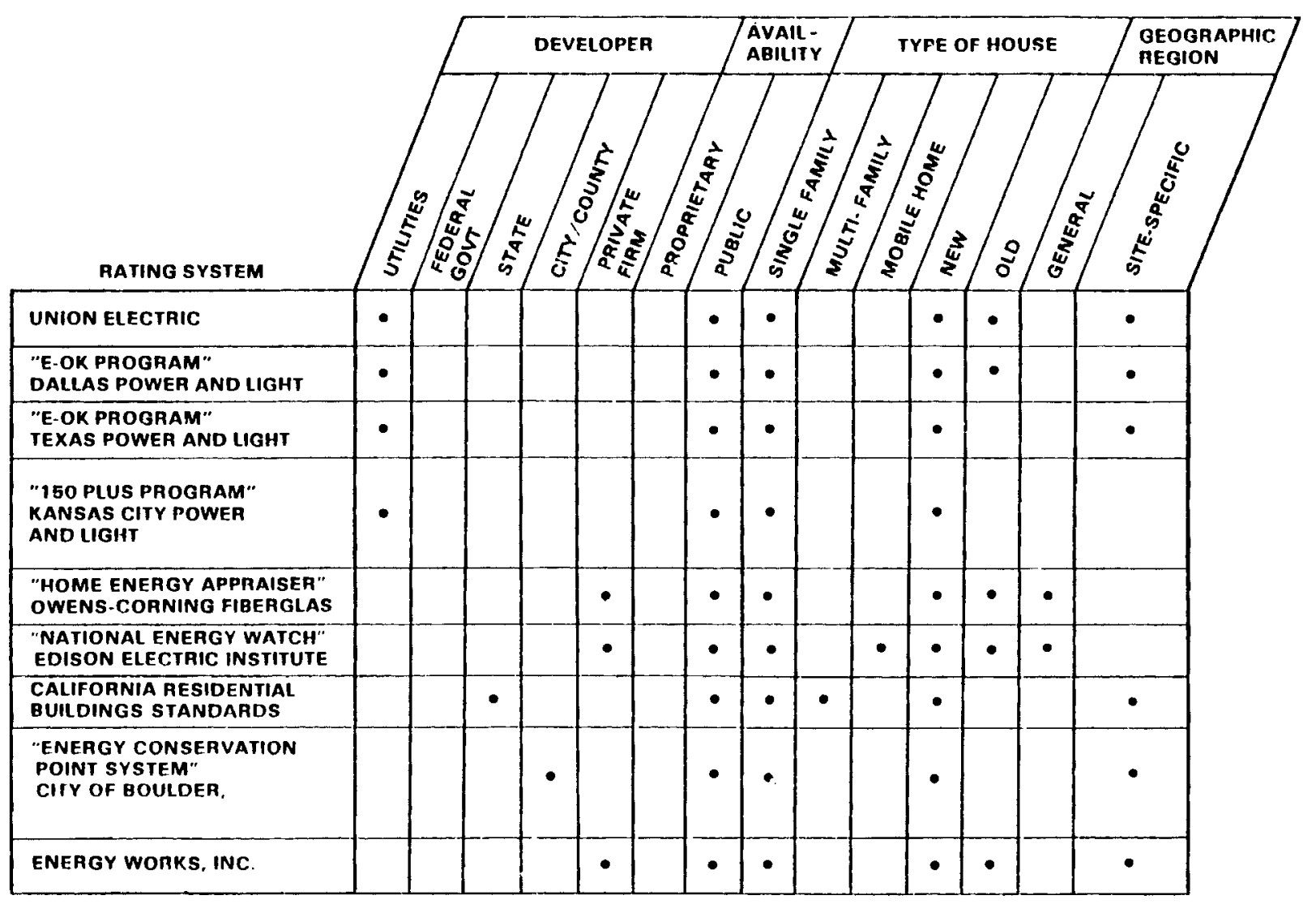


TABLE 4.1. (contd)

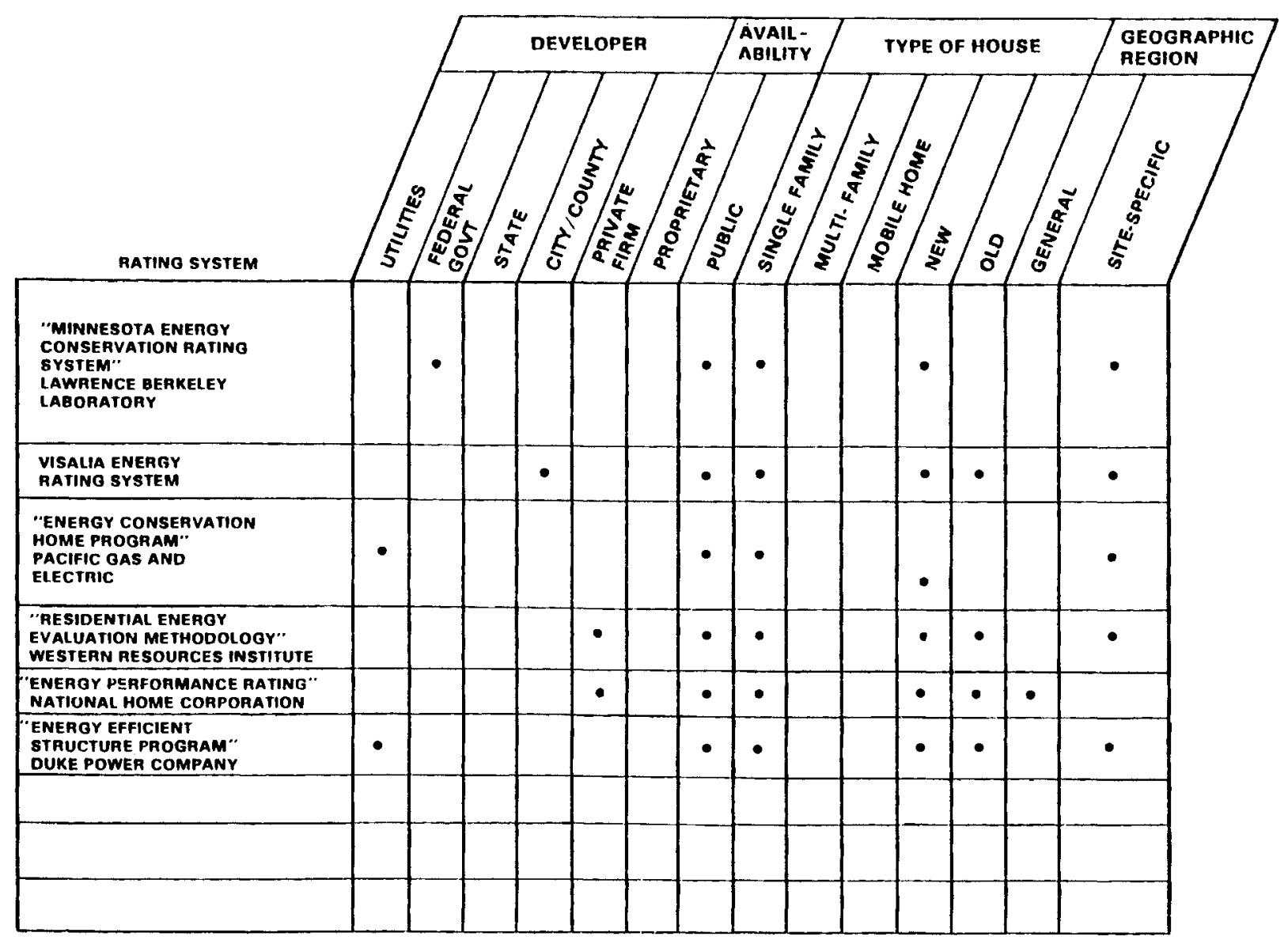


TABLE 4.1. (contd)

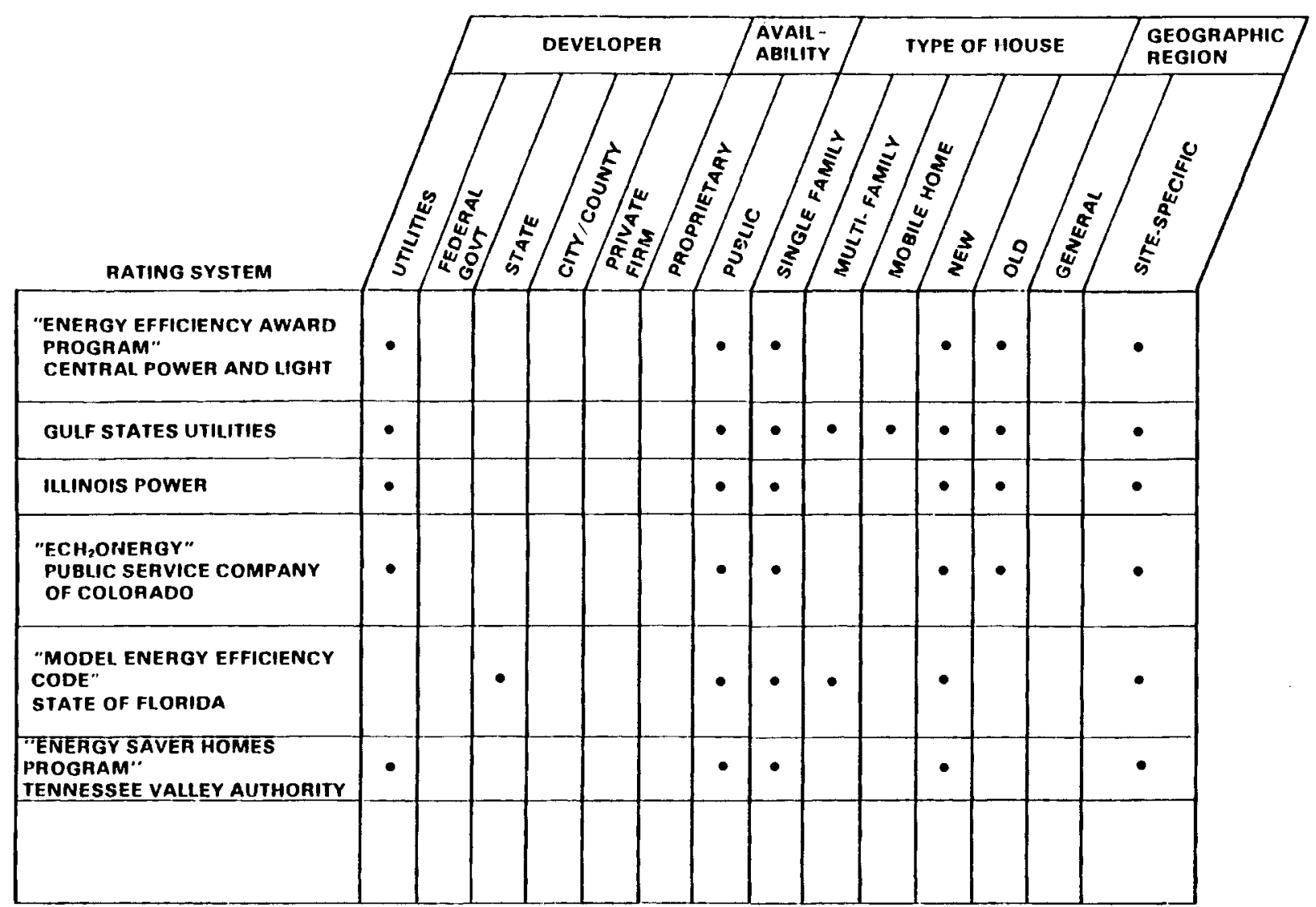


IABLE 4.2. Prescriptive Systems - Components Considered, Output, and Verification

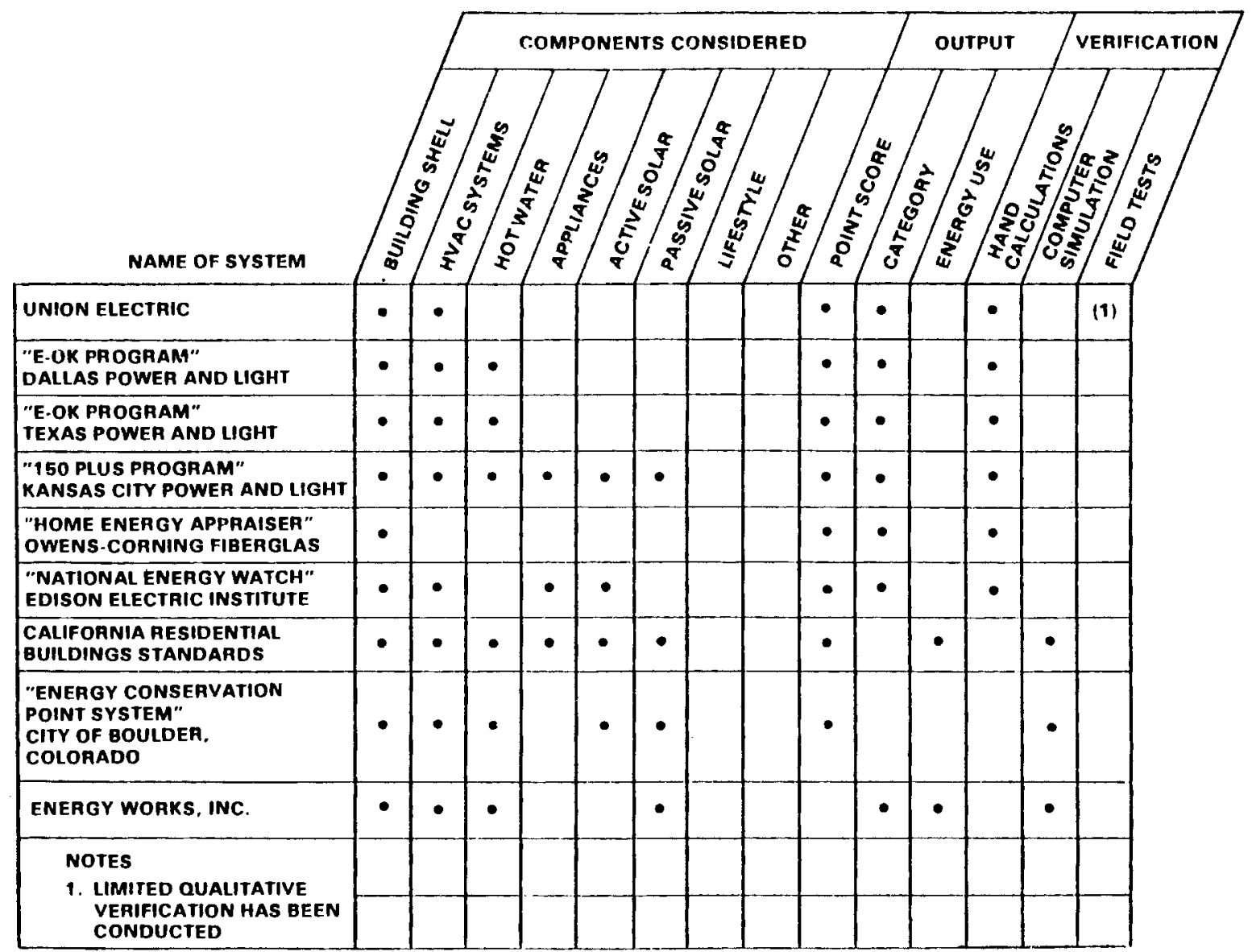


TABLE 4.2. (contd)

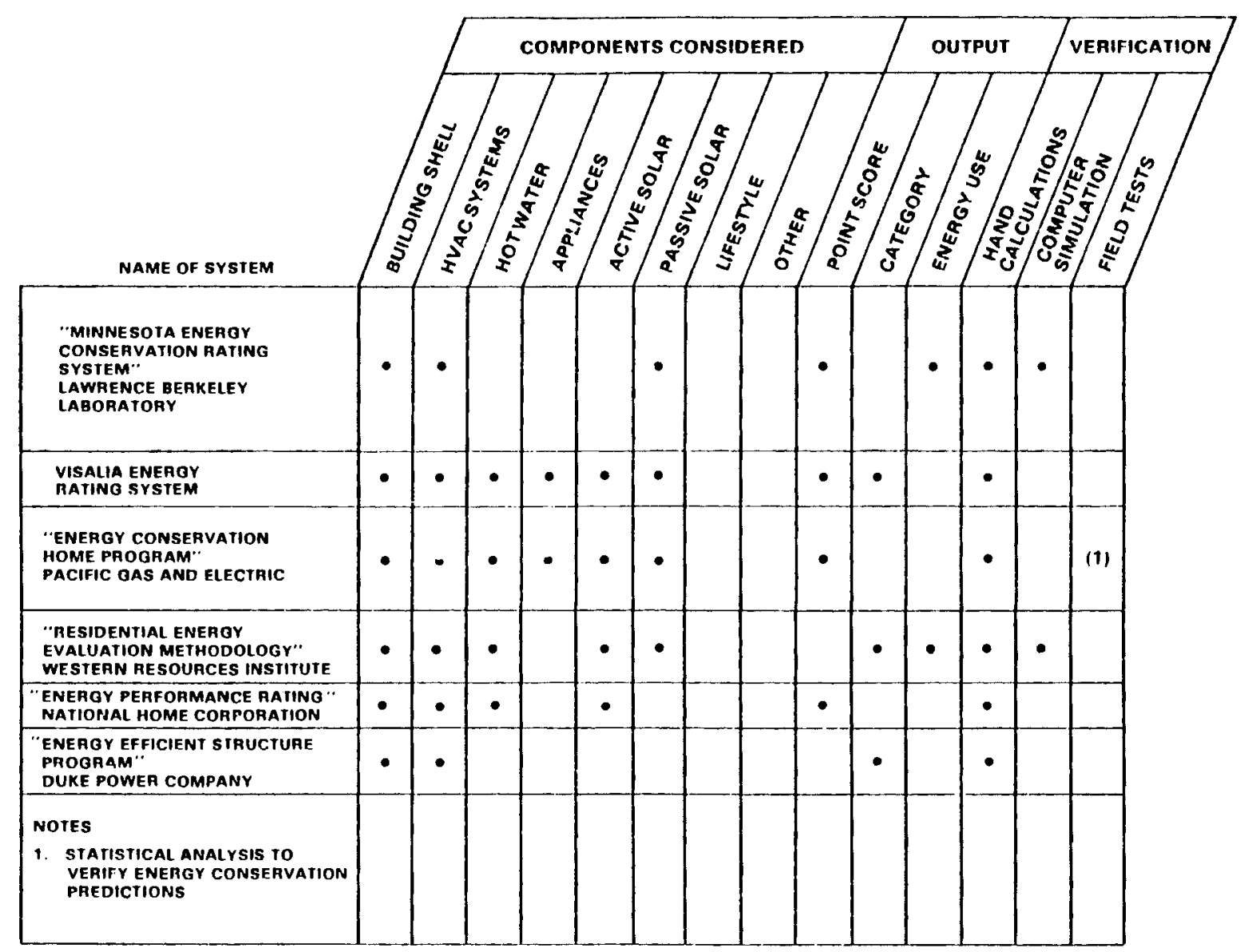


TABLE 4.2. (contd)

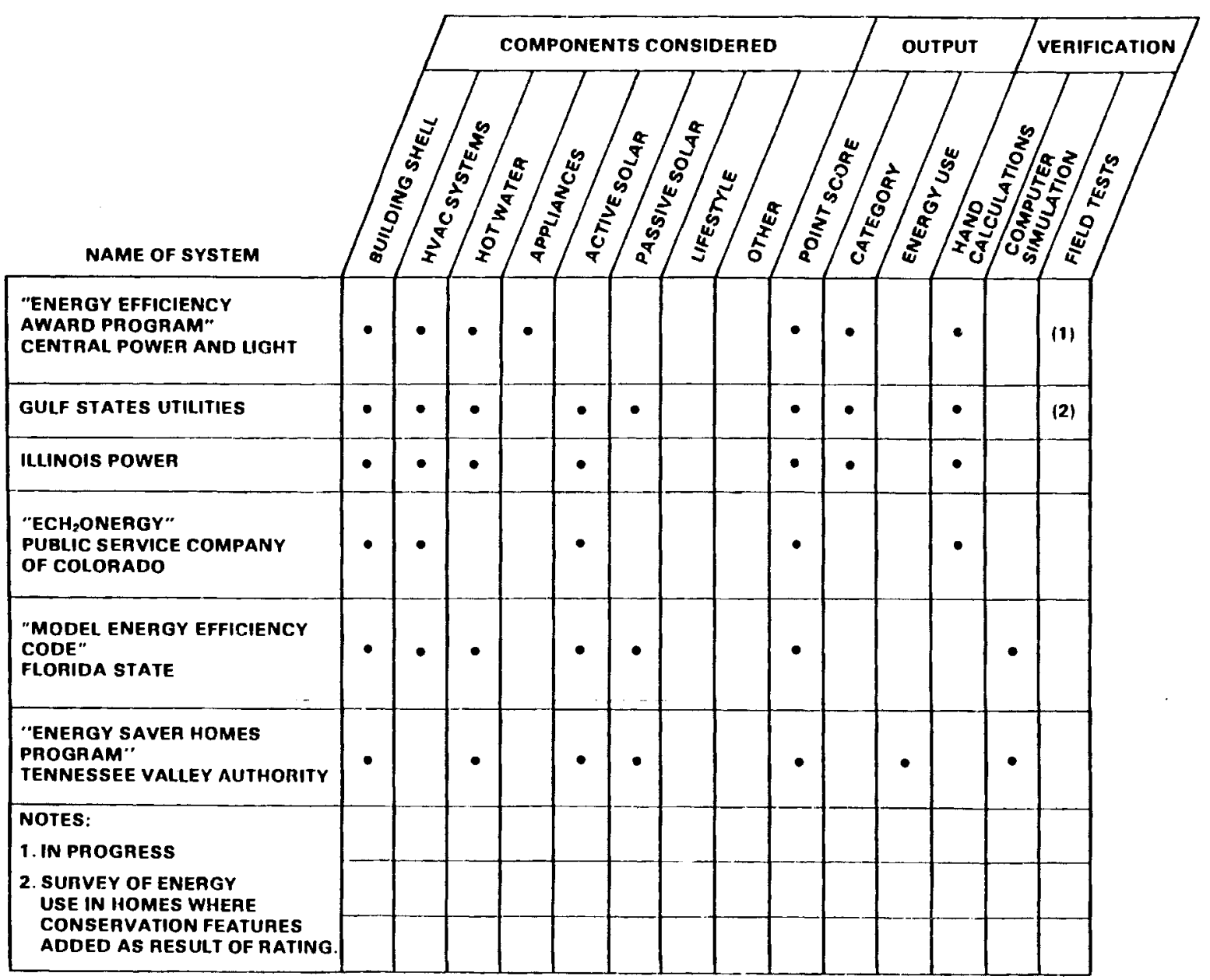


system development. Verification by field tests is done after the system has been implemented, and is aimed at tracking how well the rating system performs in actual use.

Table 4.3 provides information on the prescritive HERS that have already been implemented or are close to being implemented. This table shows who performs the rating and which groups use the rating; it provides qualitative estimates of: 1) the relative amount of rater training needed to use the system, 2) the relative amount of time required to complete a rating, 3) the relative cost of the rating, and 4 ) experience to date in using the system.

The amount of rater training is generally higher when either data collection is complicated or data analys is to produce the rating is complex. Prescriptive systems where the rating is performed by the homeowner or the builder using a self-contained package of information are categorized as "low" rater training. Systems which have formal training of several days are rated "medium." Any systems requiring a formal training period in excess of two weeks are characterized as having "high" rater training.

The time to complete a home rating is categorized as follows:

Low: $\quad$ Rating can be completed without requiring a site visit by a trained rater.

Medium: A site visit is required. The rating can be completed in less than 3 hours.

High: A site visit is required. The rating takes more than 3 hours to complete.

The cost of the rating is closely associated with the rating time required, and was either provided by the system developers or estimated based on the time to complete the rating. Rating costs were classified as follows:

Low: less than $\$ 50$

Medium: from $\$ 50$ to $\$ 200$

High: more the $\$ 200$ 
TABLE 4.3. Prescriptive Systems - Imp lementation Information

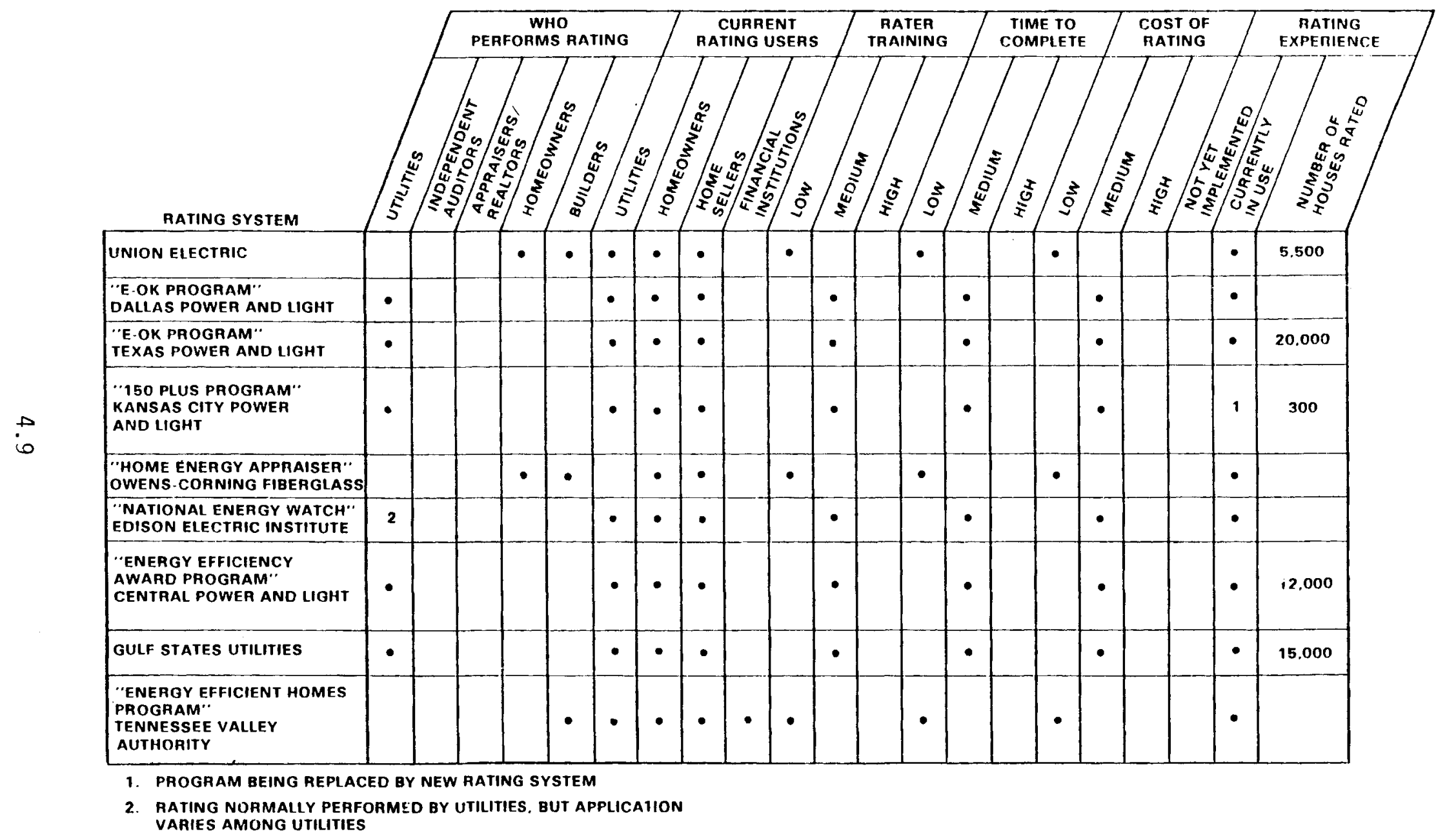


IABLE 4.3. (contd)

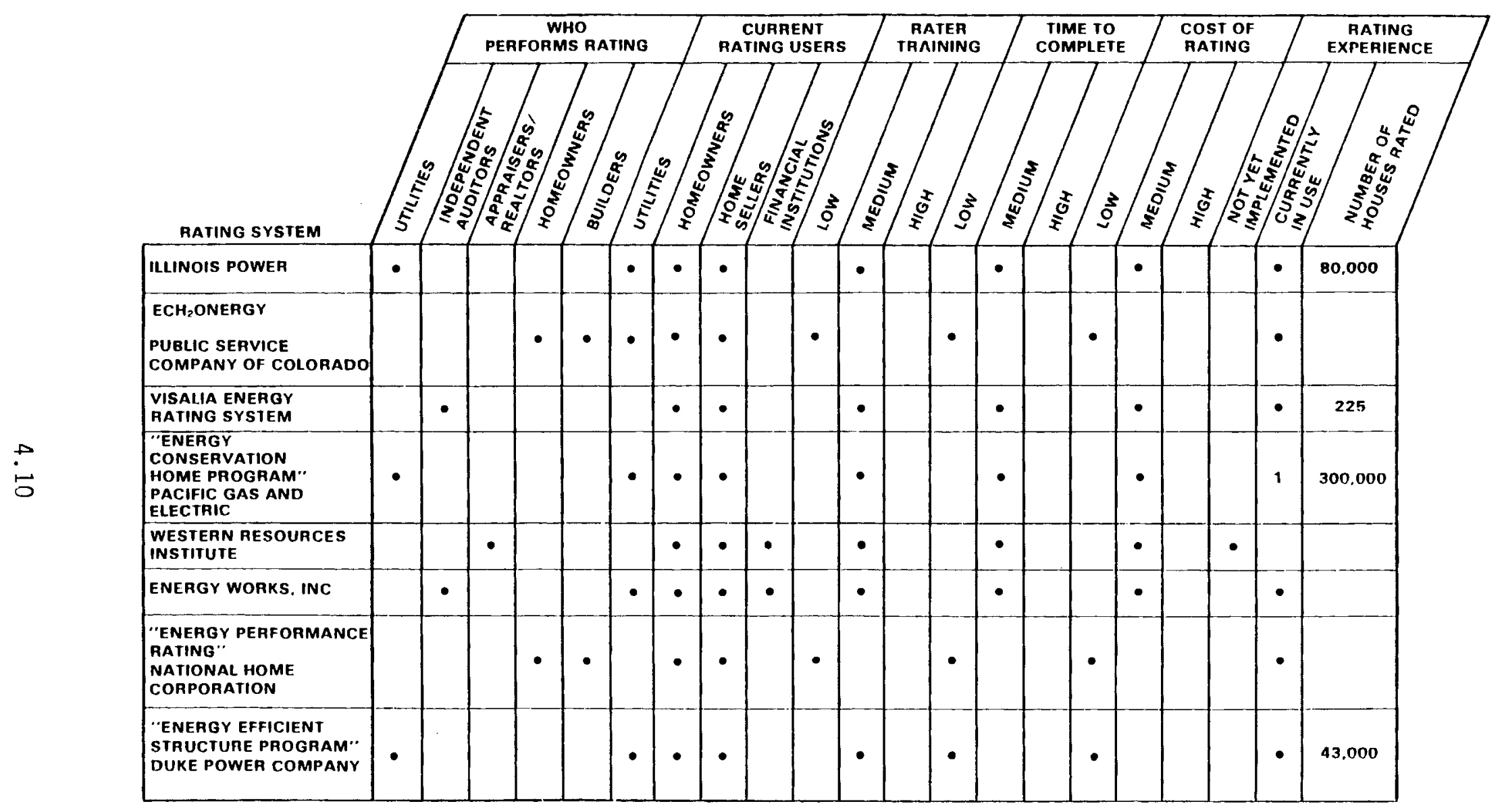

1. Program being discontinued because of California siate system. 
The rating experience information indicates whether the system has been implemented, and includes any available information on the approximate number of homes rated with the system.

\subsection{CALCULATIONAL SYSTEM}

Table 4.4 provides information on who developed the calculational system or tool. Possible developers include utilities, government agencies at the federal, state or city/county level, or private firms. Other information provide in this table includes: 1) whether the system is in the public domain or proprietary, 2) whether the system can be applied to various housing types, and 3) whether the system is site-specific or applicable nationwide.

Information on the type of house and the geographic region provides a measure of the flexibility of the system, and an idea of the extent of the modifications that would have to be made to implement the system on a wider geographic basis. If the model is already general with respect to geographic region, and if it can accommodate all of the housing types, then it can likely be implemented as a HERS without major modification. Site-specific systems and systems that model few housing types may require extensive development time to generalize them to other housing types and other regions.

Table 4.5 indicates the building features that are addressed by each system or tool. The features include:

- building shell (includes infiltration)

- HVAC system (includes heating and air conditioning)

- hot water

- appliances

- active solar

- passive solar

- lifestyle

The level of detail at which each of these features in treated varies widely among the systems. For instance, an indication of treatment of lifestyle may 
TABLE 4.4. Calculational Systems - Developer and Applicability

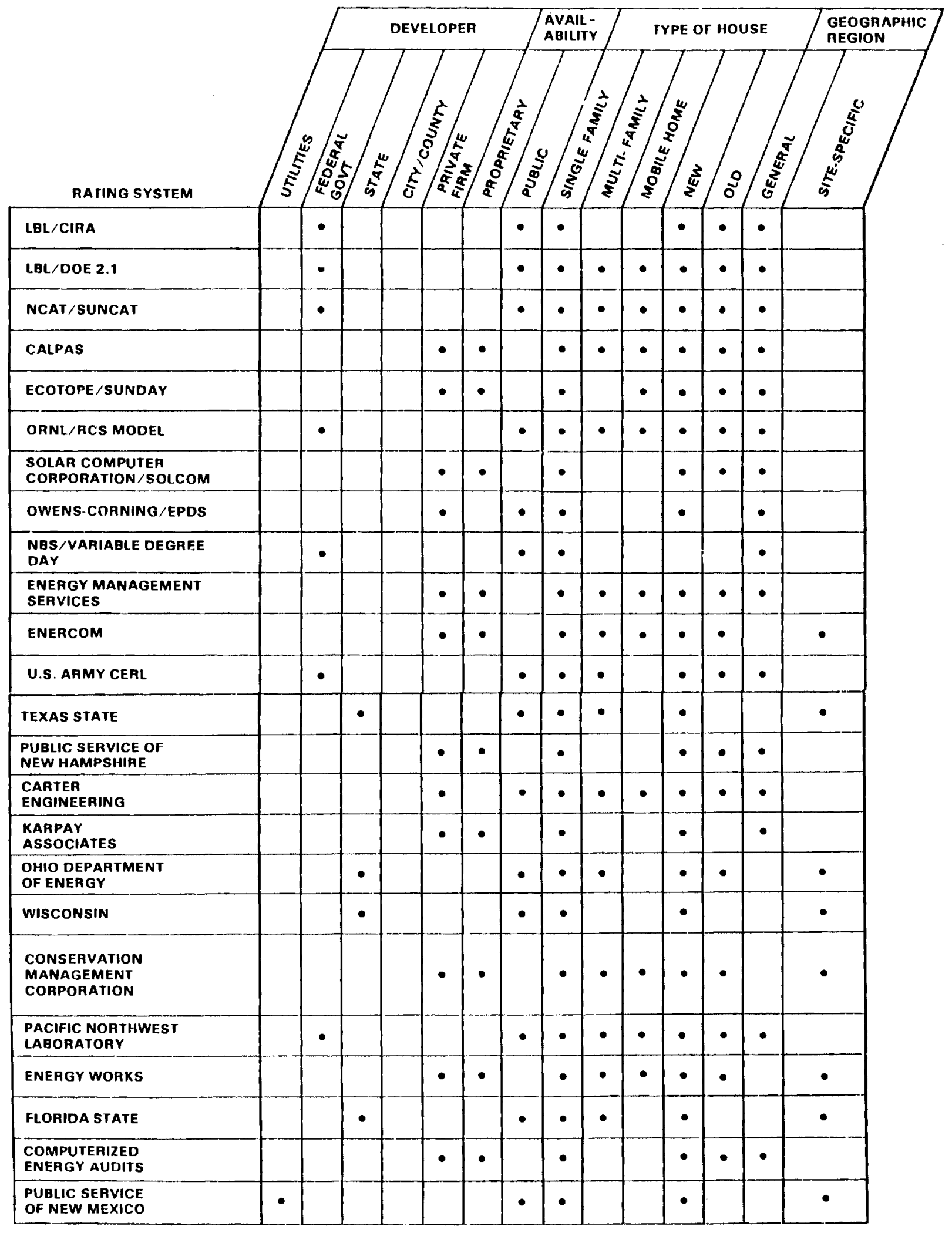


TABLE 4.5. Calculational Systems - Components Considered and Input/Output Data

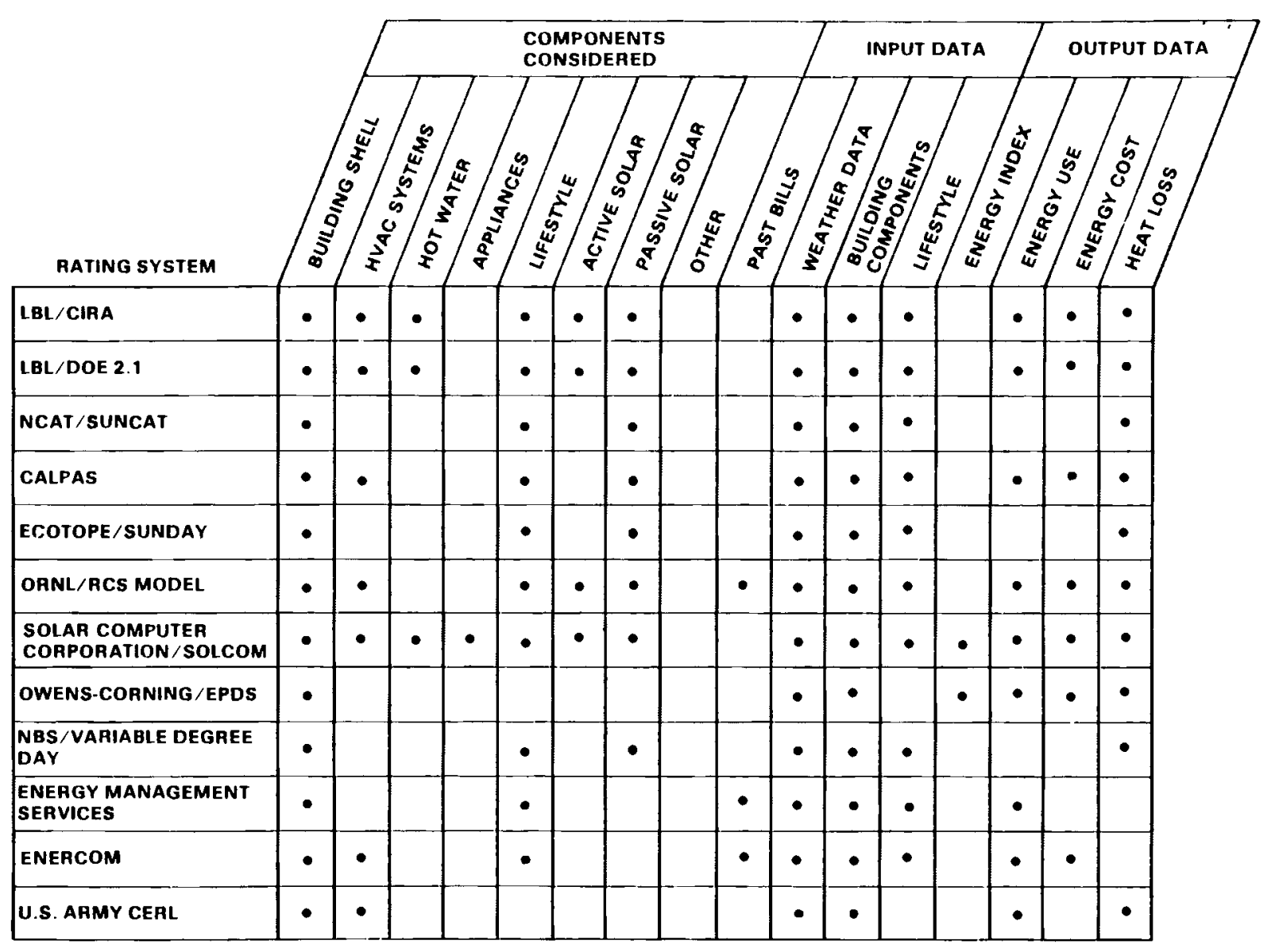


TABLE 4.5. (contd)

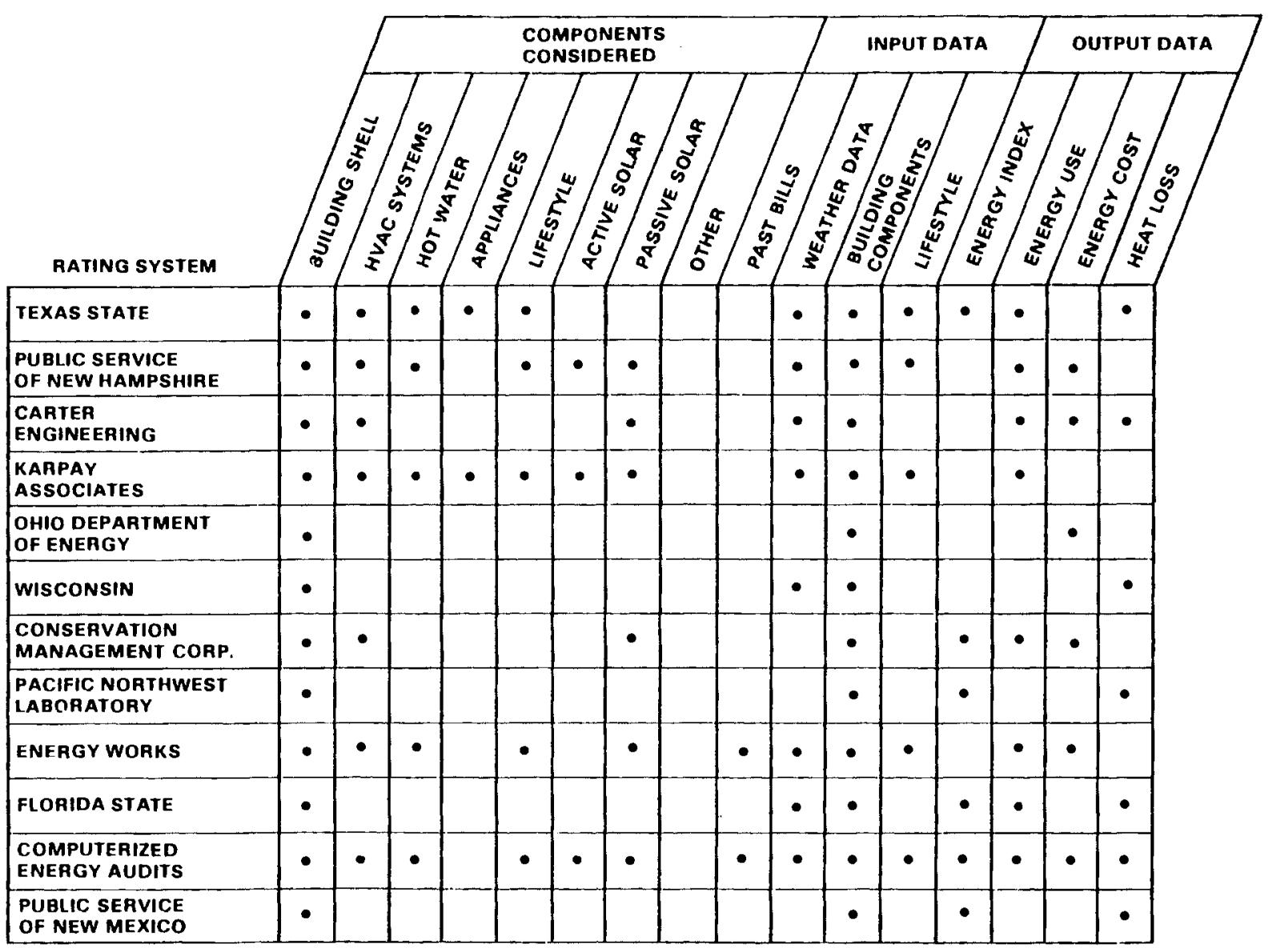


mean that only thermostat setpoints are considered, or it may mean that a number of lifestyle variables (e.g., number of occupants, water usage, etc.) have been considered.

The table also shows the type of data needed for the calculation (input data) and the type of result provided (output data). Output data nomenclature is defined as follows:

- energy index: the ratio of energy usage to either degree-days or square footage, or to an average energy usage for similar houses in the same location.

- energy use: estimated energy usage, Btu/time

- energy cost: annual cost of energy, $\$ / y r$

- heat loss: design heat loss of the building shell, Btu/hr.

Table 4.6 shows the type of equipment that is used to make the calculation, whether the calculation (if computerized) is a batch or interactive operation, the calculational interval, and the method of verification.

Types of equipment include time-share computers, mini or personal computers and programmable hand-held calculators. Hand calculations and slide calculators are classified as noncomputerized. Time-share computers are generally main-frame computers that are accessed via phone communications. The cost of using this type of equipment generally includes a charge for connect time, data processing time, and a maintenance charge for any files stored on the system. The minicomputer/personal computer category covers a wide range of systems. These systems are characterized by the fact that the only cost of using the system is the initial equipment cost. The programmable calculators are generally of the hand-held variety.

An interactive mode of operation refers to a program that prompts the user to specify certain types of information and provides immediate response. With batch operations, the user submits all of the input data at one time and the output is returned later. 
TABLE 4.6. Calculational Systems - Calculation Procedures and Verification

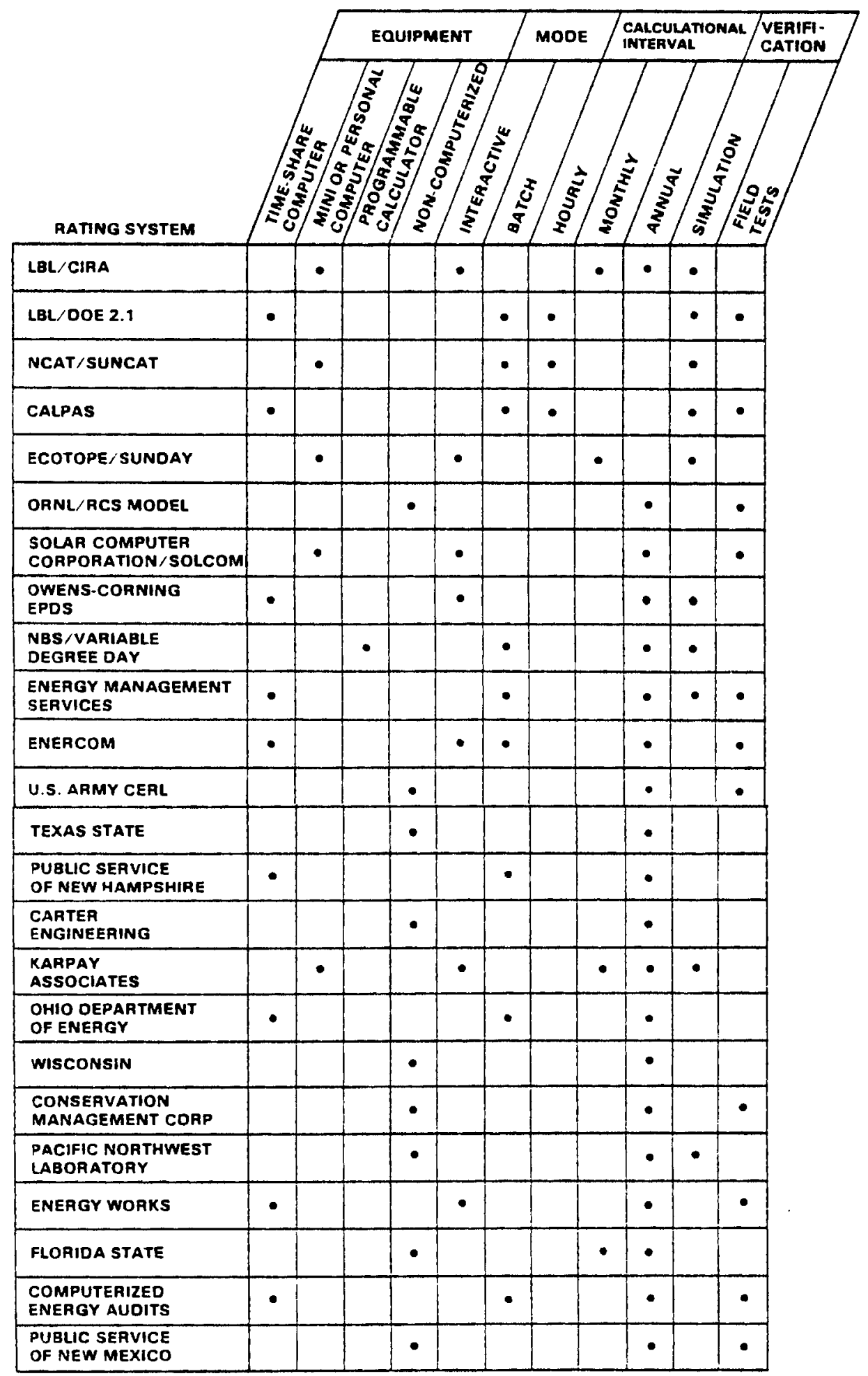


The calculational interval is an indicator of the complexity of the simulation. That is, certain input data, such as weather information, is provided for each interval. For hourly simulations, input values are required for each hour over a one-year period and hourly heat loss or energy-use estimates are available from the output. The more complex the code, the smaller the interval. It is felt that by decreasing the interval of calculation the accuracy of the calculation is improved.

Most of the calculational systems have been simulation verified. This means that their output has been compared with the output of other simulation models. Typically, models are compared with DOE-2 for validation purposes. Although a few of the models (e.g., Owens-Corning EPDS) have been compared to actual monitored information on a limited basis, none of the models have been validated with rigorous field tests.

Table 4.7 provides additional information only for those calculational tools that have been used or are proposed for use as a HERS. The table shows who performs the rating as well as who would use the results of the rating. The table also provides qualitative estimates of: 1) the relative amount of rater training needed to use the system, 2) the relative amount of time needed to complete a rating, 3) the relative cost of the rating, and 4) experience in using the system.

In many cases, site-specific systems will require only a moderate degree of rater training, because they require fewer input values and are less detailed than the generalized systems. The simplest systems, such as the slide calculators, will require very little rater training. A relatively high degree of rater training will likely be required for the computer programs because of their more complex input.

The time to complete a rating is categorized as follows:

Low: The homeowner performs the rating.

Medium: A site visit is made by the rater. Data are collected and analyzed in less than three hours. 
TABLE 4.7. Calculational Systems - Implementation Information

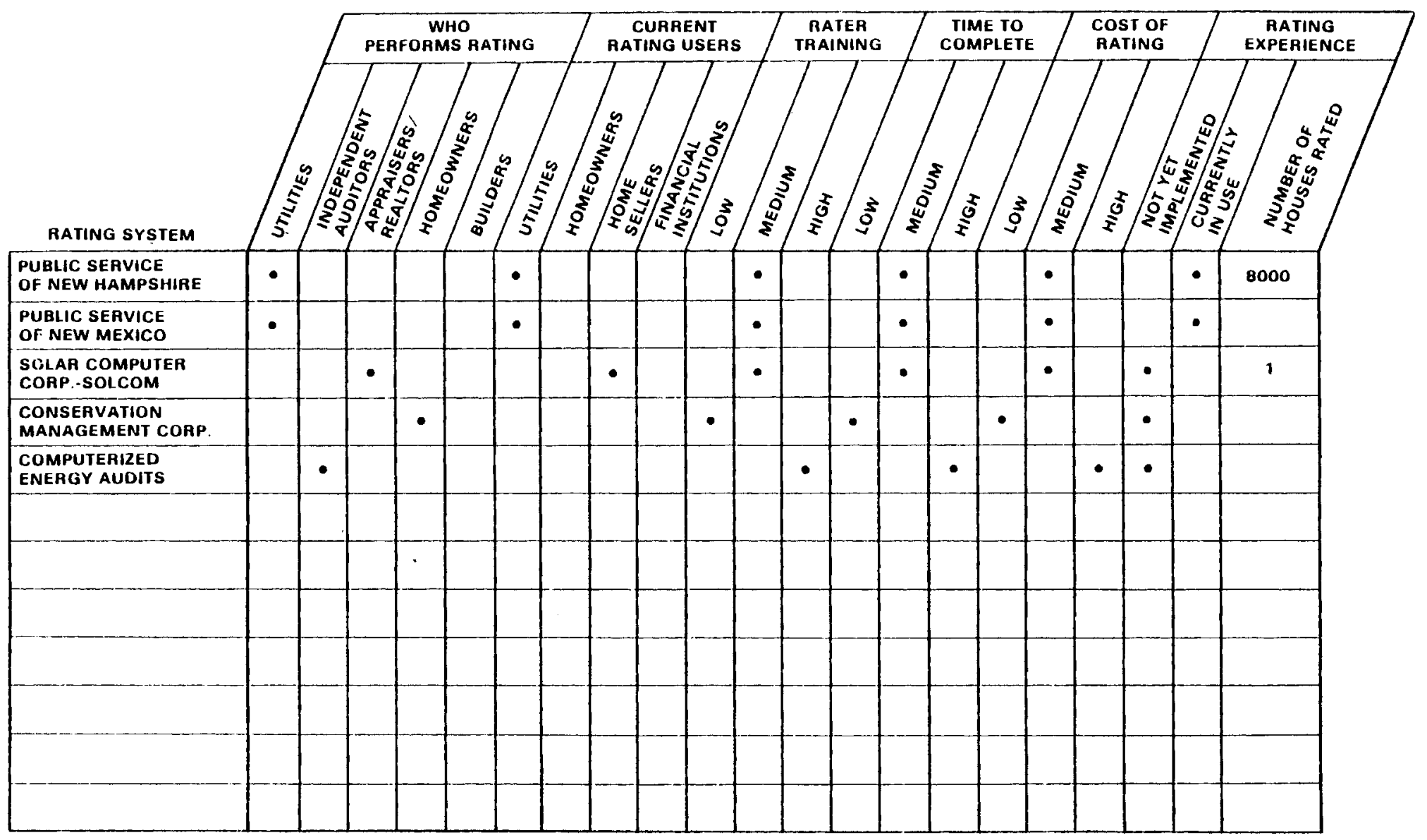


High: A site visit is made by the rater. Collection and analys is of data require more than three hours.

When information was available for systems that are already in use and when reasonable estimates could be made for those systems that are not currently being used, the typical cost of a rating was classified as follows:

Low: less than $\$ 50$

Medium: from $\$ 50$ to $\$ 200$

High: more than $\$ 200$

Rating experience indicates whether the system is currently being used and if so how many houses have been rated to date.

\subsection{PERFORMANCE SYSTEMS}

Table 4.8 provides information on who developed the performance rating system. Developers include government agencies at the federal, state and city/county levels, utilities, and private firms. Other information in the table includes: 1) whether the system is available in the public domain or proprietary, 2) whether the system is applicable to various housing types, and 3) whether the system is site-specific or generally applicable. In general, performance systems are applicable to any type of house with the exception of new homes and they are applicable nationwide.

Table 4.9 indicates the type of data used in the performance system to obtain a rating and the form of the rating. Input data include previous utility bills, square footage of conditioned space, annual degree-days for the region and a qualitative assessment of building features. Examples of the latter might include "no energy-efficient features" or "many-energy efficient features."

The output formats are defined as follows:

Efficiency ratio: the ratio of the annual energy use of the house to the average energy usage for similar houses in the same location. 
TABLE 4.8. Performance Systems - Developer and Applicability

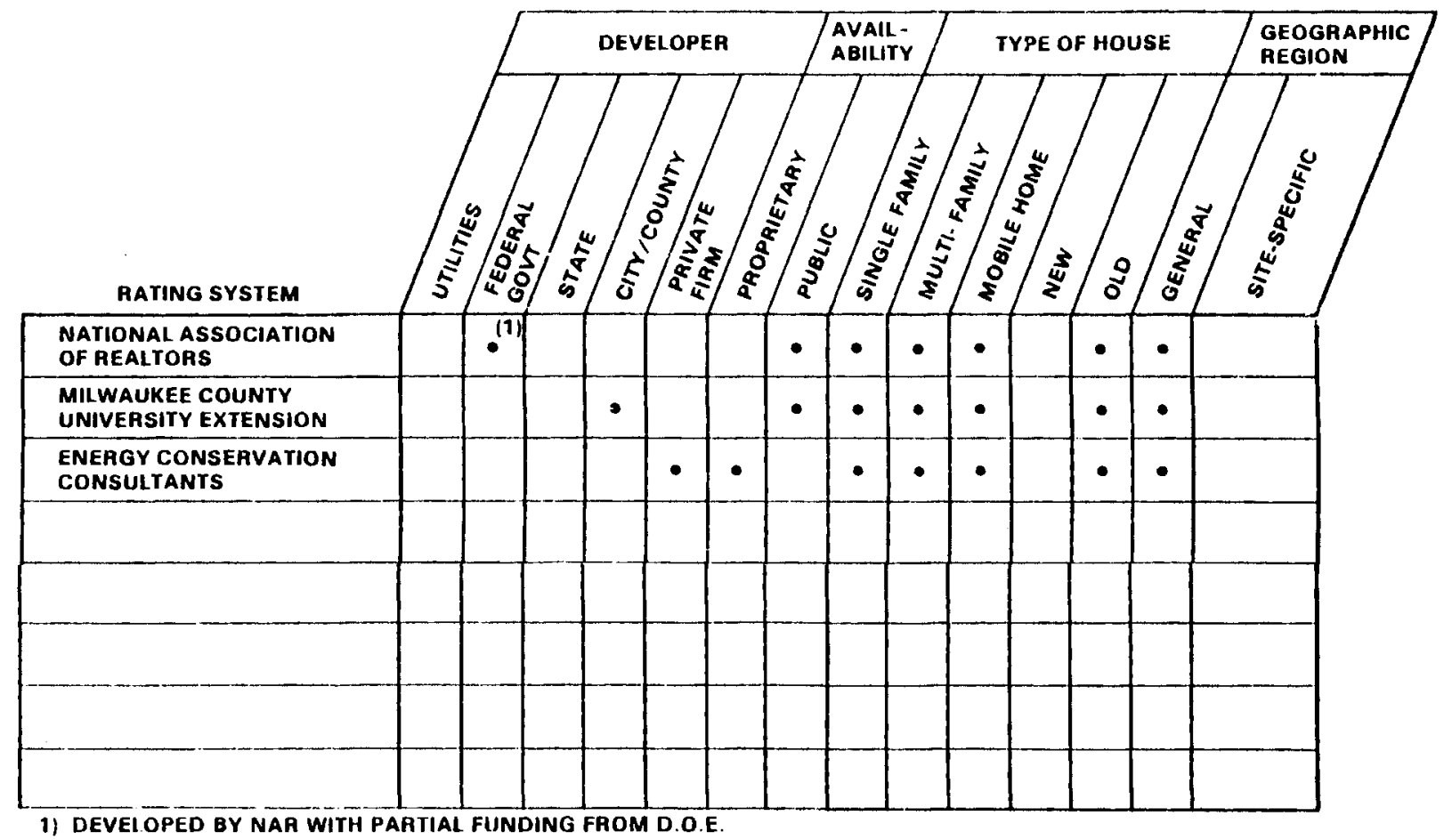

TABLE 4.9. Performance Systems - Input/Output Data

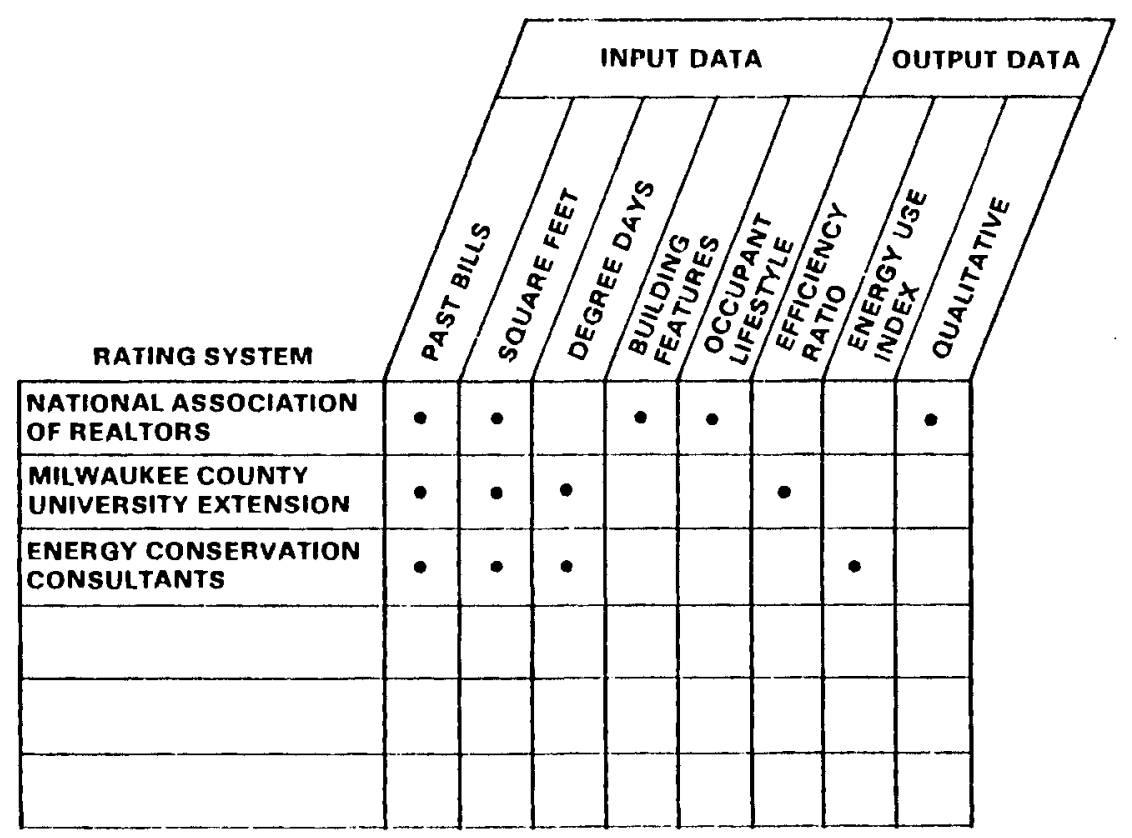


Energy-use index: the ratio of annual energy use of the house to the square footage of conditioned space, to annual degreedays, or to both.

Qualitative: a classification of efficient or inefficient.

Table 4.10 shows who performs the rating as well as who uses the results of the rating. In addition, the table provides qualitative estimates of: 1) the relative amount of rater traning needed to use the system, 2) the relative amount of time needed to complete a rating, 3 ) the relative cost of the rating, and 4 ) the experience in using the system.

In the most cases, performance systems require little training. Moderate training may be required to identify energy-efficient features for qualitative assessments.

Time to complete a rating is classified as follows:

Low: Rating is completed without a site visit or homeowner performs rating.

Medium: A site visit is made by the rater. Data is collected and analyzed in less than three hours.

High: A site visit is made by the rater. Collection and analysis of data require more than three hours.

In no case would the time needed for a performance rating be high.

The typical cost of a rating was classified as follows:

Low: less than $\$ 50$,

Medium: from $\$ 50$ to $\$ 200$,

High: more than $\$ 200$

Rating experience indicates whether the system is currently in use. Unfortunately, information on the number of houses rated was not available for any of the performance systems. 
TABLE 4.10. Performance Systems - User and Implementation Information

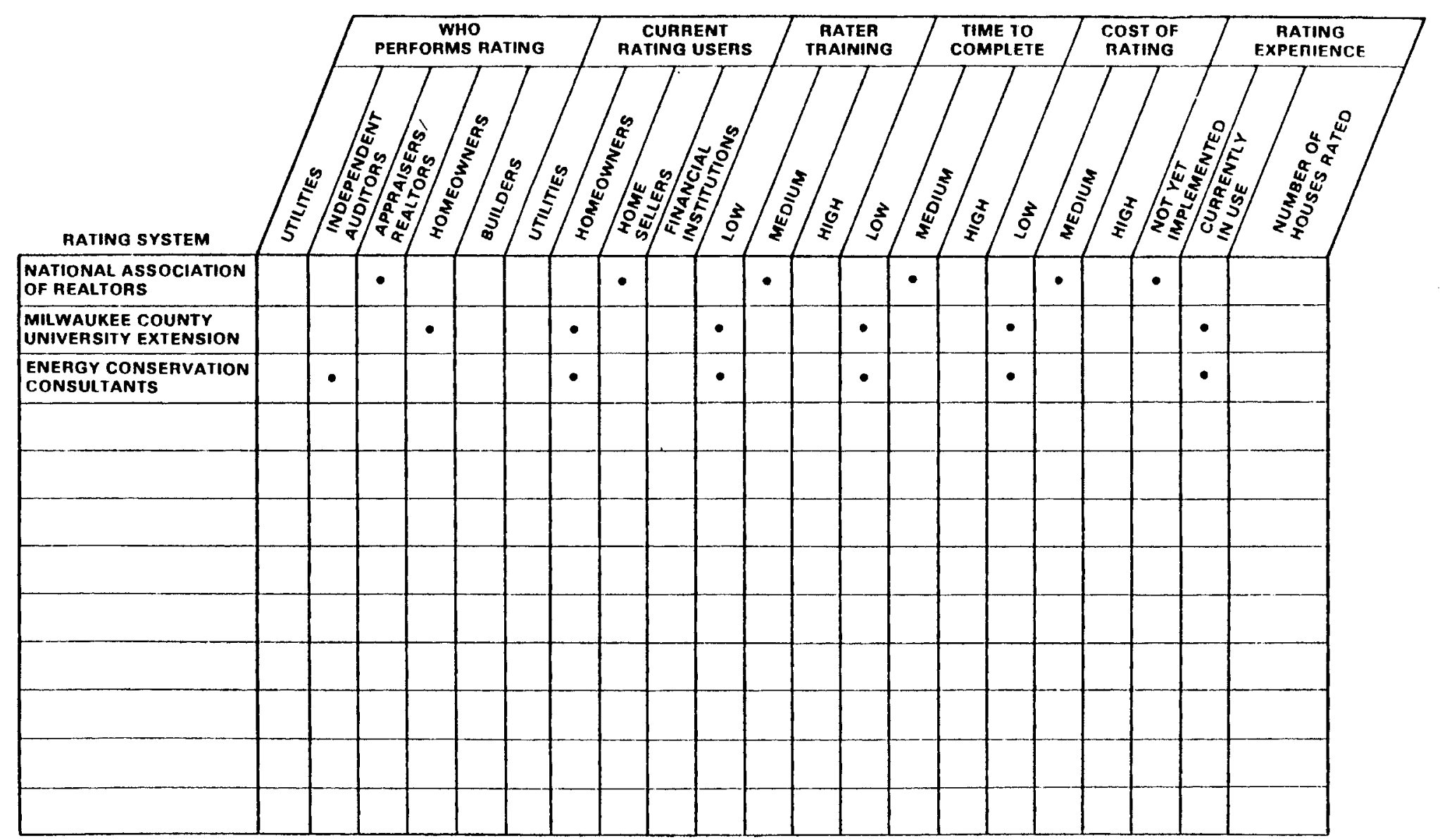




\subsection{HERS VALIDATION EFFORTS}

As discussed in Section 1.2, all of the potential systems/tools available for development of a residential energy rating system have limitations. The question of the accuracy of a rating is of particular importance since the perceived accuracy of the rating system will be a principal factor in how useful the rating is and the extent to which it will be used. In addition to being an issue in the acceptance of a rating system by various user groups, accuracy is also a prominent factor in the issue of liability.

Validation of a HERS may be approached either by assessing the technical basis of the systems or by a field validation. Validating the technical basis of the system may be done by comparing the system basis to generally accepted engineering equations and simulation methods. Field validation analyzes the performance of the rating system in actual use. Attempts at field validation of individual tools and rating systems have been limited. This is largely because field validations are technically more difficult and more expensive than theoretical validations. Adequate submetered energy consumption data (i.e., data which indicate exactly how much energy is used for space conditioning) and building description data are needed for a field validation effort. In many cases when one of these data sets is available, the other is not.

A limited amount of submetered data from throughout the country is available. The Ecotope Group of Seattle is currently compiling a listing of submetered data sets available for the Pacific Northwest region. The listing will include a description of the data set and an assessment of the quality of the data. Among the submetered data available for the Pacific Northwest are energyuse data collected by BPA on 18 residences located in Midway, Washington, (about 35 miles north of Richland). Each house is equipped with four electric submeters which monitor: 1) total electricity use, 2), water heating electricity use, 3) space heating electricity use, and 4) air conditioning electricity use. Data on house modification and occupancy changes are also available. Some data are also available for a group of homes in Eugene, Oregon. Outside 
of the Pacific Northwest, we are aware of 140 gas-heated homes submetered by the Public Service of Colorado, and submetered gas and electricity consumption data for approximately 3000 townhouses in Twin Rivers, New Jersey. ${ }^{(6)}$

A field validation effort is an important part of HERS validation for two reasons. First, field tests can shed light on how well generally accepted building calculations actually model reality. Second, the accuracy of a rating is subject both to the theoretical accuracy of the rating methodology and to the accuracy of the input data (i.e., how closely the input data represent reality). Measuring the ability to accurately obtain required input data can only be done through field testing.

Validation does not require predicting energy use with absolute certainty, since many factors will cause actual energy consumption to vary somewhat from predictions. Actual energy consumption in a given year for a home could be quite different from predictions if occupant lifestyle or yearly weather patterns vary from the mean assumptions. Studies have indicated that the resident, rather than the building structure, dominates the observed variation in energy consumption. (6) Assuming a "typical" lifestyle as a simplifying assumption could have a significant impact on the accuracy of the rating. The more simplified the rating system, the higher the probability that the predicted energy consumption will vary from reality because actual parameters may vary markedly from the simplifying assumptions implicit in these models. Also, using climate data from the nearest weather station can mask significant variations in microclimate that can exist across small areas, particularly metropolitan areas. Studies have shown significant temperature variance between data recorded at a weather station and at a residence located as little as five miles from the weather station. (7)

The following sections discuss validation efforts that have been undertaken or are planned for prescriptive and calculational systems.

\subsection{PRESCRIPTIVE SYSTEMS}

Validation efforts on prescriptive systems have consisted of comparisons of the systems to computer calculational systems and field validation efforts. 
While it is the more valuable measure of system accuracy, field validation has been done the least because it is more difficult and expensive than validation by comparison to a calculational system. Where field validation has been attempted, it has usually been of a general nature without detailed data collection.

A number of prescriptive systems were developed using computerized calculational models as their basis. In the development process, these prescriptive systems were checked against the computer model which was their basis, and so can be considered to have been validated against a calculational model. Examples of prescriptive systems that have been developed in this way include the prescriptive compliance system for the California Residential Building Standards, the Energy Conservation Point System for the City of Boulder, the Minnesota Energy Conservation Rating System developed by LBL, and the Western Resources Institute system. As discussed above, verification of the technical basis of the prescriptive systems is only a partial validation effort, since it does not necessarily address potential problem areas that could emerge under field use of the systems. These problem areas include rater error in assessing home features, technical features that may not be addressed by the prescriptive system, and the effects of microclimate.

The simplest type of field verification is determining whether homes with a high efficiency rating use, on the average, less energy than homes with low efficiency ratings. This type of verification may be done using information collected in the rating process, and tracking energy consumption of the home over time. A similar sort of verification can be done for homes where conservation features are added to improve the rating of the home, by comparing energy consumption before and after the modifications. Verifications of these types have been conducted by Union Electric and Gulf States Utilities, both NEW programs. In both cases the evidence indicated that homes which qualified for a NEW rating used less energy than average for the area.

A more detailed type of verification than the preceeding is attempting to quantify how well energy consumption is actually correlated with the home's 
rating. Because the verification is concerned with more precisely relating how energy consumption varies with home ratings, submetered energy consumption data may be required, and the problem is generally more complicated. Pacific Gas and Electric has recently completed a verification of this type on their Energy Conservation Home (ECH) Program. According to engineering predictions, homes meeting the basic ECH requirements were estimated to consume 10 percent less energy than an average home, and homes meeting higher requirements for a premium ECH (PECH) certification were estimated to consume 20 percent less energy than average. Results of a conditional demand analysis survey indicated that actual energy savings for ECH and PECH homes were 11.2 and 22.4 percent, respectively, very close to the engineering predictions. The verification study originally was to cover both gas and electrically heated homes, but was limited to electrically heated homes only because of data inconsistencies on the extent of gas heating in the sample. (8)

A detailed verification program is being conducted by Central Power and Light (CPL) in Corpus Christi on their Energy Efficiency Award (EEA) program. CPL is monitoring the energy consumption of 120 homes that have qualified for the EEA program. The monitoring program uses special metering equipment to record electricity consumption over 15-minute intervals, and will extend over a one-year period. This data base will be used along with recorded weather data to assess the accuracy and reliability of the EEA program.

\subsection{CALCULATIONAL SYSTEMS}

Typically, efforts to verify calculational systems have involved comparing the results of the calculation to those of another calculational method. For computer models this typically involves a software-software comparison. Few of the calculational systems have been tested with field data.

Efforts by the Los Alamos Scientific Laboratory (LASL) (on DOE-2.1) and the Ecotope Group (on SUNCODE) to validate complex simulation models, either with other software or with actual data, indicate that the accuracy of the input data accounts for much of the discrepancy between predicted and actual energy use. That is, the complex computer models are theoretically accurate, but perfect information is rarely available to predict actual energy use. 
With the exception of the Public Service of New Mexico (PNM) heat-loss calculation, the calculational systems have not been rigorously field tested. This lack of field verification is due in part to a lack of complete data sets needed to perform such an analysis. In cases where submetered data are available, insufficient data on building features and operation are available. Conversely, where building features and operation data are adequate, submetering has not occurred. PNM has been in a unique position of being able to validate its heat-loss model because of its practice of installing a separate meter to monitor heating system electricity use. Using the data collected by the heating meter, PNM has compared predicted heat losses to actual heat losses. Over the years, the differences between the predicted values and the actual values have been used to modify the ASHRAE equation coefficients, resulting in a simple and accurate calculational system tailored specifically to the PNM service area.

Most of the validation efforts, other than software-software comparisons, undertaken for detailed simulation programs have involved extensive monitoring of a few buildings, rather than analysis of large, cross-sectional samples of building energy data. LASL has been involved in a multiyear study to validate DOE-2.1 with data from seven monitored commercial buildings in various locations. On an annual basis the root mean square variance between actual and predicted energy use was on the order of $8 \%$. On a monthly basis, this deviation was about $15 \%$. LASL is currently analyzing the effects on the predicted energy use of user decisions and judgment in preparing the input data.

The LBL CIRA model has not been validated in its entirety with field tests, although parts of the model, such as the air infiltration section, have been validated with field tests. The CIRA model was compared to D0E-2.1 for a ranch house in seven different climates in the United States. Heating and cooling loads predicted by CIRA were found to be within $\pm 10 \%$ of DOE-2.1 predictions. Although it was not set up as a field validation of CIRA, an LBL study for BPA on the effects of weatherization projects at the Midway Substation community did compare CIRA predictions to actual energy-use data normalized to a standard year. (10) Submetered data for 18 houses at Midway, Washington, were used in the study. Although conclusions as to the accuracy of the CIRA 
model were not drawn from the study, results indicated that CIRA predictions of annual energy consumed for space heating were within $\pm 12 \%$ of the normalized energy consumption data.

Owens-Corning Fiberglas Corporation reports an extensive validation of their OCF-2 model was completed prior to development of the manual energy calculation procedure in their Energy Performance Design System (EPDS) manual. (11) Measured data from three test houses in Granville, Ohio, were used in the validation. Agreement between predicted and actual metered energy use was reportedly good. The manual procedure was verified by comparing it to the OCF2 computer model for a variety of houses and locations. Owens-Corning points out, however, that this type of validation does not ensure any better accuracy than the original computer program.

The SOLCOM model is currently being tested by appraisers in the Denver area. The focus of this effort is to determine how sensitive the output of the code is to the variability of user inputs. That is, a number of appraisers have been asked to use SOLCOM to rate a single house. The ratings will be analyzed to determine the sources of variability among the appraisers.

ORNL has performed a few field tests to verify the RCS Model Audit. Additional work planned on audit validation includes field testing with instrumented houses to determine the accuracy of load calculations and savings estimates. 0ther field studies are aimed at validating specific algorithms or assumptions in the Model Audit, including effect of attic insulation, effect of insulation degradation, and determination of thermal balance point and gas furnace efficiency. All of these specific studies are based on the analysis of field data. 
.

. 


\section{REFERENCES}

1. 10 CFR 456.105 (c).

2. 10 CFR 456.307 (b).

3. American Society of Heating, Refrigerating and Air-Conditioning Engineers, Inc. 1981. ASHRAE Handbook: 1981 Fundamentals. Atlanta, Georgia.

4. 47 Federal Register 27752, June 25, 1982.

5. "Building Energy Analys is Computer Programs Developed by Federal Agencies Cost, Use, and Need." March 22, 1982. PLRD-82-47, U.S. General Accounting office, Washington, D.C.

Merriam, R. L. 1981. Solar Heating and Cooling Simulation Programs: Assessment and Evaluation, EPRI EM-1866, prepared for the Electric Power Research Institute by Authur D. Little, Inc.

Kusuda, T. July 1980. Review of Current Calculation Procedures for Building Energy Analys is. NBSIR 80-2068. U.S. Department of Commerce, Nationa 7 Bureau of Standards, Washington, D.C.

6. Sonderegger, R. C. 1978. "Movers and Stayers: The Resident's Contribution to Variation across Houses in Energy Consumption for Space Heating." Energy and Buildings. 1(3):313-324. Elsevier Sequola Publishers.

7. Penz, Alton J. and Yacov Yasky. 1979. "Uncertainties in Predicting Energy Consumption in Houses." Energy Systems and Policy. 3(3):243269.

8. Parti, M., and J. M. Harris. 1982. Energy Conservation Home Comparative Analysis. MR-79-27, Pacific Gas and Electric Company, Energy Conservation and Services Department, San Francisco, California.

9. Diamond, S. C., and B. D. Hunn. 1981. "Comparison of DOE-2 Computer Program Simulations to Metered Data for Seven Commercial Buildings." ASHRAE Transactions 1981. V. 87, pt. 1. At lanta, Georgia.

10. Dickinson, J. B., et al. 1982. Results of the Bonneville Power Administration Weatherization and Tightening Projects at the Midway Substation Residential Community. LBL-12742, Lawrence Berkeley Laboratory, Berkeley, California.

11. Energy Performance Design System. 1981. Owens-Corning Fiberglas Corporation, Insulation Operating Division, Fiberglas Tower, Toledo, Ohio. 


\section{ACRONYMS}

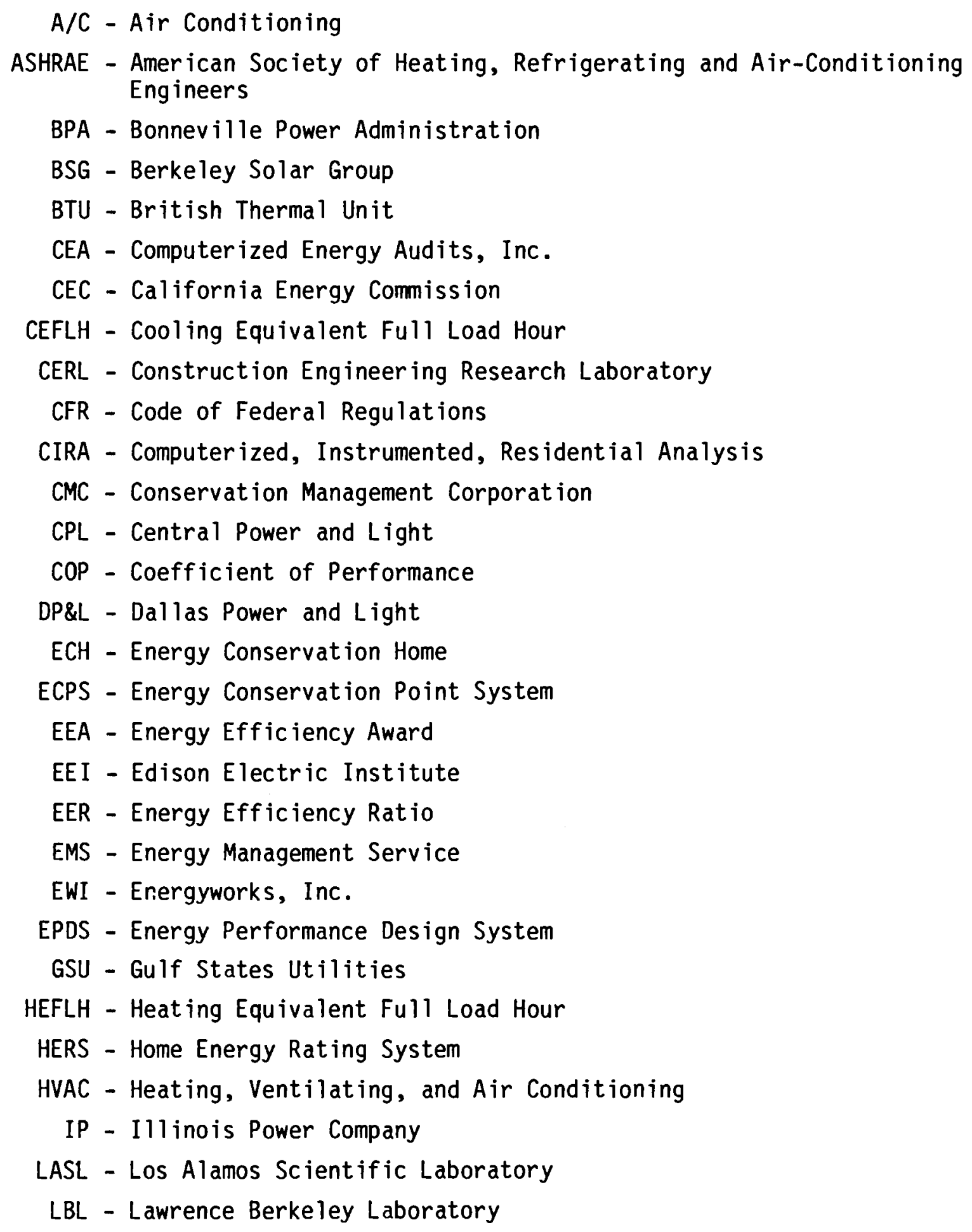




\title{
ACRONYMS (contd)
}

\author{
MEC - Minnesota Energy Conservation \\ MEEC - Model Energy Efficiency Code \\ MPLS - Multiple Listing Service \\ NAR - National Association of Realtors \\ NBS - National Bureau of Standards \\ NEW - National Energy Watch \\ NHC - National Homes Corporation \\ NIECS - National Inter im Energy Consumption Survey \\ NOAA - National Oceanic and Atmospheric Administration \\ NTIS - National Technical Information Service \\ OCF - Owens-Corning Fiberglas Corp. \\ ORNL - Oak Ridge National Laboratory \\ PITI+E - Principal, Interest, Taxes, Insurance + Energy \\ PNL - Pacific Northwest Laboratory \\ PNM - Public Service of New Mexico \\ PSC - Public Service Company of Colorado \\ PSNH - Public Service of New Hampshire \\ PUD - Public Utility District \\ RCS - Residential Conservation Service \\ REAC - Residential Energy Analysis for Conservation \\ SLR - Solar Load Ratio \\ TMY - Typical Meteorological Year \\ TP\&L - Texas Power \& Light Company \\ VCEC - Visalia Citizens' Energy Comittee \\ VER - Visalia Energy Rating
}




\section{GLOSSARY}

Design Cooling Load:

Design Heating Load:

Cooling Energy Use:

Heating Energy Use:

U-Value:

Energy Efficiency Ratio:

Therm:

Solar Load Ratio (SLR):

Conditioned Space:

Envelope:

Infiltration:

Internal Gain:
The rate at which heat must be removed from a space in order to maintain the design temperature. (Btu/hr)

The rate at which heat must be added to a space in order to maintain the design temperature. (Btu/hr)

The amount of energy used by the cooling equipment to meet the cooling load. If the efficiency of the cooling equipment is unity, the cooling energy use will equal the cooling load. (Btu/hr)

The amount of energy that must be supplied to the heating equipment in order to meet the heating load. The heating energy use is equivalent to the heat load if the efficiency of the heating equipment is unity. (Btu/hr)

Thermal transmittance or overall coefficient of heat transfer; the thermal transmission through a unit area of a particular body or assembly per unit time, divided by the difference between the environmental temperatures on ejther side of the body or assembly. Btu/hr $\mathrm{ft}^{2} \mathrm{~F}^{\mathrm{O}}$.

(EER) a means of expressing efficiency of electric electric, motor-driver cooling equipment. The ratio of cooling capacity in Btu/hr of the system, at rated conditions, divided by the electrical input to the system. Btu/watt-hour.

100,000 Btu.

The ratio of solar energy absorbed to the net building energy load.

The region of the house that is intentionally heated or cooled.

Walls, floors, windows, ceilings, etc., which separate the conditioned space from the unconditioned space.

Air entering the house through cracks or other openings.

Heat generated by people, lights, and appliances. 



\section{BIBL IOGRAPHY}

\section{$\underline{\text { LABELING }}$}

Abt Associates, Inc. June 1976. Impact of the FEA/EPA Fuel Economy Information Program, Prepared for Federal Energy Administration by Abt Associates, Inc., Cambridge, Massachesetts. PB-266 567, National Technical Information Service, Springfield, Virginia.

Committee on Consumer Policy Organisation for Economic Cooperation and Development. 1976. The Energy Labe 1, a Means of Energy Conservation. ISBN 92-64-11581-1, report by the Committee on Consumer Policy, Organisation for Economic Cooperation and Development, Paris.

Dickens, H. B. September 1981. Report to Canadian Standards Association on the Evaluation and Labelling of the Energy Conservation Features of a House. Misc..017-1981, Canadian Standards Association, 178 Rexdale Boulevard, Rexdale, Ontario, Canada.

Edison Electric Institute. November 1980. National Energy Watch Residential Program Guide Operating Manual and Promotion Catalog, Edison Electric Institute, Washington, D.C.

Edison Electric Institute. November 1980. Residential Program Guide Operating Manual and Promotion Catalog. National Energy Watch, Edison Electric Intitute, Washington, D.C.

Energy Efficiency Labels for Buildings. July 1981. Hearing before the Subcommittee on Energy Conservation and Power of the Committee on Energy and Commerce, U.S. House of Representatives, Ninety-Seventh Congress, July 1981. Serial No. 97-65.

Lawrence Berkeley Laboratory. April 1981. Energy Conservation Rating System for New Single Family Detached Residences in Minnesota. Prepared for the U.S. Department of Energy by Lawrence Berkeley Laboratory, Berkeley, California.

McNeil1, D. L. and W. L. Wilkie. 1979. "Public Policy and Consumer Information: Impact of the New Energy Labels." Journal of Consumer Research, Vol. 6, p. 1 .

\section{RESIDENTIAL ENERGY EFFICIENCY AND LENDING}

An Analys is of the Contribution of Energy Price Changes to HUD-Insured Mortgage Failures. May 1976. Prepared for Federal Energy Administration, Washington, D.C. PB-273 490, National Technical Information Service Springfield, Virginia. 
Arizona Solar Energy Commission. February 1981. Financing Solar in Arizona. Phoenix, Arizona.

Arthur Young \& Co. Guide to Energy Management for Financial Institutions. Sponsored by 0k lahoma Department of Energy, Oklahoma City, Oklahoma.

Booz-Allen \& Hamilton, Inc. May 1977. Methodology to Measure the Impact of Rising Energy-Related Household Costs on Single Family Residential Mortgage Activity: Application to Nine SMSAS (Standard Metropolitan Statistica) Areas) Volume I Report. May 1977. Prepared for Federal Energy Administation, Washington, D.C. by Booz-Allen \& Hamilton, Inc., Bethesda, Maryland. PB-274 431, National Technical Information Service, Springfield, Virginia.

Denn is, M. W. 1981. Mortgage Lending Fundamentals and Practices, Reston Publishing Co.

"Energy in the 1980's." July 1980. Federal Home Loan Bank Board Journal, Volume 13, Number 7.

Financing the Energy Efficient Home, Actions for the 80s. March 1981. California Energy Commission, State of California, Sacramento, California.

Help Home Energy Lending Program Fact Pack, Foremost Guaranty Corp., Madison, Wisconsin.

The Home Lenders' Energy Workbook. March 1981. Energy Lending Practices Project. Prepared in cooperation with The Wiscons in Department of Administration, Division of State Energy, Madison, Wisconsin.

Impact of Energy Problems on Real Estate. 1979. N4-4340, Practising Law Institute, New York City, New York.

Innovative Financing: Banks and Energy Conservation. May 1978. Prepared for the U.S. Department of Energy by Real Estate Research Corporation, San/W1201-01, National Technical Information Service, Springfield, Virginia.

Isakson, H. R., and R. L. Haney. February 1977. Lender Impacts Upon Energy Conservation in Buildings, Development and Assessment of Alternative Government Actions. Prepared for the Federal Energy Administration. FEA/D-77-125, National Technical Information Service, Springfield, Virginia.

Planergy, Inc. The Texas Loan Officer's Desk Book on Residential Energy Management. Prepared for the Texas Public Utility Commission and the Texas Energy and Natural Resources Advisory Council by Planergy, Inc., Austin, Texas.

Solar Workshops for the Financial Community, Workshop Manual on Technical, Economic, and Legal Considerations for Evaluating Solar Heated Buildings. March 1979. DOE/CS-0103/1, National Technical Information Service, Springfield, Virginia. 


\section{APPRAISING}

B loom, G. F. and H. S. Harrison. 1978. Appraising the Single Family Residence. American Institute of Real Estate Appraisers, Chicago, Illinois.

Making the Most of Energy in Real Estate, Relevant Energy Facts for Real Estate Developers, Builders, Lenders, Appraisers, and Brokers, September 1978 edition and revised March 1980 edition. Prepared for the U.S. Department of Energy, CONS-6280-02, National Technical Information Service, Springfield, Virginia.

Society of Real Estate Appraisers. April 1980. Energy Considerations in Real Estate Appraising. DDE/CS/015223-01, prepared for the U.S. Department of Energy by the Society of Real Estate Appraisers, Chicago, Illinois.

\section{BROKERS/SELLING}

Housing/Owens-Corning Fiberglas Energy Panel. December 1981. "Selling Energy Efficiency." Housing, pp. 26-28. McGraw Hill.

Making the Most of Energy in Real Estate: Relevant Energy Facts for Real Estate Developers, Builders, Lenders, Appraisers, and Brokers, September 1978 edition and revised March 1980 edition, prepared for U.S. Department of Energy. CONS-6280-02, National Technical Information Service, Springfield, Virginia.

National Association of Realtors. 1980. The Realtor's Guide to Residential Energy Efficiency, An Introduction in Using Energy to Sell Homes, National Association of Realtors.

Selling the Solar Home, The Solar Business Office, State of California.

U.S. Department of Energy, Washington, D.C. Using Energy Information to Sell Homes.

\section{CALCULATION TOOLS}

"Building Energy Analys is Computer Programs Developed by Federal Agencies Cost, Use, and Need." March 22, 1982. PLRD-82-47, U.S. General Accounting Office, Washington, D.C.

Comparison of Load Determination Methodologies for Building Energy Analys is Programs. January 1981. Prepared for International Energy Agency, Energy Conservation in Building \& Community Systems Programs, DOE/CE/20184-1, National Technical Information Service, Springfield, Virginia. 
Diamond, S. C. and B. D. Hunn. Comparison of DOE-2 Computer Program Simulations to Metered Data for Seven Commercial BuiTdings, ASHRAE Transactions V. 87, Pt. 1. AtTanta, Georgia.

Diamond, S. C., B. D. Hunn, and C. C. Cappiello. April 1981. DOE-2 Verification Project Phase I Interim Report. LA-8295-MS, Los Alamos Scientific Laboratory, Los Alamos, New Mexico.

Family Housing Utility Metering Program Annual Report. March 1980. U.S. Army Facilities Engineering Support Agency, Ft. BeTvoir, Virginia.

Feldman, S. J., R. L. Merriam, Arthur D. Little, Inc. August 1979. Building Energy Analys is Computer Programs with Solar Heating and Cooling System Capabilities. EPRI ER-1146, prepared for the Electric Power Research Institute, Palo Alto, California.

Horn, M. August 1980. Energy Performance Computer Programs. 1980 Residential Building Standards Development Project, California Energy Commission, Sacramento, California.

Horn, M. and C. Helmich. Assumptions Used With Energy Performance Computer Programs, 1980 Residential Building Standards Development Project, California Energy Commission, Sacramento, California.

Kusuda, T. July 1980. Review of Current Calculation Procedures for Building Energy Analysis. NBSIR 80-2068, U.S. Department of Commerce, Nat ional Bureau of Standards, Washington, D.C.

Kusuda, T., I. Sud, and T. Alereza. Comparison of DOE-2-Generated Residential Design Energy Budgets with Those Calculated by the Degree-Day and B in Methods, ASHRAE Transactions, V. 87, Pt. 1. Atlanta, Georgia.

Merriam, R. L. and Arthur D. Little, Inc. May 1981. Solar Heating and Cooling Simulation Programs: Assessment and Evaluation, EPRI EM-1866, prepared for Electric Power Research Institute, Palo Alto, California.

Owens-Corning Fiberglas Corp. 1981. Energy Performance Design System. Owens-Corning Fiberglas Corp., Toledo, Ohio.

Sonderegger, R. C., J. Y. Garnier and J. D. Dixon. November 1981. Computerized Instrumented, Residential Analys is (CIRA). PUB-425, Lawrence Berkeley Laboratory, Berkeley, California.

Sonderegger, R. C. and J. Y. Garnier. 1982. A Simplified Method for Calculating Heating and Cooling Energy in Residential Buildings. Presented at the Third International Symposium on Energy Conservation in the Built Environment, March 30-April 1, 1982, Dublin Ireland. 


\section{ENERGY AUDITING}

Haimes, Y. Y. 1980. Energy Auditing and Conservation Methods, Measurements, Management, and Case Studies, Hemisphere Publishing Corp, Washington, D.C.

Harris, J. P. December 1981. "Comments on Proposed Amendments to the Regulations for the DOE Residential Conservation Service." LBL-14151, Lawrence Berkeley Laboratory, Berkeley California.

Hirst, E., L. Berry and J. Soderstrom. Oak Ridge National Laboratory. "Review of Utility Home Energy Audit Programs." Energy, Vol. 6, No. 7, p. 621-630, Pergarmon Press Ltd.

Hoffman, W. L. April 1982. Overcoming Barriers to Residential Conservation: Do Energy Audits Help? Report No. 3110-02, The Urban Institute, Washington, D.C.

Home Audit Program: Management Manual. September 1980. DOE/RG/10027-01, American Public Power Association, prepared for the U.S. Department of Energy by the American Public Power Association.

Oak Ridge National Laboratory. March 1982. Evaluation of Utility Home-Energy Audit Programs: A Wiscons in Examp le. ORNL/CON-88, Oak Ridge National Laboratory, Oak Ridge, Tennessee.

Ohio Home Energy Saving Guide. 1979. Ohio Department of Energy, Columbus, Ohio.

Pacific Gas \& Electric Company. August 1980. Experiences in Energy Conservation in Residential New Construction.

Pacific Gas \& Electric Company. January 1980. Energy Conservation Home Program.

Proceedings State Energy Audit Impact 1979. American Institute of Industrial Engineers. U.S. Department of Energy.

Residential Conservation Service Auditor Training Manual. August 1980. Department of Energy, Washington, D.C. Also published as The Residential Energy Audit Manual, Fairmont Press, Atlanta, Georgia.

Thumann, A. 1979. Handbook on Energy Audits. Fairmont Press, Atlanta, Georgia.

Utility Sponsored Home Insulation Programs. June 1978. HCP/W1227-01, prepared for the U.S. Department of Energy by Booz, Allen and Hamilton, Bethesda, Maryland. 
U.S. Department of Energy. November 1980. Expansion of the Residential Conservation Service Program to Multi-Family and Small Commercial Buildings. DOE/CS-0194, National Technical Information Service, Springfield, Virginia.

U.S. General Accounting Office. March 29, 1982. The Residential Conservation Service: Issues Affecting the Program's Future. EMD-82-70. Washington, D.C.

\section{ENERGY CODES/STANDARDS}

An Analysis of Institutional Issues in the Implementation of Federal Energy Performance Standards for New Buildings, March 1980. BHARC-321/80/005, Battelle Human Affairs Research Center, Seattle, Washington.

Dublin, F. S. and C. G. Long, Jr. 1978. Energy Conservation Standards for Building Design, Construction and Operation. McGraw-Hill Book Co.

Model Energy Efficiency Code for Building Construction. October 1980. State of Florida, Department of Community Affairs, Tallahassee, Florida.

National Conference of States on Building Codes and Standards. December 1977. A Training Program for Energy Conservation in New Building Construction, Vol. I-IV, SAN/1230-2.

National Association of Home Builders. 1977. Thermal Performance Guidelines for One and Two Family Dwellings. Washington, D.C.

Nieves, L. A., J. J. Tawil and T. J. Secrest. 1981. Regional Variations in U.S. Residential Sector Fuel Prices: Implicationsfor Development of Building Energy Performance Standards. PNL-3605, Pacific Northwest Laboratory, Richland, Washington.

Proposed Residential Building Standards Final Environmental Impact Report. June 1981. California Energy Commission, Sacramento, California.

Residential Energy Efficiency Standards Study Final Report. July 1980. Submitted to the Congress of the United States by U.S. Department of Housing and Urban Development.

GENERAL

Booz-Allen, Hamilton, Inc. May 1980. Electric and Gas Utility Marketing of Residential Energy Conservation \& Case Studies. DOE/RG/3356-T1, National Technical Information Service, Springfield, Virginia.

Burby, R. J. and M. E. Marsden, eds. 1979. Energy and Housing: Consumer and Builder Perspectives. Center for Urban and Regional Studies and Institute for Research in Social Science, University of North Carolina, Chapel Hill, North Carolina. 
Dwelling with Conservation, A Guide to Home Energy Management. 1980. Aadland, Hoffmann, Pieri Energy Associates, Inc., Minneapolis, Minnesota.

Energy Analys is of a Prototype Single-Family Detached Residence: The Effects of Climate, House Size, Orientation, Internal Heat Release, and Natura T Cooling. January 1981. NBSIR 80- 2184, U.S. Department of Commerce, Washington, D.C.

Energy Cost Reduction for Multi-Family Dwellings, November 1980. Georgia Institute of Technology Engineering Experiment Station.

The Energy-Wise Homebuyer: A Guide to Selecting an Energy-Efficient Home. March 1979. U.S. Department of Housing and Urban Development in cooperation with the U.S. Department of Energy, Washington, D.C.

Fang, J. M. and J. J. Tawil. December 1980. Analys is of Alternative Strategies for Energy Conservation in New Buildings. PNL-3309, Pacific Northwest Laboratory, Richland, Washington.

Finklea, E. A., and M. P. Treiber. Spring 1981. "Residential Energy Conservation Measures: A Penny Saved is a Penny Earned." Environmental Law, p. 639.

Johnson, R. C. July 1981. Housing Market Capitalizaton of Energy-Saving Durable Good Investments. ORNL/CON-74, Energy Division, Oak Ridge National Laboratory, Oak Ridge, Tennessee.

Lee, $H$. The Role of Local Governments in Promoting Energy Efficiency. DOE $/ C S / 10047-T 6$, U.S. Department of Energy, Division of Buildings and Community Systems.

Mazzucchi, R. P., L. A. Nieves and W. J. Hopp. March 1981. Energy Conservation Manual for Builders in the Mid-Columbia Bas in Area, PNL3607, Pacific Northwest Laboratory, Richland, Washington.

Meckler, M. 1981. Energy Conservation in Buildings and Industrial Plants, McGraw-Hill Book Co.

Milstein, J. S. October 1976. Attitudes, Knowledge, and Behavior of American Consumers Regarding Energy Conservation With Some Implications for Governmental Action. DOE/TIC-10713.

Parti, M. and J. M. Harris. February 1982. Energy Conservation Home Comparative Analys is (MR-79-27). Applied Econometrics, Inc., Del Mar, California. A Report to Pacific Gas and Electric Company.

Proceedings of the 1979 National Conference on Technology for Energy Conservation. January 1979. Tucson, Arizona. U.S. Department of Energy. 
Residential Energy Conservation Outreach Activities--A New Federal Approach Needed. February 1981. EMD-81-8, U.S. General Accounting office, Washington, D.C.

Residential Energy Conservation Volume I. July 1979. Office of Technology Assessment, Congress of the United States, Washington, D.C.

Scheer, R. M., L. A. Nieves, R. P. Mazzucchi. May 1981. Conserving Energy in New Buildings: Analys is of Nonregulatory Policies. PNL-3820, Pacific Northwest Laboratory, Richland, Washington.

Office of Technology Assessment, U.S. Congress. March 1982. Energy Efficiency of Buildings in Cities. Washington, D.C. 


\section{ACKNOWLEDGMENTS}

The authors would like to thank the many individuals affiliated with various HERS programs who provided us information for this project. We would also like to thank R. P. Mazzucchi of PNL for helpful comments on earlier versions of this document, and Eileen Franklin, Ruth Laidler, and Michele Thielges for typing. 



\section{$\underline{\text { DISTRIBUTION }}$}

No. of

Copies

OFFSITE

10

\author{
S. Heard \\ U.S. Department of Energy \\ Office of Building Energy R\&D \\ Forrestal Building \\ 1000 Independence Avenue S.W. \\ Washington, D.C. 20585
}

J. Millhone

Director, Office of Building

Energy R\&D

U.S. Department of Energy

Forrestal Building

1000 Independence Avenue S.W.

Washington, D.C. 20585

Peter Bach

U.S. Department of Energy

1000 Independence Avenue S.W.

Washington, D.C. 20585

\section{E. Freeman}

Office of Building Energy R\&D

U.S. Department of Energy

1000 Independence Ave. S.W.

Washington, D.C. 20585

27 DOE Technical Information Center

L. Athmer

Salt River Project

P.0. Box 1980

Phoenix, AZ 85001

B. Batson

Bonneville Power Administration

P.0. Box 3621

Portland, OR 97208

I. Birnbaum

Solar Applications Branch

Tennessee Valley Authority

310 TVA Credit Union Building

Chattanooga, TN 37401
No. of

Copies

J. B. Bishop

Gulf States Utilities Company

P.0. Box 2951

Beaumont, TX

K. Bittenbeyder

110 Athol Road

North Orange, MA 01364

C. Bloodgood

Bumb lebee Energy Systems

28 Richey Place

Trenton, NJ 08618

C. R. Booz

Solar Computer Corporation

1580 Gaylord

Denver, CO 80206

B. Bower

Department of Veteran \& Community Affairs

Howard Building

2571 Executive Center Circle East

Tallahassee, FL 32301

J. Cade

Bonneville Power Administration

P.0. Box 3621

Portland, OR 97208

D. G. Carter

Carter Engineering, Inc.

1107 Spring Street

Silver Spring, MD 20910

N. Clark

Bonneville Power Administration

P.0. Box 3621, M.S.-KT

Portland, OR 97208

R. Copper

Chestnut $\mathrm{Ha} 11$

3900 Chestnut Street

Philadelphia, PA 19104 
No. of

Copies

K. Cox

Energyworks, Inc.

45 Border Street

West Newton, MA 20910

T. Crow

Ohio Department of Energy

30 East Broad Street

Columbus, $\mathrm{OH} 43215$

D. Davia

Public Service Company of Colorado

550 15th Street

Denver, CO 80202

G. Duffy

Air Conditioning, Htg. \&

Ref. News

Box 2600

Troy, MI 48099

Energy Lending Practices Project

302 E. Washington Avenue

Madison, WI 53703

D. Fielman

California Energy Ccommission

1111 Horre Avenue, MS 23

Sacramento, CA 95818

D. Ford

Colorado Office of

Energy Conservation

1525 Sherman Street, 4th Floor

Denver, C0 80203

B. Fournier

Public Service Company of New Hampshire

1000 Elm Street

Manchester, NH 03105
No. of

Copies

M. Frankel

Centaur Associates

Suite 465

1120 Connecticut Ave. N.W.

Washington, D.C. 20036

E. G. Galassi

Illino is Power Company

500 South 17th Street

Decatur, IL 62525

B. Gillmore

Public Service Company of New Mexico

Alvarado Square

Albuquerque, NM 87158

J. Grady

Federal National Mortgage Association

510 Walnut Street, 16th Floor

Philadelphia, PA 19106

T. Grether

Insulation Division

Owens-Corning Fiberglas Corporation

Toledo, $\mathrm{OH} 43659$

B. Griffin

Edison Electric Institute

1111 19th Street, N.W.

Washington, D.C. 20036

G. Haddow

Pacific Gas and Electric Company

77 Beale Street

A-1114

San Francisco, CA 94106

J. Hailey

Pacific Gas and Electric Company

77 Beale Street

San Francisco, CA 94106 
No. of

Copies

C. Hibberd

Division of Facilities

Construction and Management

4110 State Office Building

Capitol Complex

Salt Lake City, UT 84114

D. C. Hittle

P.0. Box 4005

U.S. Army Construction

Engineering Research Lab.

Champaign, IL 61820

P. Hollander

Cornerstones Energy Group

54 Cumber land Street

Brunswick, ME 04011

B. Hunn

Los Alamos National

Laboratory

P.0. Box 1663

Los Alamos, NM 87545

D. M. Ikle

Conservation Management Corporation 7010 Glenbrook Road

Washington, D.C. 20014

M. Karnitz

P.0. Box $X$

Oak Ridge National Laboratory

Oak Ridge, TN 37830

R. Kent

New Technologies Institute

44 Monterey B Ivd.

San Franisco, CA 94131

D. Kitts

Dow Chemical Company

Drawer $\mathrm{H}$

Walnut Creek, CA 94596

J. Kortecamp

Director of Education

National Association of Realtors

430 North Michigan

Chicago, IL 60611
No. of

Copies

T. Kusuda

National Bureau of Standards

Department of Commerce

Washington, D.C. 20234

A. Larson

Swed ish Consulate General

10880 Wilshire Blvd, Suite 914

Los Angeles, CA 90024

M. Levine

Lawrence Berke ley Laboratory

University of California

Berkeley, CA 94720

J. Luboff

Institute for Public Policy

University of Washington

3935 University Way N.E.

Seattle, WA 98105

T. S. Lundy

Oak Ridge National Laboratory

P.0. Box $X$

Oak Ridge, TN 37830

J. Marquardt

Enercom, Inc.

2323 South Hardy Drive

Tempe, AZ 85282

D. McCowen

Energy Extension Service

Deschutes County Courthouse Annex

Bend, OR 97701

M. Messenger

California Energy Commission

1100 Howe Avenue MS 5

Sacramento, CA 95816

D. Metzler

City of Visalia

707 West Acequia Street

Visalia, CA 93291 
No. of

Copies

B. Miller

Central Power and

Light Company

P.0. Box 2121

Corpus Christi, TX 78403

M. Mintz

Nationa 1 Association of Home Builders

15 th and M Streets N.W.

Washington, D.C. 20005

W. R. Mixon

Oak Ridge National

Laboratory

P.0. Box $X$

Oak Ridge, TN 37830

D. Morazzi

Governor's Energy Counc il

P.0. Box 8010

Harrisburg, PA 17105

S. Morgan

T.D.C.

11 Beacon Street, \#1100

Boston, MA 02108

Nationa 1 Commun ity Energy Management Center

400 North Capitol Street N.W.

Suite 390

Washington, D.C. 20001

H. 01 in

Director, Architectura 1 \& Construction Research

U.S. League of Savings Associations

111 East Wacker Drive

Chicago, IL 60601

$P$. Ossinger

Bonneville Power Administration

P.0. Box 3621

Portland, OR 97208
No. of

Copies

L. Palmiter

Ecotope Group

2328 East Madison

Seattle, WA 98112

D. Patterson

Texas Power \& Light Company

Box 226331

Dallas, TX 75266

F. Porter

Puget Sound Power

\& Light Co.

Puget Power Building

Bellevue, WA 98009

T. Potter

SERI $15 / 3$

1617 Cole Bivd.

Golden, CO 80401

N. L. Raab

Union Electric Company

1901 Gratiot Street

St. Louis, MO 63103

J. Reese

New York State Energy Office

Building 2

Empire State Plaza

Albany, NY 12223

M. Schaeffer

Federal Home Loan Mortgage

Corporation

1776 G Street N.W.

P.0. Box 37248

Washington, D.C. 20013

N. Schalch

City of Boulder Energy Office

P.0. Box 791

Boulder, C0 80306 
No. of

Copies

K. Schmid

National Homes Corporation

Earl Avenue and Wallace Street

Lafayette, IN 47903

L. Schuck

Alliance to Save Energy

1925 K Street N.W.

Suite 507

Washington, D.C. 20006

J. Shaw

Kansas City Power and

Light Company

P.0. Box 679

Kansas City, MO 64141

G. Simon

Sigma Group

$1029 \mathrm{~J}$ Street, Suite 500

Sacramento, CA 95814

K. Smith

California Energy Commission

1111 Howe Avenue

Sacramento, CA 95825

$R$. Sonderegger

Building 90-3074

Lawrence Berkeley Laboratory

Universtiy of California

Berkeley, CA 94720

L. Stiles

Office of Energy Research

University of Illinois

901 South Mathews

Urbana, IL 61801

National Institute for

Building Sciences

1015 15th Street N.W.

Suite 700

Washington, D.C. 20005
No. of

Copies

B. Taylor

Duke Power Company

422 South Church Street

Charlotte, NC 28242

G. Thompson

Conservation Foundation

1717 Massachusetts Auenue

Washington, D.C. 20036-2094

J. Veigel

Alternative Energy Corp.

P.0. Box 12699

Research Triangle Park, NC 27709

D. Vohs

Iowa Energy Policy Council

Capital Complex

Des Moines, IA 50319

B. Wagner

Lawrence Berkeley Laboratory

Building 90-3058

Berkeley, CA 94720

J. Walsh

Computerized Energy Audits, Inc.

2430 Broadway

Boulder, CO 80302

M. Weedal

Bonneville Power Administration

P.0. Box 3621

Portland, OR 97208 
ONS ITE

DOE Richland Operations Office

H. E. Ransom

41 Pacific Northwest Laboratory

W. B. Ashton

S. Balistocky

C. H. Bloomster

B. A. Garrett-Price

P. L. Hendrickson (25)

R. P. Mazzucch i

R. G. Rivera

T. J. Secrest

T. A. Williams

L. D. Williams

Publishing Coordination (2)

Technical Information (5) 